Institutional arrangements for community-based rangeland management in Mongolia 



\section{Propositions}

1. The share of poor households in the rural population of Mongolia negatively affects rangeland quality

(this thesis)

2. Promoting exports of meat and its byproducts increases herders' incomes and reduces the high pressure on Mongolia's rangelands in the short run (this thesis)

3. Government actions are not a necessary condition for the development of tourism

4. Learning a coding language is a huge contribution to the future of scientists

5. Experience is built on failures, success is the product of your determination

6. Political propaganda is primarily targeted at the less educated

Propositions belonging to thePhDthesis, entitled

'Institutional arrangements for community-based rangeland management in Mongolia'

\section{Erdenechuluun Tumur}

Wageningen, 17 March 2021 


\section{Institutional arrangements for community-based rangeland management in Mongolia}




\section{Thesis committee}

\section{Promoters}

Professor Dr W.J.M. Heijman

Professor of Regional Economics

Wageningen University \& Research

Professor of Economics

Czech University of Life Sciences in Prague

Professor Dr. Nico Heerink

Personal professor at Development Economics Group

Wageningen University \& Research

\section{Co-Promotor}

Academician, Professor Sc.Dr Bakey Agipar

Director of Center for Agricultural Economics \& Innovation Development, Mongolian University of Life Science, Ulaanbaatar, Mongolia

\section{Other members}

Prof.dr.ir. J.D. van der Ploeg, Professor of Rural Sociology, Wageningen University Dr. X. Zhu, Associate Professor, Environmental Economics and Natural Resources Group, Wageningen University \& Research

Dr. Erdenebaatar Batjargal, Policy \& Institutional Consultant, Center for Policy Research, Ulaanbaatar, Mongolia

Prof.dr. M. Liu, Professor at College of Pastoral Agriculture Science and Technology, Lanzhou University, P.R. China

This research was conducted under the auspices of the Wageningen School of Social Sciences 


\title{
Institutional arrangements for community-based rangeland management in Mongolia
}

\author{
Erdenechuluun Tumur
}

Thesis

submitted in fulfilment of the requirements for the degree of doctor at Wageningen University

by the authority of the Rector Magnificus,

Prof. Dr A.P.J. Mol,

in the presence of the

Thesis Committee appointed by the Academic Board

to be defended in public

on Tuesday 17 March 2021

at 01:30 p.m. in the Aula. 
Erdenechuluun Tumur

Institutional arrangements for community-based rangeland management in Mongolia, 136 pages.

PhD thesis, Wageningen University, Wageningen, the Netherlands (2021) With references and summary in English

ISBN: 978-94-6395-632-1

DOI: https://doi.org/10.18174/535995 


\section{Table of Contents}

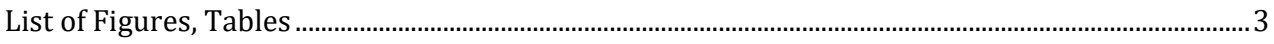

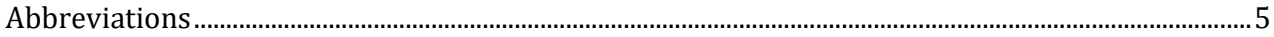

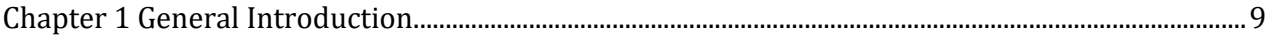

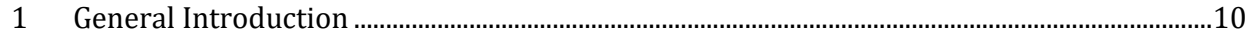

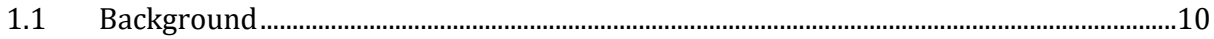

1.2 Problem Statements ......................................................................................................... 12

1.3 Research Objective and Questions …….......................................................................... 14

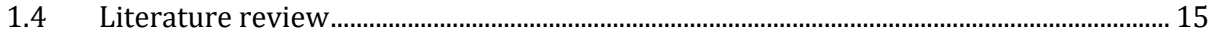

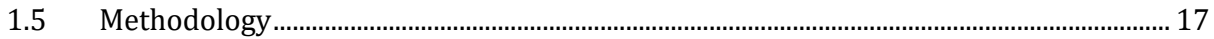

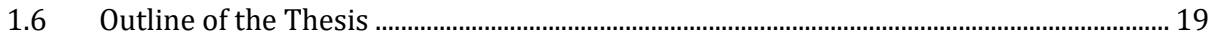

Chapter 2 Pastureland degradation and poverty among herders in Mongolia: data analysis and game estimation.

2 Pastureland degradation and poverty among herders in Mongolia: data analysis and

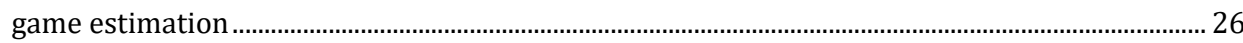

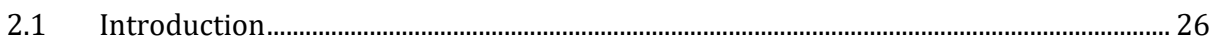

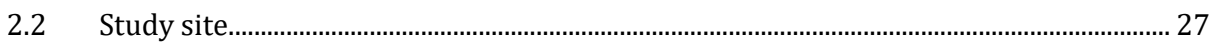

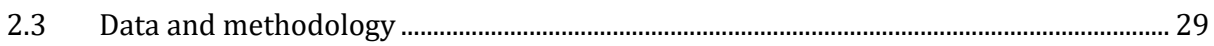

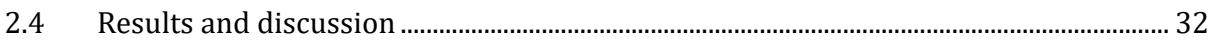

2.5 Conclusions and policy recommendations ........................................................................... 38

Chapter 3 Institutional Framework for Sustainable Pasture Management ....................................... 43

3 Institutional Framework for Sustainable Pasture Management ............................................... 44

$3.1 \quad$ Background ....................................................................................................................... 44

3.2 Different donor approaches........................................................................................... 46

3.3 Longer-term vision for the Pasture User Group System.................................................... 47

3.4 Institution partners of the Pasture User Group System ....................................................... 48

3.5 Achievements of the Pasture User Group System............................................................... 50

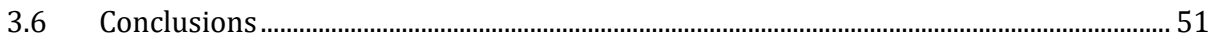

Chapter 4 Community development to improve rangeland management in Gobi region............. 57

4. Community development to improve rangeland management in Gobi region.................... 58

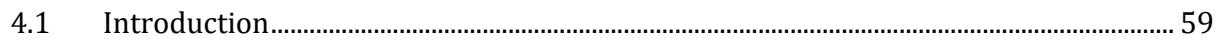

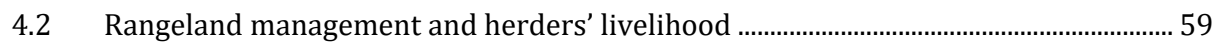

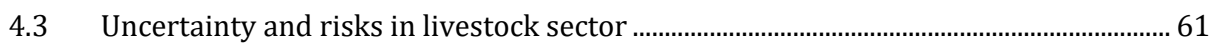

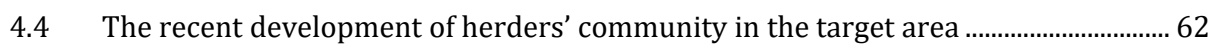




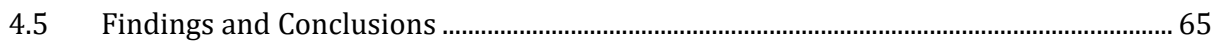

Chapter 5 Sustainable Governance of Rangeland in Mongolia ................................................................ 69

5. Sustainable Governance of Rangeland in Mongolia.................................................................... 70

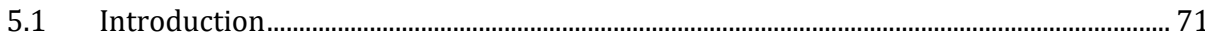

5.2 Rangeland management practices and livestock sector development in Mongolia.. 73

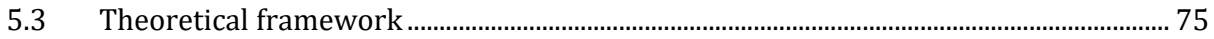

5.4 Research methodology and hypotheses ………...................................................................... 76

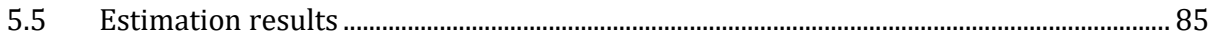

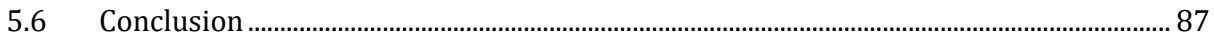

Chapter 6 Options for Increasing Mongolia's Livestock Sector Exports A Revealed Comparative Advantage Analysis.

6. Options for Increasing Mongolia's Livestock Sector Exports - A Revealed Comparative

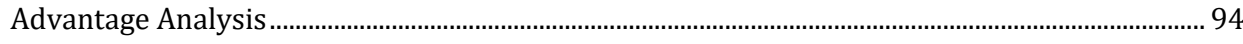

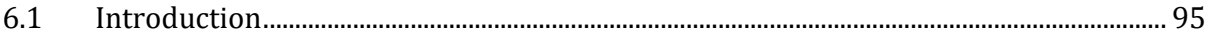

$6.2 \quad$ The Livestock Sector and its Exports ……...................................................................... 97

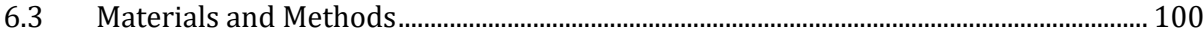

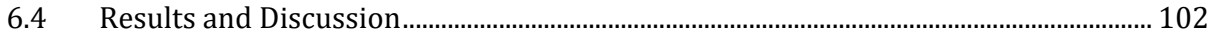

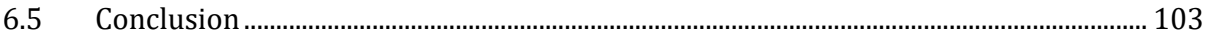

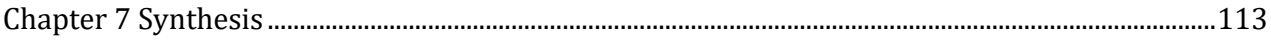

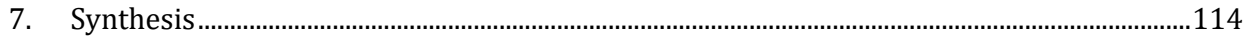

7.1 Research objectives and questions ..................................................................................114

7.2 General conclusions and implications …….......................................................................119 


\section{List of Figures, Tables}

\section{Tables}

Table 2.1. Livestock number in Ugtaal soum

Table 2.2. Livestock number in the Gurvansaikhan soum

Table 2. 3. Payoff matrix for the game between two symmetric herders.

Table 2. 4. Drought and dzud conditions in Ugtaal and Gurvansaikhan in 1998-2002 compared to average situation in 1990-2002, and assessment of theoretical carrying capacity compared with actual livestock numbers.

Table 2.5. Caloric terms of trade in Ugtaal and Gurvansaikhan, 1998 and 2002

Table 2.6. The estimated herder game using primary data, when the strategy is to choose herd growth rate.

Table 4.1. Statistical Information on PUGs in Ulziit soum

Table 5.1. Operationalization and expected effects of explanatory variables

Table 5. 2. Descriptive statistics

Table 5. 3. Regression results for rangeland quality

Table 6.1. Export of Products of Animal Origin from Mongolia, thousand US Dollar

Table 6.2. The occurrences of 'A-level' animal diseases in Mongolia

\section{Figures}

Figure 2. 1. Carrying-capacity model

Figure 2. 2. Estimated optimal livestock numbers (sheep units x 1000) in Ugtaal and Gurvansaikhan

Figure 2.3. Scatter plot of strategies in Ugtaal and Gurvansaikhan

Figure 4.1. Major risk elements its causes identified by herders of Ulziit soum

Figure 4.2. Stakeholders are discussing and debating to define PUGs boundaries, Photo by Erdenechuluun Tumur

Figure 5.1. Livestock numbers and rangeland area in Mongolia, from 1986-1990 to 2009-2012 (NSO 1986-2012)

Figure 5.2. Carrying capacity, actual utilization and grazing pressure by aimags, 2010 (ALAGC, 2013).

Figure 5.3. Distribution of livestock by herding households, 2010 (NSO, 2011) 
Figure 6.1. Trends in livestock numbers, source: NSO data (National Statistical Office (NSO), 1990-2018)

Figure 6.2. The occurrences of the foot-and-mouth disease by location between 2000 and 2017 Source: GAVS, 2020

Figure 6.3. Average share of exported products of animal origin from Mongolia by country, 2010-2018, Source: Customs Office of Mongolia (Mongolian Customs, n.d.) 


\section{Abbreviations}

ADB Asian Development Bank

ALAGC Administration for Land Affairs, Geodesy and Cartography

APUGs Associations of Pasture User Groups

CBNRM Community-Based Natural Resources Management

CC Carrying Capacity

CGIAR Consultative Group on International Agricultural Research

CPR Centre for Policy Research

CToT $\quad$ Caloric Terms of Trade

ETP Potential Evapotranspiration

FMD Foot-and-Mouth Disease

GAVS General Agency for Veterinary Services

GDP Gross Domestic Product

GG Green Gold

GGPEMP Green Gold Pasture Ecosystem Management Programe

IFPRI International Food Policy Research Institute

IMF International Monetary Fund

ITC International Trade Center

MFSPA Mongolian Forage Seed Producers' Association

MMM Mongolian Meat Association

MoFALI Ministry of Food Agriculture and Light Industry

MSRM Mongolian Society for Rangeland Management

NAFUG National Federation of Pasture User Groups

NAMHEM National Agency for Meteorology, Hydrology and Environment Monitoring

NGO Non-Governmental Organization 


$\begin{array}{ll}\text { NSO } & \text { National Statistical Office } \\ \text { NSOM } & \text { National Statistical Office of Mongolia } \\ \text { OIE } & \text { World Organization for Animal Health } \\ \text { PMP } & \text { Pasture-Management Plans } \\ \text { PREM } & \text { Poverty Reduction and Environmental Management } \\ \text { PUGs } & \text { Pasture User Groups } \\ \text { RCA } & \text { Relative Comparative Advantage } \\ \text { RIAH } & \text { Research Institute of Animal Husbandry } \\ \text { SCC } & \text { Savings and Credits Cooperative } \\ \text { SDC } & \text { Swiss Agency for Development and Cooperation } \\ \text { SLMCD } & \text { Sustainable Land Management for Combating Desertification } \\ \text { SLP } & \text { Sustainable Livelihood Project } \\ \text { SU } & \text { Sheep Unit } \\ \text { UNDP } & \text { United Nations Development Program }\end{array}$






\section{Chapter 1}

General Introduction 


\section{GENERAL INTRODUCTION}

The transition of a centralized socialist economy to a market economy in Mongolia since 1990 has led to significant changes in the socio-economic and environmental conditions of the country. One of them was a sharp increase in livestock numbers versus a deterioration of open-access rangeland conditions and climate changes. On the one hand, livestock is the primary livelihood source of rural households in Mongolia directly, and the sector provides major foodstuffs to all over Mongolia. On the other hand, the massive increase in livestock numbers creates high pressure on the rangeland and leads to rangeland degradation caused by overgrazing and other problems in the long run. Finding the appropriate ways to balance these two interlinked issues raises the global question of rural poverty and natural resource use. In recent years, different initiatives promoting community-based rangeland management have emerged to address these problems. It is crucial to obtain insights into the relationship between poverty and sustainability of rangeland use under different arrangements for community-based rangeland management systems in different agro-ecological zones in Mongolia.

\subsection{Background}

The agricultural sector of Mongolia was the third-highest growth sector in 2019 after mining and service sector. The export of the agricultural output was 494.8 million US dollars, which accounted for 8.0 percent of the total export of the country, and the livestock sector produces more than 80 percent of total agricultural production (NSO, 2020). Mongolia has a high potential to export livestock origin products as the country has 70 million open-range pastoral livestock and a vast territory to develop agri-business. The main export products of the livestock sector from Mongolia are meat, cashmere, and hides, and skins (Mongolian Customs, 2020).

Rangeland or grassland covers about 80 percent of the total land area of Mongolia and supports the livelihood of almost 170,000 households herding more than 70 million heads of livestock (NSO, 2020). In other words, about one third of the Mongolian population relies directly on proceeds from an extensive livestock economy. However, the grazing land feeding the animals is severely degraded mainly by human behavior-related factors such as taking advantage of free grazing land and access to water without sustainably managing these natural resources. As a result, some forms of degradation indicated about two-thirds of the total rangeland area by 2017 (Densambuu et al., 2018). The present degraded condition and further risk for degradation are alarming such that in the future it will be even more challenging to provide for the necessary amount of feed for the increasing livestock.

Rangeland degradation caused by overgrazing is one of the most significant environmental challenges that Mongolia is facing mainly because the livestock number has tripled from 1990 to 2019 (NSO, 2020). The number of livestock increased from 25.8 million in 1990 to 70.1 million in 2019. According to various scientific studies, the livestock population is much overstocked compared to the carrying capacity of the rangeland by more than 30 million heads (MoFALI, 2018; NSO, 2018; Densambuu et al., 2018; SDC, 2015). Exceeding the carrying capacity of the pastureland caused scarcity of fodder, increased vulnerability to drought, $d z u d$, and other natural disasters, which can cause loss of millions of livestock in a short time. The main reason for the increase in livestock number is a lack of Government policy on rangeland management and markets to regulate its natural expansion. 
At the beginning of the transition period in 1990-1993, the Soviet style system of agricultural cooperatives (negdels) was abolished. The herds were privatised and the negdels dissolved. Consequently, the livestock sector shifted to mainly subsistence-level production based on small household economic units. At that point, policymakers thought that the privatization of livestock and the liberalization of prices for livestock products would promote a smooth shift of the agriculture sector to the market system. Privatization of the livestock took place before the appropriate livestock support services, capable of functioning under market conditions could be in order to replace the former negdel service and state procurement system. These changes meant that all of the risks related to weather and prices as well as the responsibilities for production and marketing passed to herding families who had no experience of running businesses in a market economy. Herders responded rationally to these risks by increasing the herd size to the detriment of free state-owned pasturelands and by decreasing the utilization of purchased inputs.

Under the pressure of increased livestock numbers and the absence of adequate regulations, the traditional best-practice grazing patterns were violated. The subsequent overstocking began to destroy the ecological balance, the keystone of nomadic pastoralism. The overgrazing and degradation of rangeland became more severe in areas close to water points and rural settlements. The reserve rangeland, which were used in former times in times of scarcity such as dzud and drought, were occupied permanently, which contributed to mass losses of animals during emergencies.

The gap between rich and poor herders increased, and the incidence of poverty among herding communities is becoming more acute. Because of transportation possibilities, need for seasonal labor, and possibilities to market their products, poor herders must stay close to urban centers where pasture quality has declined.

Three consecutive years of severe dzud from 1999 to 2002 resulted in a total loss of 11 million head of livestock, leaving about $6 \%$ of 190 thousand families with no livestock at all. The second severe dzud happened in 2009-2010, where more than 10 million heads of livestock died. Besides being a social disaster, the reduction of livestock numbers temporarily reduced the stress on the environment. The harsh consequences of $d z u d$ and drought proved that the national pastoral risk management system was weak and could not protect the extensive livestock sector in a sufficient way.

Governance issues at different levels present challenges to promoting improved rangeland, livestock, and enterprise management practices. Despite being on Parliament's agenda for three decades, and intensive society-wide discussions in recent years, the new law on rangeland management is still not discussed for approval in the Parliament. Therefore, it is clear that political will backed by widespread consensus on the need for new laws to address open-access and regulate rangeland use is challenging to achieve.

Many policy goals relevant to herders are being pursued through subsidy programs funded by the Government of Mongolia. Concerns with equity of access, transparency in decision making, patronage for political gains, and shortcomings in program effectiveness are pervasive in all issues, including subsidies for intensification of livestock production and support for cooperative development. Central government funds for subsidies will increase in the coming years, in addition to which the new Integrated Budget Law requires increased decentralization of funds to 
allow local levels to decide how funds are spent. Thus, improved participatory governance at a local level is ever more critical in ensuring that funds are allocated equitably and effectively to local constituents' genuine needs, and in ways that support and do not hinder sustainable rangeland management.

Since 2000, donor agencies have been supporting the development of herders' community-based rangeland management as a framework for collective action by herders. The opportunities and challenges presented by the development context can be addressed by building on past lessons and achievements. Donor agencies have been using two main approaches to the introduction of community-based rangeland management in Mongolia (Amgalan et al., 2010). These are: i) a territorial approach to rangeland management, where all traditional users of a certain territory are organised in Pasture User Groups (PUGs), ii) the formation of voluntary herder groups, which are organised primarily on the basis of a combination of kinships, shared use of key resources and common interest for joint activities. Little is known, however, about the impact of these community-based management institutions on the quality of rangeland.

In the future, rangeland-based livestock production will continue to be the backbone of Mongolia's food security, rural employment, and rural livelihoods, even as increasing numbers of the younger labor force shift into non-agricultural sectors. The transformation of rangelandbased livestock production from traditional risk-prone, extensive systems to more productive, market-oriented systems is clearly the long-term direction required to support livelihoods and well-being in rural Mongolia. Mongolia increasingly has the necessary financial resources to support this transition. But significant challenges are faced in achieving this transition. Improved rangeland management, livestock productivity and herders' economic unit all require collective action among herders, enabled by supportive actions of local Government operating in accountable ways within a clear legal and policy framework, and informed by relevant range assessment and reliable data. The development of influential collective herder organizations and the active participation of herders in local budgeting processes can make critical contributions to overcome these challenges.

\subsection{Problem Statements}

As a consequence of the transition of a centralized socialist regime to a market economy in Mongolia since 1990, the herding system changed from state-controlled pasture management to open access with herders being free to move anywhere and use pasture freely. During the collectivization era (1960-1990), the management of natural resources like rangeland and water was brought under state control and executed by the negdel (cooperative). The cooperatives played a significant role in allocating rangeland and campsites and directing seasonal movements, often respecting pre-existing customary rights, but seasonal movements between soums (secondary administrative unit and subdivisions of aimags in Mongolia) and aimags (the largest admininstrative unit in Mongolia equivlient as province) were regulated and tightly controlled (Fernandez-Gimene, 2006).

The collapse of the socialist system had a huge impact on rural livelihoods. The collectives disbanded, and livestock ownership transferred to individual herders. Pasture management by the state virtually disappeared, rendering the herding system de facto open access. The dismantling of the collectives left a regulatory void in the area of pasture management and the services they once provided deteriorated or disappeared. Consequently, herders became 
responsible for all production inputs, risks, and decisions. The hot ail (a primary unit of herding society comprised of cooperating households who customarily camp together and jointly possess winter/spring shelters and associated rangelands) reemerged as the smallest socio-economic unit, and customary informal norms of land use coordination reemerged (Usukh et al., 2010).

The setting aside of reserve rangeland, haymaking, and regular seasonal movements of herders declined sharply. Livestock services shift to local governments, but their limited capacity also led to a sharp decline. As a result of the economic transition, livestock numbers increased from 24.7 to 70.1 million animals during the last three decades. Moreover, the open-access system, combined with the rapidly growing livestock numbers, has resulted in significant deterioration of rangeland. Available estimates of rangeland degradation indicate that between 13 - 65 percent is deteriorated in some form (Densambuu et al., 2018).

The most recent policy document 'Action plan for the Mongolian Agenda for Sustainable Livestock' approved by the Minister of Food, Agriculture and Light Industry in June 2018 has set targets to restore, rehabilitate and utilize pastureland and water resources sustainably and responsibly, to adapt to climate change and to reduce the livestock number by 5 million sheep units from 2017 to 2020 based on the fact that the pasture carrying capacity is exceeded by 25 million sheep units.

A third of Mongolians continue to live in poverty, with the rural poverty rate remaining stubbornly high at over $30 \%$ in 2018 . Rural poverty rate always higher than national average in all years during last decades although poverty rates has shown a decreasing trend. According to the "Poverty Profile in Mongolia" conducted by the National Statistical Office of Mongolia and the World Bank in 2018, the high food price has a negative impact on poor urban citizens while it has a positive impact on poor rural citizens (NSO \& World Bank, 2020). The majority of herders practice extensive grazing, with little if any intensification of production inputs. Herds and incomes are vulnerable to a frequent natural disasters. Livestock productivity is low, and herders receive limited returns due to limited product diversity, poor product quality, and weak integration into value chains. Economic incentives for improved rangeland management and livestock production are limited by constraints on the export of livestock products due to frequent outbreak of contagious diseases and phytosanitary concerns. Increasing herd size remains the primary household strategy for increasing incomes, and overgrazing on open-access rangelands is a widespread threat to the longer-term sustainability of the agricultural sector and natural environment.

Like in most agriculture-based countries, socio-economic and ecological developments are inextricably linked in Mongolia. In particular, pasture degradation and poverty are causally related and reinforce each other. Degrading rangeland leads to a net loss in the productivity of the livestock economy and thus is a serious threat to the sustainability of rural livelihoods. Increasing poverty drives herders into less and less sustainable resource utilization patterns, such as limited or no seasonal mobility, out-of-season grazing, and the preference for resistant but ecologically more harmful livestock species such as goats.

Economic, as well as non-economic interventions, may be considered to stimulate herders towards sustainable rangeland management and thereby alleviate their poverty. Therefore, a thorough understanding is needed of the behavioral responses of herders to economic and noneconomic factors and signals. Unfortunately, there are no rigorous economic, social, or 
anthropological studies of the factors influencing herder behavior in Mongolia yet (Usukh et al., 2009).

Traditionally Mongolian herders cooperated in neighborhood groups. These customary communities are formed around the use of one and other type of area-based key resources such as seasonal camping areas and water points. In forest-steppe areas these groups are generally called afterea valley and river. In the steppe and Gobi regions they called as after a specific water source. They usually have customary arrangements for regulating the use of key resources. The strength and frequency of cooperation among members of this type of herding community varies greatly from case to case starting from just simple consultation on one and other issue to deep joint collaboration on complicated business-related activities such as organizing joint longdistance migration and marketing efforts.

Since 1999, Mongolia has become a de facto testing ground for community-based rangeland management, with the establishment of over 2000 "herder groups" and "pasture user groups" facilitated by over 12 different donor and NGO sponsored programs (Mau \& Chantsallkham, 2006). Donor agencies have been using three main approaches to the introduction of communitybased pasture management in Mongolia. The Sustainable Livelihood Project (SLP) financed by the World Bank and the Green Gold Pasture Ecosystem Management Programe (GGPEMP) funded by the Swiss Agency for Development and Cooperation rely on a territorial approach to rangeland management, which has been endorsed by the Administration for Land Affairs, Geodesy and Cartography (ALAGC) in Mongolia. This approach has included in the draft law on rangeland. The SLP relies on the leadership and capacity of local governments to develop and implement pasture management plans in consultation with herder groups. At the same time, the GGPEMP uses a more intensive bottom-up approach where pasture user groups and their federations lead planning as well as implementation. The Sustainable Land Management for Combating Desertification (SLMCD) project of the UNDP, on the other hand, builds on voluntary herder groups, which has organized primarily based on a combination of kinships, shared use of key resources and common interest for joint activities.

The extent to which these institutional arrangements will be able to promote sustainable rangeland management will depend to a large degree on prevailing local conditions in different parts of Mongolia. A wide variety of agro-ecological zones characterizes Mongolia, thus varying from equilibrium to disequilibrium systems. An equilibrium system with short and regular seasonal migration routes exits in the forest-steppe region, and a disequilibrium system, with very long and irregular seasonal and inter-annual movement, is in the desert steppe and the steppe regions. Pasture management systems must be adapted to the prevailing conditions in each zone, and institutional arrangements must be able to accommodate both seasonal and interannual movements, which differ in scope and frequency across the different agro-ecological zones.

\subsection{Research Objective and Questions}

The objective of this study is "to obtain insights into the relationship between poverty and sustainability of rangeland use under different arrangements for community-based rangeland management system in different agro-ecological regions in Mongolia." 
In order to achieve the research objective, the following questions, and sub-questions addressed. Thus:

1. What are the characteristics of current rangeland management in Mongolia? To what extend is the pastoral livestock sector in Mongolia different from that in other countries? (Chapter 1 - 6)

2. Which specific properties distinguish rangeland from other common pool resources? What are the implications for the design of institutional arrangements to promote sustainable rangeland use? (Chapter 2-3)

3. What are the impacts of current institutional arrangements for community-based rangeland management on rangeland conservation? (Chapter 5)

4. What are the impacts of existing institutional arrangements for community-based rangeland management on poverty alleviation? (Chapter 2, 5 and 6)

In the brackets after each research questions indicate the respective chapters that are dealing with present research question.

\subsection{Literature review}

There is a considerable body of literature that tries to identify the set of conditions that are crucial for the sustainable governance of common-pool resources.

Common pool resources, such as forests, aquatic resources, and rangelands, contribute significantly to rural livelihoods in many parts of the world (Fernandez-Gimenez, 1999; 2002; Meinzen-Dick et al., 2006; Mwangi \& Markelova, 2009). Although humans have used rangelands for consumptive and non-consumptive purposes for centuries, it was only in the early 1900 s that researchers first began to study problems associated with sustainable management of rangelands. In this context, sustainable management of rangeland refers to "the manipulation of rangeland components to obtain the optimum combination of goods and services for society on a sustained basis" (Holechek et al., 2001).

Sustainable rangeland management has received considerable attention amongst common pool resource scientists and scholars during the last three decades (Baland \& Platteau 2003; Fratkin \& Mearns 2003; Mearns 2004; Mau \& Chantsallkham 2006; Mwangi 2007; Ho \& Azadi 2010; Ykhanbai et al., 2011). Fratkin (1997) reviewed governance and development issues of pastoralism in different countries including Maasai pastoralists in East Africa, and pastoralists in India, Mongolia and China, and argued that the future of pastoralist populations is far from certain. Pastoral practices, including the tendency of individual herders to maximize their herds, coupled with an increasing number of herders, are viewed as major factors promoting desertification. In Western China, rising livestock prices have contributed to a massive increase in the number of livestock and a sharp decline in the available rangeland area per livestock unit. In contrast, in Northern China, rangeland degradation is caused by changing livestock demography, mushrooming permanent grazing encampments, year-round grazing, and an almost entirely new disaster preparation and response method (Cao et al., 2013). Agrawal $(2001,2003)$ summarises the terms put forward in the influential works by Wade (1988), Ostrom (1990) and Baland and Platteau (1997), as well as extending the set of conditions distinguished in sustainable 
governance of common-pool resources studies further, and grouping them into six clusters: resource system characteristics, group characteristics, the relationship between resource system characteristics and group characteristics, institutional arrangements, the relationship between resource system and institutional arrangement, and external environment (Ostrom, 1990; Agrawal, 2001; Ostrom, 2009).

Degradation of common-pool resources through open access has been named the "tragedy of the commons" (Hardin, 1968). However, there are many common property regimes where access is well managed and limited to specific users, and where no degradation occurs. The terminology is therefore somewhat unfortunate. It would be better to call it the "tragedy of open access" (Bromley \& Cerna, 1989).

Economic theory and observed practice across the world suggest that a variety of common-pool resources (forests, pastures, fisheries, water, air) have threatened by open access. In economic terms, open-access goods are rivalrous and non-exclusive goods. Increasing pressure on such resources leads to the dissipation of resource rents through overuse (Gordon, 1954). While full privatization is one way of eliminating open access (Hardin, 1968), it is often not feasible. In the case of the Mongolian pasture, where mobility of animals within years and across years is required, it is also inefficient. Common pool resources can often be sustainably managed by clearly defining resource boundaries, use rights, withdrawal quantities, and monitoring rules that have implemented via collective management (Ostrom, 1990; 2009). In the case of rangeland management, defining rangeland boundaries and membership of user groups are considered important factors and essential prerequisites of secure tenure, and are therefore of crucial importance for successful common-property rangeland management regimes (FernandezGimenez, 2002).

There are many examples of successfully managed common pool resources (Hardin 1968; Baland \& Platteau, 1997; 1998; Fratkin \& Mearns, 2003; Baland \& Francois, 2005; Ho \& Azadi, 2010). Several of these examples have shown how to avoid a tragedy in a situation where the population is overgrowing, and the absolute number of people who live in poverty is steadily increasing (Heijman, 1991; Fernandez-Gimenez \& Batbuyan, 2004). What can we learn from these experiences in managing common-pool resources, so that it can emerge as an institution on a larger scale? To address these kinds of questions, an analysis of their basic characteristics may help to understand why, how, and what kind of institutions can emerge at the community level to manage common-pool resources (Hardin, 1968).

Mau, G. and J. Chantsallkham studied the establishment of herders' self-help groups under various terms like groups and partnerships facilitated by different donor and NGO sponsored programs that has testing ground for community-based rangeland management in Mongolia since 1990 (Mau, G. \& J. Chantsallkham., 2006). Following advice from external experts, some donor projects began to support community-based natural resource management (CBNRM) in Mongolia as a potential option to address problems of rural poverty and resource degradation in the absence of strong pastoral institutions. The process of engaging herder communities in resource management expanded from the initial efforts to address the consequences of the dzud, to institution building objectives through devolution of rights to herder groups (Upton, 2005). According to Ulambayar et al, Mongolian herders' groups have greater ultimate social outcomes, specifically, they undertake more traditional and innovative management practices, exhibit more 
proactive behavior to solve resource issues, and members have more household assets, one indicator of enhanced livelihoods (Ulambayara \& Fernández-Giménez, 2017).

\subsection{Methodology}

Each chapters of research deals with different methodologies to answer the research questions.

The concept of 'carrying capacity' is a center of the research and it generally deals with the relationship between land (rangeland) and livestock. To get an idea about the carrying capacity of the land for livestock, range management scientists use 'rules of thumb' to assess whether there are too many animals on the land, and hence a high probability of land degradation because of overutilization. Overutilization can result in further degradation (erosion, diminishing biomass production, desertification), and hence a downward spiral of deteriorating conditions for livestock production. Often, these rules of thumb are rather crude and static.

The carrying capacity is the stocking rate that can be sustained by a particular grazing unit during the grazing season without degrading the quality of the land, taking into account rangeland productivity (ALAGC, 2013; Tserendash \& Altanzul, 2013).

The research also includes the concept of 'population supporting capacity' in our analysis. In its most simple form, it translates the calculated carrying capacity, or the observed numbers of animals, into the number of people that can be fed from the land on a subsistence basis. Apart from the size of the livestock, information on meat and milk production of these animals is incorporated in the analysis and the associated caloric values are compared to people's caloric requirements.

The 'population supporting capacity', which holds the restrictive assumption of full subsistence herding, we also look at 'caloric terms of trade'. This indicator gives the caloric rate which animal products can be traded against other food products such as grain and potatoes. In most parts of the world these terms of trade are favorable for the herder, but they also vary with rangeland conditions, as these influence the supply of animal products.

The application of 'game theory analyses' is one of the tools to investigate stakeholder's behavior to consider open-access resources to deal with sustainability and carrying capacity dynamics. Through game theory analysis research aim to highlight the unsustainable nature of herder behavior. The herders are playing a game about which herd size to maintain. Herders' decisions, however, have inevitable consequences when they choose to maximize their herd sizes, the risk of adverse impacts of possible $d z u d$ or drought, or diseases increases.

On the other hand, when they choose to slaughter a more substantial proportion of their herds, they may not fully benefit from the (winter) grazing opportunity. Since they compete for the same rangeland/grassland, they also have to take the strategies of other herders into account. We can demonstrate the mechanism of this game by a hypothetical two-person, two-strategy representation. We assume two identical herders, Herder 1 and Herder 2, where Herder 2 represents all the other herders contesting for the same winter pasture. In the analysis, Herder 1 is 'played' in turn by every herder in our sample. 
A mixed effect regression model was used to identify the main characteristics of herders community that influence rangeland quality. The quality of the rangeland, as perceived by herder households, is used as the dependent variable. It is measured through the answer to the question concerning perceived changes in quality of the rangeland.

The research has investigated export of animal-oriented products in combination with other policies to limit the number of livestock such as developing of a meat export and industry along with strategic animal breeding, reintroducing of livestock tax, supporting more productive animals, etc. In this purpose, the comparative advantage of animal-oriented products assessed using the revealed comparative advantage index in order to identify export opportunities for different types of animal-oriented products.

A popular approach to estimating the effect of technology and factor supplies on comparative advantage uses Balassa's measure of Revealed Comparative Advantage (Balassa 1965). This index, sometimes so-called Balassa index, is share of a good in a country's exports divided by the share of that good in world exports. The normalized dependent variable of the index can be interpreted directly as a measure of the relative trading position of the country. In other words, the Balassa index measures normalized export shares concerning the exports of the same industry in a group of reference countries. These theoretical concepts provide a brief description of the relevance of the theories and methodologies used and how these theories are related to the study context-further discussions of the methods presented in the respective chapters from two to six.

Relevance to policy questions (valorization) and dissemination of results

Research on the linkages between human behavior, poverty, and the degradation of rangeland in Mongolia is severely lacking. The dominant policy have limited until recently to supporting livestock privatization and price liberalization as primary conditions for shifting the sector to a market economy. Herders subsequently adopted the maximization of animal numbers as their primary livelihood strategy. Community-based rangeland management provides more opportunities for herders to invest in their herding business collectively, especially in activities that are beyond individual households' investment capacity and interest like animal breeding, rangeland protection, and fodder preparation. The Government of Mongolia is now making a policy shift towards the promotion of more productivity-oriented strategies, including support of community-based rangeland management in remote areas. This shift in policy was not easy and it took a long way. Still it will take a long way until Mongolian herders adopt it. The absence of proper research in this area seriously undermines the effectiveness of development efforts by the Government and donors. Therefore, a through understanding of linkages between institutional innovation, poverty alleviation, and rangeland conservation have needed for policy and practical considerations. The study is linked to policies of the World Bank and other bilateral/multilateral organizations specifically by the subject of community-driven development and institutional innovation.

Contributions to the literature

Despite the availability of studies on common property resources and their implications for resource management and poverty alleviation, the case of vast rangeland resources and the case of Mongolia has not been studied well. Earlier studies produced did not go far beyond the general 
observation that the behavior of herders to maximize animal numbers contributed to the degradation of rangeland. Moreover, there was no attempt made to separate the effect of nonhuman factors such as climatic change. The impact of the rangeland degradation to market on the herders' livelihood was also studied poorly.

\subsection{Outline of the Thesis}

In chapter 2, we analyze herders' behavior and the dynamics of the pastures' carrying capacity. Herders' behavior analyzed by game theory to characterize the type of game that is being 'played' in the Mongolian livestock sector. Depending on the type of game, different actions can be taken to address the problem of overgrazing and herder poverty. The second objective of chapter 2 is to provide a better insight into the dynamics of the pastures' carrying capacity. The traditional approach of having a fixed carrying capacity is not sufficient to explain the large numbers of animal losses that occurred. It has shown that when we allow the carrying capacity to be dynamic by letting it depend on weather conditions, the cycle of animal losses and increases can have better explained. A final objective is to establish whether a further developed market system might have prevented part of the disaster or could prevent overgrazing in the future. To accomplish this, we look at the so-called Caloric Terms of Trade (CToT) that the herders faced during both good and bad years. This indicator describes at which caloric rate the herders can trade their animal products against other food sources. If these rates are favorable, especially during bad periods, more trading could relieve the pressures faced by the herders.

Chapter 3 is descriptive; therefore, no hypotheses have tested. Instead, the main approaches under development have described concerning organizing herders and local governments to overcome the problem of open access to Mongolia's rangelands. The chapter has covered different approaches of donor organizations such as the World Bank, UNDP, and SDC. The particular attention has paid to the Green Gold-inspired approach for territorial organization of herders and the delineation of territories for PUGs. Since 2006, these have been the standard approaches promoted by the Administration of Land Affairs, Geodesy and Cartography. The vision of the PUG system is a bold one, in which PUGs and Associations of Pasture User Groups (APUGs) are comprehensively organized throughout Mongolia and take the lead in pasture and animal management and improvement. In chapter 5 , we investigate how much progress the PUG system has achieved in the pilot soums, and compare its performance with approaches that are more reliant on local Government for leadership and voluntary herder groups.

Chapter 4 focuses on best practices and challenges of pasture user groups in the Gobi region as represented by Ulziit soum of Dundgobi aimag. The chapter deals with specification rangeland management in the Gobi region where needs to have a long distance move to seek better grazing areas or areas with less $d z u d$ and drought and have high pasture yields and good water supply. This chapter developed a case study basis to present conditions in the Gobi region with the comparison of soums supported by Green Gold projects to other soums. Establishing PUGs is recognized as an essential tool to help collective action of herders not only in the Green Gold project target areas but also in other areas like their neighboring soums and otor arrangement. The descriptive analysis of the study shows the importance of policy attention for livestock sector in the Gobi region. For instance, in addition to PUGs approach, specific attention still required for large mobile communities outside the boundaries of the PUGs as well as soum and aimag 
territory. Finding a solution for this phenomenon would be a great support to secure herders' livelihood in the Gobi region.

Chapter 5 is a study of community-based rangeland management experiences of Mongolia. In recent years, community-based rangeland management approaches such as PUGs have introduced in selected regions of Mongolia to explore appropriate mechanisms for countering rangeland degradation. The chapter analyze the performance of this newly introduced institutional arrangement in Mongolia. The critical enabling conditions for sustainability of the concept of the commons form the theoretical framework. The empirical results indicate that clear definitions of the boundaries of rangeland and its users are essential preconditions for the sustainable governance of rangeland management. Inequality in herd sizes within a PUG negatively affects rangeland quality, the impact of group size resembles an inverted U-shaped relationship. Thus intermediate group sizes, therefore, have the highest monitoring effort on rangeland management and lead to the best outcomes in terms of natural resource quality. PUGs with lower external financial aid have fewer opportunities to implement right rangeland management strategies.

Chapter 6 investigates the comparative advantage of selected livestock-oriented products using the revealed comparative advantage index to show export opportunities for different types of livestock-oriented products. The results of the study illustrate that there are possibilities to develop export-oriented livestock production in Mongolia in various stages. The export of livestock-oriented products in combination with other policies are a way to substantially reduce the livestock population to sustainable levels, reduce overgrazing pressure, and increase the country's export income. Long term policy on meat and other livestock-oriented products should provide for a legal framework of rangeland use to secure the sustainable development of the livestock sector of Mongolia.

Finally, chapter 7 discusses the main conclusions, explores their implications, and presents recommendations for policymakers and other relevant stakeholders.

\section{References}

Agrawal, A. (2001). Common property institutions and sustainable governance of resources. World Development 29(10): 1649-1672.

Agrawal, A. (2003). "Sustainable governance of common-pool resources: context, methods, and politics." Annual Review of Anthropology 32: : 243-262.

ALAGC (2013). Grazing pressure and stocking rates by aimags. Administration for Land Affairs, Geodesy and Cartography (ALAGC), Retrieved June 17, 2013, from http://www.gazar.gov.mn.

Amgalan, O., D. Avaadorj, B. Batbuyan, A. Batmandakh, M. H. Binswanger, B. Bolormaa, D. Buyankhishig, J. Chantsallkham, D. Dorligsuren, M. Dovuuch, B. Erdenetsetseg, M. Erdenetuya, E. Tumur, E. Ganbat, R. Himmelsbach, S. Jigjidsuren, T. Khishigjargal, M. Olonbayar, B. Purev, K. Schuler, T. Sukhtulga, M. Suvd, Udval and Y. Zagdsuren (2010). Livelihood study of herders in Mongolia, Swiss Agency for Development and Cooperation (SDC), Mongolian Society for Rangeland Management (MSRM), Selengepress Co.Ltd. Ulaanbaatar Mongolia 
B. Balassa (1965). Trade liberalisation and 'revealed' comparative advantage, Manchester.

B. Densambuu, S. Sainnemekh, B. Bestelmeyer and U. Budbaatar. (2018). National report on the rangeland health of Mongolia: second assessment," Green Gold-Animal health project, Swiss Agency for Development and Cooperation (SDC); National Federation of Pasture User Groups (NAFUG) Mongolia, Ulaanbaatar

Baland, J. M. and J. P. Platteau (1997). "Wealth inequality and efficiency in the commons .1. The unregulated case." Oxford Economic Papers-New Series 49(4): 451-482.

Baland, J. M. and J. P. Platteau (1998). "Wealth inequality and efficiency in the Commons, part II: the regulated case." Oxford Economic Papers-New Series 50(1): 1-22.

Baland, J. M. and P. Francois (2005). "Commons as insurance and the welfare impact of privatization." Journal of Public Economics 89(2-3): 211-231.

Baland, J.-M. and J.-P. Platteau (2003). Chapter 4: Economics of common property management regimes. In: K. G. Maler and J. R. Vincent (eds.), Handbook of Environmental Economics. Vol. 1. Amsterdam, Elsevier.

Batsaikhan Usukh, Hans P. Binswanger-Mkhize, Raffael Himmelsbach and Karl Schuler (2010) Fostering the sustainable livelihoods of herders in Mongolia via collective action, Swiss Agency for Development and Cooperation (SDC), Mongolian Society for Rangeland Management (MSRM), Selengepress Co.Ltd. Ulaanbaatar Mongolia

Bromley, D.W. and Cernea, M.M. (1989). The management of common property natural resources: some conceptual and operational fallacies. World Bank Discussion Paper 57. World Bank, Washington DC.

Cao J., T., E.T. Yeh, N. M. Holden, Y. Qin and Z. Ren (2013). "The roles of overgrazing, climate change and policy as drivers of degradation of China's grasslands." Nomadic Peoples 17(2): 82-101.

Fernandez-Gimenez, M. E. (1999). "Sustaining the steppes: A geographical history of pastoral land use in Mongolia." Geographical Review 89(3): 315-342.

Fernandez-Gimenez, M. E. (2002). "Spatial and social boundaries and the paradox of pastoral land tenure: A case study from post socialist Mongolia." Human Ecology 30(1): 49-78.

Fernandez-Gimenez, M. E. (2006). Land use and land tenure in Mongolia: A brief history and current issues. pages 30-36. U.S. Department of Agriculture, Forest Service, Fort Collins.

Fernandez-Gimenez, M. E. and B. Batbuyan (2004). "Law and disorder: Local implementation of Mongolia's Land Law." Development and Change 35(1): 141-165.

Fratkin, E. (1997). "Pastoralism: Governance and development issues." Annual Review Anthropology 26: 235-261.

Fratkin, E. and R. Mearns (2003). "Sustainability and pastoral livelihoods: Lessons from East African Maasai and Mongolia." Human Organization 62(2): 112-122. 
Gordon, H. S. (1954). The economic theory of a commonproperty resource: The fishery. Journal of Political Economy, 62(2):124-142.

Hardin, G. (1968). "The Tragedy of the Commons." Science 162(3859): 1243-1248.

Heijman, W. J. M. (1991). Depletable resources and the economy. Department of General Economics. Wageningen, Wageningen Agricultural University. PhD thesis.

Ho, P. and H. Azadi (2010). "Rangeland degradation in North China: Perceptions of pastoralists." Environmental Research 110(3): 302-307.

Holechek, J. L., R. D. Pieper and C. H. Herbel (2001). Range management principles and practices. Upper Saddle River NJ, Prentice-Hall.

Mau, G. and J. Chantsallkham (2006). Herder group evaluation. Ulaanbaatar, United Nations Development Program (UNDP) Mongolia.

Meinzen-Dick, R., E. Mwangi and D. S (2006). "Securing the commons." Policy Brief No. 4 CGIAR Systemwide programme on collective action and poverty rights. Washington, D.C., IFPRI.

MoFALI. (2018). Introduction of the pastureland law of Mongolia, Ministry of Food Agriculture and Light Industry (MoFALI), Ulaanbaatar

Mongolian Customs. (2020). "Mongolian Customs: Trade statistics data," Mongolian Customs, [Online]. Available: http://www.customs.gov.mn/en/services/trade. [Accessed 93 2020].

Mwangi, E. (2007). "Subdividing the Commons: Distributional Conflict in the Transition from Collective to Individual Property Rights in Kenya's Maasailand." World Development 35: 815-834.

Mwangi, E. and H. Markelova (2009). "Collective Action and Property Rights for Poverty Reduction: A Review of Methods and Approaches." Development Policy Review 27(3): 307-331.

NSO and the World Bank. (2018). Mongolia poverty update 2018: Main report of household socioeconomic survey 2018, National Statistical Office (NSO) of Mongolia, Ulaanbaatar

NSO. (2018). Livestock number and rangeland carrying capacity, Monthly Statistical Bulletin, National Statistical Office (NSO), Ulaanbaatar

NSO. (2020). Statistical Yearbook of Mongolia, National Statistical Office (NSO), Ulaanbaatar, Soyombo Printing.

Ostrom, E. (1990). Governing the Commons: The Evolution of Institutions for Collective Action. Cambridge University Press, Cambridge; New York.

Ostrom, E. (2009). Social-ecological systemsa general framework for analyzing sustainability of socialecological systems. Science, 325:419.

SDC. (2015). National report on the rangeland health of Mongolia, Green Gold-Animal health project, Swiss Agency for Development and Cooperation (SDC), National Federation of Pasture User Groups (NAFUG) Mongolia, Ulaanbaatar 
Tserendash, S., \& Altanzul, T. (2013). Handbook for pasture management. (Ulaanbaatar, Mongolia).

Tungalag Ulambayara and María E. Fernández-Giménez. (2017) How community-based rangeland management achieves positive social outcomes in Mongolia: a moderated mediation analysis, Land Use Policy 82 (2019) 93-104.

Upton, C. (2005). Institutions in a pastoral society: Processes of formation and transformation in postsocialist, Central Asia and its neighbors, Comparative Studies of South Asia, Africa and the Middle East A Duke University Press, Vol. 25, No. 3, 584-599.

Wade Robert. (1988) Village republics: Economic conditions for collective action in South India, New York and Cambridge, Cambridge University Press.

Ykhanbai, H., B. Narantungalag, S. Tserendash, T. Saipolda, U. Beket, Z. Tsogt, B. Bolormaa, T. Tserenbaljir, E. Bulgan, T. Odgerel, B. Bynyie, B. Miagmarjav, N. Munknasan, N. Togtokhbayar, L. Erdenetugs and N. Baatarbileg (2011). Community based co-management of natural resources in Mongolia. Ulaanbaatar, ADMON. 



\section{Chapter 2}

Pastureland degradation and poverty among herders in Mongolia: data analysis and game estimation 


\section{PASTURELAND DEGRADATION AND POVERTY AMONG HERDERS IN MONGOLIA: DATA ANALYSIS AND GAME ESTIMATION*}

\subsection{Introduction}

After the collapse of communist rule in Mongolia, in 1991, the demise of the livestock collectives resulted in private (household-based) livestock ownership and unclear range management institutions. Between 1991 and 1998 the livestock sector rapidly expanded, partly assisted by relatively good weather conditions, and partly by many new entrants in the livestock economy as a result of de-industrialisation of the urban economy. In 1990 Mongolia had 25.9 million domesticated animals. In 1998 this had grown to 32.9 million, an increase of $27 \%$.

Between 1990 and 1998 the weather conditions were indeed rather favourable. Compared to the 1980s rainfall was higher, and winters were less severe (Batjargal et al., 2000). The carrying capacity of the Mongolian grazing lands improved, and the growing livestock population could, on average, be accommodated by these improved grazing conditions. However, changes in livestock mobility and range management styles, as well as unclear grazing institutions under privatized livestock regimes, already created carrying-capacity tensions in some areas. Where water wells were no longer maintained, some grazing areas were abandoned, resulting in condensed grazing in other areas ${ }^{1}$.

These early signs of overuse in some places turned into a national disaster when weather conditions worsened after 1998. Between 1999 and 2002, winter conditions were very severe and Mongolian herders and livestock were faced with consecutive $d z u d s$; the Mongolian term for winters when ice and snow prevent animals from foraging on pastures. Furthermore, the spring and summer rainfall was also disappointingly low during these years. This meant grass was less abundant in the autumn when the animals usually renew their fat reserves for the coming winter. Together this resulted in estimated losses of 12 million animals nationwide; out of an estimated 190,000 herding households in 1998, 11,000 families lost all of their animals (Danker, 2004, p. 26). In December 2002 the total number of animals had gone down to only 24 million, back to the level of the late 1980s.

Part of the reason these losses were so extreme is because the capability to provide emergency feed for the animals (which used to be the responsibility of the collectives) had been eroded. Most district authorities did not have enough feed stored, nor was there enough transport capacity to distribute the stocks that were available to the distressed herders and animals. The livestock sector found itself in a transitory state between the collectives of the old system and a mature

\footnotetext{
* Paper by Sebastiaan M. Hess, Auyrzana Enkh-Amgalan, Antonius J. Dietz, Tumur Erdenechuluun and Byamba Purev, published as a book chapter in Cambridge University Press, Nature's Wealth: The economics of ecosystem services and poverty, 2013, pp. 373-390, ISBN 978-1-107-69804-8
}

${ }^{1}$ According to CPR, 2003, out of 41,600 wells operational in 1990, only 30,900 were still operational in 2000 . 
free-market system with its own emergency relief mechanisms ${ }^{2}$. Because 70 years of communist rule had also destroyed the old communal institutions this transitory period basically meant the range lands were in a state of open access, illustrated by the large of new, inexperienced entrants in the livestock sector. The disasters of the late 1990s and the early years of the new century are therefore a case example of Hardin's 'Tragedy of the Commons' (1968), or more fittingly, a 'Tragedy of Open Access' (Bromley \& Cerna, 1989).

This tragedy is often associated with the prisoners' dilemma game, in which actors make choices about their natural resource use in isolation and end up in a suboptimal situation. If the situation can indeed be characterized as a prisoners' dilemma, and had the actors taken their decisions cooperatively, both they and the environment would have been better off. Establishing institutions that facilitate such cooperative decision-making can alleviate the Tragedy.

In this chapter, one of the main objectives is to use game theory to characterize the type of game that is being 'played' in the Mongolian livestock sector. Depending on the type of game, different actions can be taken to address the problem of overgrazing and herder poverty.

A second objective of this chapter is to provide a better insight into the dynamics of the pastures' carrying capacity. The traditional approach of having a fixed carrying capacity is not sufficient to explain the large numbers of animal losses that occurred. It is shown that when we allow the carrying capacity to be dynamic by letting it depend on weather conditions, the cycle of animal losses and increases can be better explained.

A final objective is to establish whether a further developed market system might have prevented part of the disaster or could prevent others in the future. To accomplish this we look at the socalled Caloric Terms of Trade (CToT) that the herders faced during both good and bad years. This indicator describes at which caloric rate the herders can trade their animal products against other food sources. If these rates are favourable, especially during bad periods, more trading could relieve the pressures faced by the herders.

The remainder of this chapter is organized as follows. Section 2.2 starts with a description of the study sites and Section 2.3 presents our research methods. Results and their discussion are provided in Section 2.4 followed by conclusions and policy recommendation in Section 2.5.

\subsection{Study site}

Two areas were studied. The first area, Ugtaal soum (district) in the Tov aimag (province) is in the north (in an area often referred to as the 'forest steppe'). This area has more rainfall and more severe winter conditions. The second area, Gurvansaikhan soum in Dundgovi aimag, is in the south close to the Gobi desert.These two districts were selected for the following reasons:

They have different levels of pasture degredation.

They are in different ecological regions, varying ecological conditions and land-use patterns. They vary in terms of how they were impacted by the 1999-2002 dzuds.

\footnotetext{
${ }^{2}$ According to the National Statistical Office of Mongolia (unpublished data, 2003) the land for the natural hay production for winter storage decreased from 1.2 million to 0.8 million hectares (out of c. 129 million hectares of natural pasture), between 1989 and 2002. Green fodder and silage production more or less disappeared, and manufactured feed production was more than halved.
} 


\subsubsection{Ugtaal}

Ugtaal is located in Mongolia's steppe region and was created in 1924. The soum centre is closer to the capital $(155 \mathrm{~km})$ than to its own aimag centre $(177 \mathrm{~km})$. It covers a land area of 154800 ha, out of which 110700 ha is pasture. The remainder consists mostly of arable land and forests, but there is also some land reserved for haymaking. According to the 2003 soum statistics, 23000 hectares of pastures had been degraded. The soum's population stood at 2816 as of January 2004, with a total of 715 households.

Table 2.1. Livestock number in Ugtaal soum

\begin{tabular}{lrrrrr}
\hline & 1999 & 2000 & 2001 & 2002 & 2003 \\
\hline Camel & 2 & 9 & 2 & 4 & 6 \\
Horse & 8402 & 7858 & 6949 & 6296 & 5490 \\
Cattle & 7088 & 6758 & 3836 & 3238 & 2630 \\
Sheep & 38011 & 41358 & 28810 & 24901 & 19737 \\
Goat & 12712 & 16319 & 14105 & 14987 & 13357 \\
Total & 150804 & 151644 & 113174 & 101909 & 85998 \\
\hline
\end{tabular}

Note: Total is expressed in sheep units (SU): 1 sheep $=1 \mathrm{SU}, 1$ horse $=7 \mathrm{SU}, 1$ cattle $/$ yak $=6 \mathrm{SU}, 1$ camel $=5 \mathrm{SU}, 1$ goats $=0.9 \mathrm{SU}$.

Source: Soum's livestock census data, 1999-2003. Livestock data are collected in the autumn of each year.

The main economic activity is livestock herding and crop farming. Livestock was severly affected by the dzuds in 2000-02. In 2000 the number of livestock reached its maximum level of 152000 sheep units. At the end of 2003, there were only 86000 sheep units left in the soum (a decrease if $43 \%$ ). The available data on livestock are presented in Table 2.1 .

There were also corresponding socio-economic tensions. In 2002 there were 105 households who lost all their animals. On the other hand, the share of households with more than 200 animals increased from 6\% in 1997 to almost 10\% in 2003; a clear case of asset polarization.

\subsubsection{Gurvansaikhan}

The second study site is located in the Gobi region. The district centre lies $331 \mathrm{~km}$ south of the Ulaanbaatar and the distance to the aimag centre is $71 \mathrm{~km}$. Gurvansaikhan is much less densely populated than Ugtaal. Its population is just a bit smaller, standing at 2960 (673 households) in January 2004, but the soum covers 542000 ha. Consisting almost entirely of pastureland (99\%).

As with most other soums in Mongolia, the primary economic activity is livestock herding. Gurvansaikhan was hit especially hard by the 1999-200 dzud and drought. Fifty per cent of all horses died, and losses among cattle amounted to a staggering $82 \%$. In total sheep units, numbers went down from 289000 to 142000 . However, from 2000 onwards, livestock numbers increased again to a level of around 203000 sheep units in 2003 (see Table 2.2). 
Table 2.2. Livestock number in the Gurvansaikhan soum

\begin{tabular}{lrrrrr}
\hline & 1999 & 2000 & 2001 & 2002 & 2003 \\
\hline Camel & 1794 & 1465 & 1369 & 1324 & 1303 \\
Horse & 13475 & 6701 & 7099 & 7628 & 8321 \\
Cattle & 10157 & 1867 & 1673 & 2174 & 2862 \\
Sheep & 73275 & 48161 & 54100 & 58277 & 65731 \\
Goat & 57674 & 31222 & 41963 & 49724 & 61549 \\
Total & 289419 & 141695 & 158443 & 176089 & 203059 \\
\hline
\end{tabular}

Note: Total is expressed in sheep units (SU): 1 sheep $=1 \mathrm{SU}, 1$ horse $=7 \mathrm{SU}, 1$ cattle $/$ yak $=6 \mathrm{SU}, 1$ camel $=5 \mathrm{SU}, 1$ goats $=0.9 \mathrm{SU}$.

Source: Soum's livestock census 2000-2003. The animal numbers are collected in the autumn of each year.

Household herds are generally larger in Gurvansaikhan, but we see the same trend as in Ugtaal with the share of households with larger numbers of animals increasing from 2000 onwards. The two dstricts also differ in one other important factor: migration. In Ugtaal the number of households decreased between 2000 and 2003, whereas Gurvansaikhan showed an increase, although there was some out-migration in 2000-01.

\subsection{Data and methodology}

As mentioned in the introduction, there were three main objectives in the project. In this section the methods used to reach these objectives will be described.

\subsubsection{Carrying-capacity dynamic and market-based population supporting capacity}

The concept of 'carrying capacity' generally deals with the relationship between land (pasture) and livestock. To get an idea about the carrying capacity of the land for livestock, range management scientists use 'rules of thumb' to assess whether there are too many animals on the land, and hence a high probability of land degradation because of overutilization. Overutilization can result in further degradation (erosion, diminishing biomass production, desertification), and hence a downward spiral of deteriorating conditions for livestock production. Often, these rules of thumb are rather crude and static. Current thinking in range management circles recognizes that livestock management on collective levels needs to be based on more complex models and therefore talk more notice of the variability in range conditions. These include:

- The availability and accessibility of range lands, whilst also looking at the distribution of water points, and the relative differences in security, social and legal barriers, and labour availability for movements to remote areas;

- The relative usefulness of different types of biomass for livestock utilisation, which partly depends on range management institutions;

- The weather conditions, with lower-than-average (spring and summer) rainfall translating into more than proportional decreases of feed availability (including hay production for winter storage). Moreover, the differences in severity and length of winters, particularly in Mongolia, directly affects range lands' stress level.

In our quantitative analysis we will focus on the third aspect to start making concept of carrying capacity more dynamic, and try to establish the cause of environmental degradation in Mongolia. 
We also include the concept of 'population supporting capacity' in our analysis. In its most simple form it translates the calculated carrying capacity, or the observed numbers of animals, into the number of people that can be fed from the land on a subsistence basis. Apart from the size of the livestock, information on meat and milk production of these animals is incorporated in the analysis and the associated caloric values are compared to people's caloric requirements.

To move away from this simple form of population supporting capacity, which holds the restrictive assumption of full subsistence herding, we also look at CToT. This indicator gives the caloric rate which animal products can be traded against other food products such as grain and potatoes. In most parts of the world these terms of trade are favourable for the herder, but they also vary with pasture conditions, as these influence the supply of animal products. Using primary and secondary data on prices and caloric values of both animal and non-animal food products, we can show the changes in the CToT over the cycle of the disasters that struck Mongolian herders.

\subsubsection{The inter-herder game in Mongolia}

Through game theory analysis we aim to highlight the unsustainable nature of herder behaviour. To picture the kind of game we will try to estimate, let us consider the following situation: it is November and winter is about to start. Imagine a delineated winter grazing area in a Mongolian region. The summer grass-growth season is over and the winter pasture is restored and ready to be grazed. This is the time for the herders to decide on the off-take in their herds by slaughtering a number of their animals.

This situation can be formalised by identifying strategies and players in a game as follows. The herders are playing a game about which herd size to maintain. Herders' decisions, however, have certain consequences. When they choose to maximise their herd sizes the risk of negative impacts of possible $d z u d$ or drought, or diseases increases. On the other hand, when they choose to slaughter a larger proportion of their herds, they may not fully benefit from the (winter) grazing opportunity. Since they compete for the same pastures, they also have to take the strategies of other herders into account.

We can demonstrate the mechanism of this game by a hypothetical two-person, two-strategy representation. We assume two identical herders, Herder 1 and Herder 2, where Herder 2 represents all the other herders contesting for the same winter pasture. In the analysis, Herder 1 is 'played' in turn by every herder in our sample3

Both one's own strategy and that of other herders will determine the survival rate of the herd and hence, one's payoff. According to strategies adopted, payoffs can be classified in different groups: when both herders keep their livestock constant they both obtain $x$, when herders increase their livestock they both obtain $y$, when one herder increases his herd and the other keeps his herd constant, the herd increasing herder obtains $a$ and the herd maintaining herder obtains $b$. Table 2.3 shows the resulting payoff matrix.

\footnotetext{
${ }^{3}$ Hence, we assume a 1 versus n-1 persons game (see also Lise 2001, lise et al. 2001) in which Herder 1 interprets the actions of other herders as a simultaneous move. One of the earliest accounts of games among herders is the herdsman game by Muhsam (1973), which is also analysed in a 1 versus $n-1$ person setting.
} 
The type of game herders face when competing for grazing pastures is determined by looking at actual herder behaviour. In a field survey carried out in winter of 2003-04 we collected data on the strategy of herder households, their view of other herders' strategy and payoff of each household. In both Ugtaal and Gurvansaikhan 60 herding households were interviewed in an even split between 'poor' (<200 animals) and 'rich' households (>300 animals).

Table 2. 3. Payoff matrix for the game between two symmetric herders.

\begin{tabular}{llll}
\hline & \multicolumn{3}{c}{ Herder 2: } \\
\hline \multirow{3}{*}{ Herder 1: } & Keep herd constant & $x, \mathrm{x}$ herd constant & Increase herd size \\
& Increase herd size & $a, b$ & $b, a$ \\
\hline
\end{tabular}

We base herders' strategies on information about offtake and offspring, indicating the growth rate of the herd. The perceived strategy of other herders was proxied by the perceived environmental conditions of the herders. We assume that a negative perception is linked to a herder's view that the other herders are maximizing their herds, since this will have a negative effect on the pastures, and vice versa. Finally, for the payoff we used net income from the herd, including costs of fodder purchases, veterinary services, sales of animals and animal products. Unfortunately, own consumption of animal products by the household could not be included in the net income because of the response to these questions in the survey was incomplete. For details on the survey and the constructed variables the reader is referred to Lisa et al. (2006).

Knowing both the strategy of Herder 1 and his perception of the strategy of the other herders, we can place his payoff in one of the four cells in Table 2.3. By calculating the average payoff in each group and determining the order between the groups we will be able to establish which type of game is played on the windy plains of Mongolia ${ }^{4}$.

Since we hypothesized a prisoners' dilemma game we expect to find the following relationship between the payoff groups:

$a>x>y>b$,

which can be conceptualized as such: if Herder 2 (all other herders) maintains his/her herd, there will be more grass left for Herder 1 who can feed his herd without purchasing additional and expensive fodder. If Herder 2 maximizes his/her herd, it is still better for Herder 1 to do the same, as he/she may not be sure whether the pasture will be in good condition, once he/she accesses it in the winter. Both herders, however, are best off with a mutual constant herd size, so that they are in a better position to face a possible dzud, since the impact of a dzud will be much more severe in the case where they both start with a large herd. The sane reasoning is true for droughts, as it is much more difficult to maintain a large herd during a drought than a smaller more mobile herd.

\footnotetext{
${ }^{4}$ For more details on the technical aspects of the estimation process the reader is referred to Lise (2001).
} 


\subsection{Results and discussion}

\subsubsection{Carrying capacity and market-based population}

In order to make the concept of carrying capacity more dynamic, we looked at weather data for the 1990s and early years of the twenty-first century. We calculated an aridity index for all years, based on the precipitation data for the vegetable period ${ }^{5}$, divide by a proxy for evapotranspiration for the same period 6 .

In Ugtaal rainfall was mostly in the semi-arid range prior to $1995(>0.25)$ and in the arid range after 1995. Rainfall in Gurvansaikhan was in the arid range for the whole period. If we compare the severity of drought and dzud conditions for 1998-2002 with the period as a whole we find that Ugtaal in 1998 was a drought and severe dzud year. In 2000 there was another severe dzud, followed by a somewhat warmer summer in 2001 and another severe drought in 2002. In Gurvansaikhan 1998 was not a problematic year, but 1999 and especially 2000 were very problematic drought years, made worse by an additional dzud in 2000. The year 2002 was also a severe drought year.

These drought and dzud conditions are summarized in Table 2.4. We also add a tentative assessment of the variations in carrying capacity in sheep units based on both the aridity index for the two areas and on a hypothetical carrying capacity model; this combines the aridity index

\footnotetext{
${ }^{5}$ We define vegetative periods for grasslands as all 10-day periods between the first and the last measurement of an average temperature of $5^{\circ} \mathrm{C}$ for that 10 -day period, based on data provided by the Meteorological Service of Mongolia for Ugtaal and Gurvansaikhan. For both areas the vegetative period is between 140 and 180 days, normally between somewhere in April and somewhere in September.

6 This was based on the assumption that the average temperature for the vegetative period (see note 5) $\mathrm{x}$ 100 gives an adequate evapotranspiration assessment. With the existing evapotranspiration levels in summer, and spread of rainfall during the year, we estimate that Mongolia has arid conditions $(\mathrm{P} / \mathrm{ETP}<$ $0.25)$ when annual rainfall is below $250 \mathrm{~mm}$. and semi-arid conditions $(0.25<\mathrm{P} / \mathrm{ETP}<0.40)$ when rainfall is between 250 and $400 \mathrm{~mm}$. This means that we assume that for Mongolia as a whole the annual evapotranspiration is in the range of $1000 \mathrm{~mm}$.
} 
with Environmentally sustainable sheep unit numbers. ${ }^{7}$ Figure 2.1 shows the carrying-capacity model and the results for the two soums are depicted in Figure 2.2.

Table 2. 4. Drought and dzud conditions in Ugtaal and Gurvansaikhan in 1998-2002 compared to average situation in 1990-2002, and assessment of theoretical carrying capacity compared with actual livestock numbers. ${ }^{8}$

\begin{tabular}{|c|c|c|c|c|c|c|c|c|c|c|}
\hline \multirow[t]{4}{*}{ Variable } & \multicolumn{5}{|l|}{ Ugtaal } & \multicolumn{5}{|c|}{ Gurvansaikhan } \\
\hline & 1998 & 1999 & 2000 & 2001 & 2002 & 1998 & 1999 & 2000 & 2001 & 2002 \\
\hline & /99 & $/ 00$ & /01 & /02 & $/ 03$ & /99 & $/ 00$ & /01 & /02 & $/ 03$ \\
\hline & & + & + & + & ++ & & + & ++ & & ++ \\
\hline $\begin{array}{l}\text { Temperature } \\
\text { vegetative period }\end{array}$ & & & & & & & & & & \\
\hline $\begin{array}{l}\text { Precipitation } \\
\text { vegetative period }\end{array}$ & - & & & & -- & & -- & -- & & -- \\
\hline Aridity assessment & 16 & .20 & .25 & .17 & .09 & .10 & .04 & .04 & .07 & .04 \\
\hline Aridity & - & & & & -- & & -- & -- & & -- \\
\hline DROUGHT & Yes & No & No & No & Yes! & No & Yes! & Yes! & No & Yes! \\
\hline Temp. Oct-Mar & - & & -- & & NA & & & -- & & NA \\
\hline Snow-d. Oct-Mar & ++ & & + & & NA & + & & & & NA \\
\hline DZUD & Yes! & No & Yes! & No & No & Yes & No & Yes & No & NA \\
\hline SU/ha & 1.1 & 0.8 & 1.3 & 1.2 & 0.5 & 0.5 & 0.3 & 0.2 & 0.4 & 0.2 \\
\hline $\begin{array}{l}\text { Theoretical carrying } \\
\text { capacity }^{9}\end{array}$ & 132 & 96 & 156 & 144 & 60 & 265 & 159 & 106 & 212 & 106 \\
\hline $\begin{array}{l}\text { Carrying capacity } \\
\text { based on sample } \\
\text { areas }\end{array}$ & 114 & 96 & 128 & 136 & 54 & 90 & 60 & 80 & 130 & 10 \\
\hline Actual SU & 156 & 145 & 147 & 109 & 98 & 276 & 281 & 139 & 154 & 173 \\
\hline
\end{tabular}

\footnotetext{
7 This is based on Dietz (1987: 83), which in turn was based on an analysis of carrying capacity assessments for African rangelands, derived from aridity indexes. The most sophisticated source was KSS (1982: 46-47). The model is based on an empirically derived assumption that if aridity (P/ETP) is equal to $0.1,0.25$ and 0.4 , the carrying capacity would be $0.5,2.5$ and 10 sheep units per hectare, respectively. This is based on the overall assumption that one sheep unit would have a live-weight of $30 \mathrm{~kg}$, and a total annual feed consumption of $300 \mathrm{~kg}$, with less than $15 \%$ of all bio-mass production consumable in the hyper-arid area, between 15 and $25 \%$ in the arid area, and between 25 and $40 \%$ in the semi-arid area. ${ }^{8}$ In this theoretical assessment of the Carrying Capacity the accessibility of rangelands is not taken into account. As was stated in section 3, a shortage of water points, social and legal boundaries, a shortage of labour availability, etc. can reduce the amount of actually usable pastures. As we know, livestock mobility reduced and rangeland management (e.g. the maintenance of wells) deteriorated after 1990. This resulted in condensed grazing in some areas, particularly around sum and aimag centres, where some social services are provided, and around the remaining water points. The actual Carrying Capacity of the two sums is therefore probably lower.

${ }^{9}$ We use 120000 ha of realistic pastureland for Ugtaal and 530000 ha of realistic pasture land for Gurvansaikhan.
} 


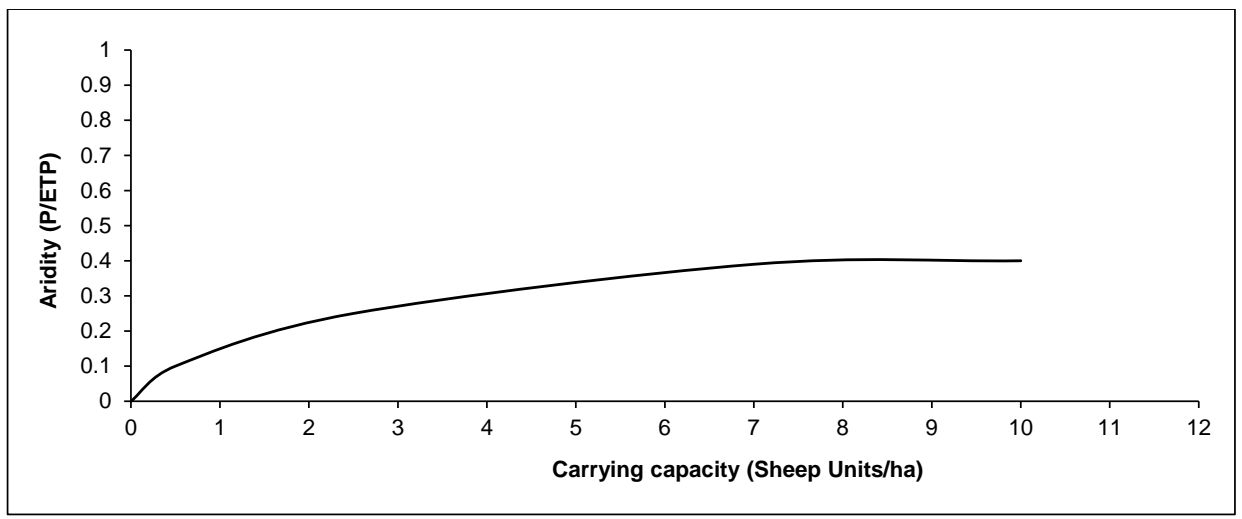

Figure 2. 1. Carrying-capacity model

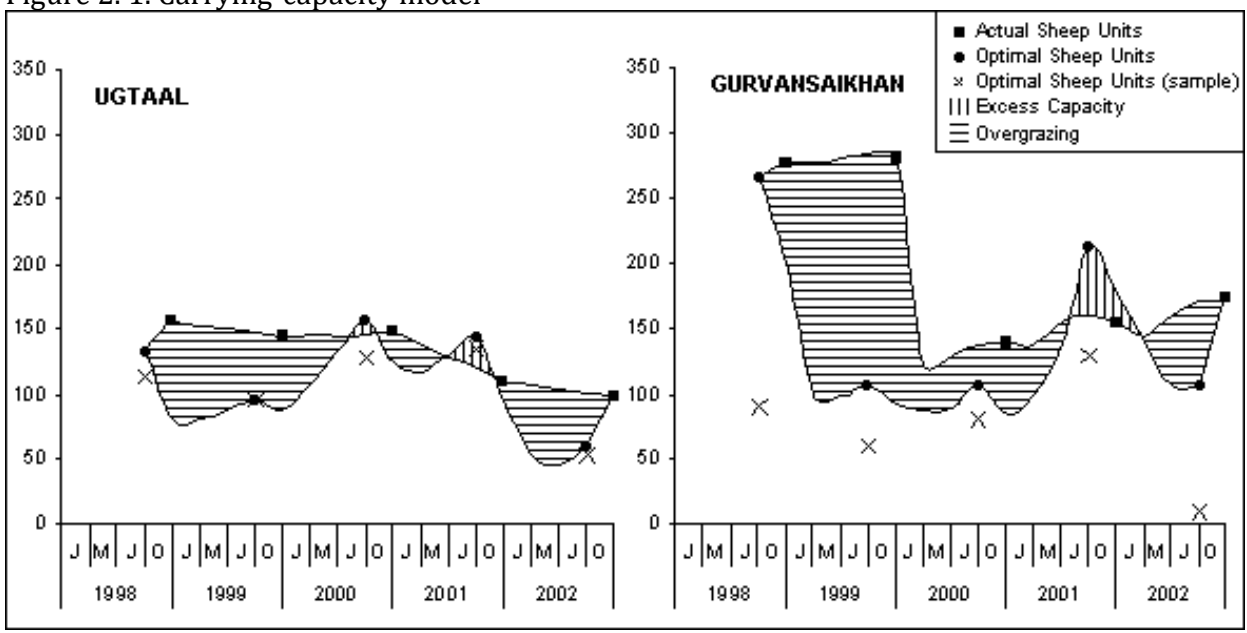

Figure 2. 2. Estimated optimal livestock numbers (sheep units $x 1000$ ) in Ugtaal and Gurvansaikhan

During the worst rainfall years in Gurvansaikhan (i.e. 2000 or 2002) the potential sheep units per hectare can be estimated around 0.2. During high rainfall (e.g. 1996) the carrying capacity increases to 0.7 sheep units per hectare. The average 'static' measure for 1990-2002 as a whole is 0.4 sheep units/ha. Actual sheep units decreased from 289000 in 1999 to 142000 in 2000. However, after 2000 livestock numbers increased again to a level of 176,000 sheep units in 2002. In Gurvansaikhan stock numbers were (far) in excess of optimal (theoretical) carrying capacity in 1999 and 2000, due to the adverse conditions. Indeed the slump in livestock numbers brought an adjustment to much lower levels. In 2001 weather conditions improved a bit and so did livestock numbers, which for a few months were below the optimum carrying capacity. However, soon the actual numbers exceeded the optimum numbers again.

For Ugtaal the worst rainfall years (i.e. 2002) have a carrying capacity of close to 0.5 sheep units per ha, and the best rainfall years (e.g. 1994) close to 3 sheep units/ha, with an average 'static' figure for Ugtaal of 1.4 sheep units/ha. In actual sheep units, the situation deteriorated from about 150000 in 1999-2000 to 100000 in 2002. Compared to the theoretically derived assessment of 
sustainable numbers of sheep units the situation between late 2000 and early 2002 was close to the optimum level, with some excess grazing capacity around October in both years. In the period before late 2000 and after early 2002 there were more sheep units than the theoretical carrying capacity. In 2003 the carrying capacity was locally judged to be exceeded by $20 \%$, and patches of degraded pasture were visible.

In Table 2.4 and Figure 2.2 we also add an assessment of optimal numbers of sheep units, based on actual grass yields in a few sample areas in the two areas. These were collected by the Range Management Department of the Government of Mongolia. Extrapolation of these data for the area as a whole has been done rather conservatively, which is why we regard the overall figures as being too low. However, the trend based on grass yield samples does resemble the theoretical trend based on our aridity assessment very closely.

\subsubsection{Market-based population supporting capacity}

For both areas we may hypothesize that the deterioration of livestock numbers and of local food production conditions caused a food crisis, which could only be solved by importing food from elsewhere. One possibility would be to sell livestock and buy grain, if the caloric exchange rates were favourable. Let us look at the evidence.

Table 2.5. Caloric terms of trade in Ugtaal and Gurvansaikhan, 1998 and 2002

\begin{tabular}{lcccc}
\hline & \multicolumn{2}{c}{ Ugtaal } & \multicolumn{2}{c}{ Gurvansaikhan } \\
\cline { 2 - 5 } & 1998 & 2002 & 1998 & 2002 \\
\hline Beef t/kg & 550 & $(900)$ & 380 & 700 \\
Mutton t/kg & 600 & $(850)$ & 400 & 700 \\
Horse milk t/l & $\mathrm{NA}$ & $\mathrm{NA}$ & 450 & 550 \\
Wheat flour t/kg & 320 & 380 & 350 & 400 \\
Rice t/kg & 450 & 420 & 420 & 400 \\
beef/wheat & 1.7 & 2.4 & 1.2 & 1.8 \\
CToT beef/wh & 3.2 & 4.6 & 2.3 & 3.4 \\
beef/rice & 1.2 & 2.1 & 0.9 & 1.8 \\
CToT beef/rice & 2.3 & 4.0 & 1.7 & 3.4 \\
mutton/wheat & 1.9 & 2.2 & 1.1 & 1.8 \\
CToT mut/wh & 3.4 & 4.0 & 2.0 & 3.2 \\
horse milk/wheat & NA & NA & 1.3 & 1.4 \\
CToT milk/wh &.. &.. & 9.6 & 10.4 \\
\hline
\end{tabular}

For both areas we can estimate the trends in CToT of trade, based on data on price levels for various products, adjusted to local circumstances: horse milk only has $487 \mathrm{Cal} / \mathrm{l}$, beef $1872 \mathrm{Cal} / \mathrm{kg}$ and mutton $2029 \mathrm{Cal} / \mathrm{kg}$, but wheat flour and rice are both estimated to have 3,600 Cal $/ \mathrm{kg}$ and hence the horse milk/wheat-rice conversion factor is 7.4; the mutton/wheat-rice conversion factor is 1.8, and the beef/wheat-rice factor is 1.9. Table 2.5 compares 1998 with 2002 for both soums.

Looking at the findings for the CToT for these two case study regions we can conclude that in all cases the CToTs improved during the livestock crisis, as expected. However, in Ugtaal levels were always higher than in Gurvansaikhan, probably reflecting the difference in distance to Ulaanbaatar, with 1.2 million inhabitants (out of the current 2.5 million Mongolians) is the 
primary centre of demand. However, CToT levels in and around Ulaanbaatar are much better, both in 1998 and in 2002, than in either of the two case study regions. ${ }^{10}$ The meat-wheat exchange ratio (CToT) in 1998 was almost four times better around the capital city than in Ugtaal and almost six times better than in Gurvansaikhan. In 2002 the relative situation of Gurvansaikhan had slightly improved. When looking at the horse milk-wheat exchange rate(only data for Gurvansaikhan) the difference with the situation around Ulaanbaatar is less extreme.
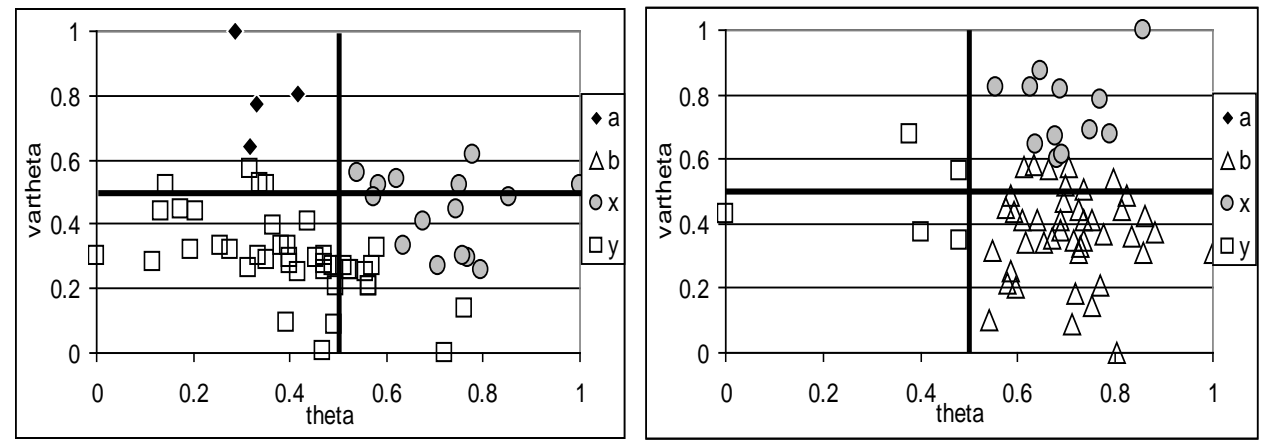

Figure 2.3. Scatter plot of strategies in Ugtaal and Gurvansaikhan

\subsubsection{Game estimation}

In order to obtain insights into the assignment of payoffs to the four payoff groups, the strategies of Herder 1 and Herder 2 are plotted in Figure 2.3 (the strategies are normalized between 0 and 1). ${ }^{11}$ The strategy of Herder 1 is represented by the growth in herd size; low growth is associated with high values, and vice versa, since low growth suggests that the herder scores high on cooperative behaviour. The strategy of Herder 2 is represented by the perception of the environment; high scores stand for positive perceptions. And low ones for negative perceptions, since a positive perception implies that the herder assumes that his/her competitors adopt cooperative behaviour. Figure 2.3 shows the results, where observations in the lower left corner are assigned to payoff group $\mathrm{y}$, those in the upper right to group $\mathrm{x}$, and upper left and lower right are assigned to groups a and $b$, respectively.

The interpretation of Figure 2.3 already leads to an interesting finding, namely that there is more herd size maximizing behaviour in Ugtaal than in Guvansaikhan. This is shown in the figure by the concentration of data in the lower left-hand side in Ugtaal (increasing herd size, quality of the environment perceived to be low) and the right-hand side in Gurvansaikhan (more constant herd size, irrespective of perceived environmental quality).

\footnotetext{
${ }^{10}$ For the calculations of the CToT in Ulaanbaatar see Dietz er al. (2005).

${ }^{11}$ Preliminary results from our game analysis have previously appeared in Lise et al. (2006). Due to improvements in the estimations and the data, the results presented here deviate significantly from those in this prior publication. We believe the current results offer a better interpretation of the actual games played in Ugtaal and Gurvansaikhan.
} 
Table 2.6. The estimated herder game using primary data, when the strategy is to choose herd growth rate.

\begin{tabular}{lllllll}
\hline & $\mathrm{a}$ & $\mathrm{b}$ & $\mathrm{x}$ & $\mathrm{y}$ & Payoff order Name of the game \\
\hline Ugtaal & 655.0 & 455.3 & 268.9 & 248.1 & $\mathrm{a}>\mathrm{b}>\mathrm{x}>\mathrm{y}$ & Non-coordination game \\
& & & & & & \\
Gurvansaikhan & $(8)$ & $(19)$ & $(6)$ & $(27)$ & & \\
& 1330.1 & 942.8 & 1126.9 & 862.0 & $\mathrm{a}>\mathrm{x}>\mathrm{b}>\mathrm{y}$ & Chicken's game \\
& $(2)$ & $(36)$ & $(19)$ & $(3)$ & & \\
\hline
\end{tabular}

Note: the number in the brackets denotes the number of observations within the payoff group. Payoffs are expressed in thousand Tugrik (the local Mongolian currency), which was equivalent to $€ 0.74$ in January 2004 .

The game estimation results are presented in Table 2.6. These results suggest a so-called noncoordination game for Ugtaal and a chicken's game for Gurvansaikhan. This would mean that there are two equilibriums, both characterized by one herder maintaining his/her herd size and the other herder maximizing his/hers. These outcomes suggest that the highest payoffs correspond to a mix of herders, with some striving for low growth and others maximizing their animal numbers. This is difficult to interpret, especially since we simplified our analysis by assuming a two-person game whereby the whole group of herders compete for the same pastures. In any case, maintaining herd numbers leads to a higher payoff than maximizing the size of the herd, so there are no incentives for everyone to simultaneously maximize herd size. The difference in payoff between the two strategies is 20000 Tugriks in Ugtaal and 265000 Tugriks in Gurvansaikhan. However, neither of these strategies constitutes an equilibrium.

Finding a non-coordination game in Ugtaal suggests that there is no voluntary institutional solution to the problem. In view of the lack of institutional solutions, one could think of more coercive government intervention that forces herders to maintain a certain herd size. An alternative would be to create ownership or user rights of the land, which, when adequately enforced, gives clear incentives to take better care of the pastures.

Finding the chicken's game with this particular payoff structure in Gurvansaikhan suggest that in the long run. When the chicken's game us repeated, there could be an equilibrium in which herders keep their herd size constant. ${ }^{12}$ This is only the case, however, if they attach a relatively high value to future income, i.e. if they have a low discount rate. The discount rate will be lower when current income can (easily) satisfy basic needs; otherwise this naturally takes precedence over any longer term considerations. If current income is not high enough, raising it or providing income security could lower the discount rate and increase the chance of reaching an equilibrium in which herds are smaller.

These games were estimated using current payoffs. Of course, expectations about future availability and quality of grazing pastures will also affect herders' decisions about herd size. Offering them better information about the long-term detrimental consequences of continued overgrazing will affect these expectations and could lead to alternative equilibriums.

${ }^{12}$ See Lise (2005) on the estimation of repeated games. 


\subsection{Conclusions and policy recommendations}

After communist rule collapsed the weather became one of the main regulatory factors of animal numbers in Mongolia in the late 1990s and early years of the twenty-first century. Favourable conditions in the years up to 1998 allowed large increases and many new entrants in the sector, leading to overgrazing and land degradation. In a way, nature corrected the overuse when severe winters and droughts hit Mongolia in the latter part of the period and brought animal numbers bac to their old level. This correction mechanism worked, but had disastrous consequences for the people who were dependent on their herds for food and income. Letting nature handle things also has the drawback that land degradation caused by overuse can cause permanent damage to the land.

Fortunately, there are alternatives. Our game estimation results tentatively suggest that the current conditions in Ugtaal provide incentives to some herders to maximize their herds and to others to keep growth low. If this result holds when we relax some of the simplifying assumptions, it would suggest that top down coercive measures would be required to force all herders in lower growth, more sustainable, herding strategies. This could for instance be achieved through fines or taxes. A different approach would be to assign land or use rights to individual herders or herder groups. The game indicates that such strategies would mean lower overall payoffs.

This could partly be compensated by a move towards more market-based livestock rearing. Our analysis on the terms of trade herders faced during the period shows that smaller herds do not necessarily have to mean lower incomes as well. Better use could be made of both the urban and export markets. These markets can be provided with livestock products in exchange for grains, which then become more important in pastoralists' diets.

Increasing herders' payoff from the herding business by taking a more market-based approach would also be very important in Gurvansaikhan. By making it easier to provide for current needs, herders can give more consideration to future effects, and this would lower their discount rate. Our game estimation results for Gurvansaikhan suggest this will increase the chance of ending up in an equilibrium where everyone aims for low growth in animal numbers.

Government agencies can support a move towards more market-based livestock rearing and the accompanying change in diets. This can be done, for instance, by stimulating food trade (e.g. giving credit and training to grain providers) and by stimulating dietary changes (e.g. by modifying school dinners or by including recipes in the popular media). In Mongolia some changes are already visible. Although the official figures about the composition of the Mongolian diet (National Statistical Office of Mongolia, unpublished data, 2003) are rather doubtful ${ }^{13}$, it is quite clear that cereals have indeed become important during the last few years. One can expect further developments along this road of ever more market-oriented pastoralism. Our comparison of the CToT between different regions also suggests that market access is very important. Improving infrastructure could provide market access to more distant regions and increase the profit herders could make from marketing their animal products.

\footnotetext{
${ }^{13}$ Calculated diets for the 1999-2002 periods consists of an average of $507000 \mathrm{Cal} /$ capita, which is much below the necessary food intake of the 'required $950000 \mathrm{Cal} / \mathrm{cap}$ '. Probably a lot of consumption is not measured or taken into account. So the figures about the composition of food intake should also be interpreted with care.
} 
A more market-based approach could be combined with a move towards intensification of the sector, at least for those regions that are close to a large market with the ability to supply additional forage, such as concentrated feed. This could result in further reductions of the pressure on pastures, which is especially large near these large centres.

Even a system with smaller herds, where a larger share of animal products is marketed, needs well-functioning institutions for successful management of water sources and emergency relief during disasters. These institutions do not have to be set up by the government alone.

Considering Mongolia's old communal society, herder cooperation should be actively stimulated by creating more herder groups in which agreements about water source and land management are made. If herders cooperate and have faith in such institutions, the need to maximize the herd as a form of insurance will also diminish.

\section{References}

Batjargal, Z., D. Dagvadorj \& P. Batima (eds.) (2000), Mongolia National Action Programme on Climate Change. Ulaanbaatar: National Agency for Meteorology, Hydrology and Environment Monitoring and JEMR Publishing.

Bromley, D.W. and Cernea, M.M. (1989). The management of common property natural resources: some conceptual and operational fallacies. World Bank Discussion Paper 57. World Bank, Washington DC.

Centre for Policy Research (CPR) (2003). PREM Mid-term Report. CPR, Ulaanbaatar.

Danker, M. (2004), Hörs-Gazar. Cry of a woken bull: changes in pastoral life and pastureland management in Mongolia. MSc Thesis, PREM programme, VU University, Amsterdam

Dietz, A.J. (1987). Pastoralists in dire straits. Survival strategies and external interventions in a semi-arid region at the Kenya/Uganda border: Western Pokot 1900-1986. PhD thesis, University of Amsterdam (published as Netherlands Geographical Studies).

Dietz, A.J., Enkh-Amgalan, A., Erdenechuluun,t. and Hess, S.M. (2005). Carrying capacity dynamics, livestock commercialisation and land degradation in Mongolia's free market era. PREM working paper 05/10. Institute for Environmental Studies, Department of Economics and Technology.

Hardin, G. (1968). The tragedy of thecommons. Science, 162: 1243-1248

Kenya Soil Survey (KSS) (1982). Exploratory Soil Map and Agro-Climatic Zone Map of Kenya 1980. Nairobi: KSS.

Lise, W. (2001). Estimating a Game theoretic model, Computational Economics 18: 141-157.

Lise, W. (2005). A game model of people's participation in forest management in Northern India, Environment and Development Economics, 10: 217-240. 
Lise, W., Garrido, A. and Iglesias, E. (2001). A game model of farmer's demand for irrigation water from reservoirs in Southern Spain. Risk Decision and Policy, 6: 167-185

Lise, W., Hess, S.M. and Purev, B. (2006). Pastureland degradation and poverty within herder communities in Mongolia: data analysis and game estimation. Ecological Economics, 58: 350-364

Muhsam, H.V. (1973). A world population policy for the world population year. Journal of Peace Research, 10: 91-99.

NSOM (2001). National Statistical Office of Mongolia, and World Bank, Mongolia, Participatory Living Standard Assessment 2000, Summary report prepared for the Donor Consultative Group Meeting, Paris, 15-16 May 2001. 




\section{Chapter 3}

\section{Institutional Framework for Sustainable Pasture Management}




\section{INSTITUTIONAL FRAMEWORK FOR SUSTAINABLE PASTURE MANAGEMENT*}

Economic theory and observed practice across the world suggests that a variety of common pool resources (forests, pastures, fisheries, water, air) ${ }^{14}$ are threatened by open access, which leads to the dissipation of resource rents through overuse (Gordon, 1954). In economic terms, they are rival goods and non-exclusive. While full privatization is one way of eliminating open access (Hardin, 1968), it is often not feasible, and particularly not in the case of the Mongolian pasture where mobility of animals within years and across years is required. However, many common pool resources have been sustainably managed by clearly defining resource boundaries, use rights, withdrawal quantities and monitoring rules that are implemented via collective management (Ostrom, 1990, 2009).

In this descriptive chapter, no hypotheses are tested. Instead, the main approaches under development are described in relation to organizing herders and local governments to overcome the problem of open access to Mongolia's rangelands. While we cover the approaches of the Sustainable Livelihood Project (SLP) financed by the World Bank and the Sustainable Land Management for Combating Desertification (SLMCD) project implemented by UNDP, we pay particular attention to the Green Gold-inspired approach for territorial organization of herders and for the delineation of territories for PUGs. Since 2006, these have been the standard approaches promoted by the dministration of Land Affairs, Geodesy and Cartography.

The vision of the PUG system is a bold one, in which PUGs and APUGs are comprehensively organized throughout Mongolia and take the lead in pasture and animal management and improvement. In chapter 6, we investigate how much progress the PUG system has achieved in the pilot soums, and compare its performance with approaches that are more reliant on local government for leadership and on voluntary herder groups.

\subsection{Background}

Management practices of the Mongolian grasslands can be divided into four periods: Manchu rule, early independence, collectivization, and transition to democracy and a free market economy (Upton, 2005; 586).

Under Manchu rule, local nobility and the Buddhist clergy controlled yearly land allocations and the seasonal movement patterns of herders. They were themselves large herd owners and their

\footnotetext{
* Paper by Tumur Erdenechuluun, D.Dorligsuren, D.Buyankhishig, Ts.Sukhtulga and J.Chantsallkham published as a book chapter in Selengepress, Livelihood study of herders in Mongolia, 2010, pp. 33-40, Ulaanbaatar, Mongolia
}

\footnotetext{
14 The terms 'common pool' and 'common property' are sometimes used in a confusing manner. 'Common pool' describes the economic and ecological properties of a resource, while 'common property' is a form of legal tenure. Tenure can be individual or collective, and a range of cumulative privileges are attached to it (Ostrom, 2000; 339). Of relevance to this discussion are usage, possession and ownership rights.

Possession is the right to exclude others, but it does not include the right to sell or lease management and exclusion rights, as is the case with ownership. Technically, user-group managed CPRs are not open access because access is restricted by some form of common tenure. Common property tenure arrangements for use and possession provide planning security that generates incentives for sustainable resource appropriation.
} 
livestock was tended by "common" people. These herders had small herds of their own and were not allowed to leave their territorial unit of residence (khorshoo) (Sneath, 2003).

With the socialist revolution in 1924, the feudal system was abolished. Livestock was distributed among the population, however the land remained public property. Vertical control gave way to informal coordination among groups of households (khot ail). In the 1930s, the Mongolian state began a collectivization program, which proved unpopular and ultimately failed. However, a second attempt at collectivization finally succeeded by the late 1950s. Herders were organized into brigades within collectives (negdel). A negdel covered the area of an entire soum. Livestock was negdel property and was tended in single-species herds by herders who were salaried employees of the collectives. As was the case during Manchu rule, individual herders were allowed small herds for domestic needs. Under the collective system, a number of reforms and innovations in livestock husbandry were introduced and regulations for pasture use were developed. The collective managed seasonal land allocations, planned and logistically supported seasonal movements, established fodder reserves and a system of reserve pastures for emergency use, and provided veterinary and breeding services. The collective also provided nonlivestock services, such as health services and schools.

The collectives were dissolved in the 1990s as part of the transition to the free market. Livestock was privatized, although pastures remained in public hands according to the 1992 Constitution. The dismantling of the collectives left a regulatory void in the area of pasture management, and the services they once provided deteriorated or disappeared. Consequently, herders became responsible for all production inputs, risks and decisions. The khot ail reemerged as the smallest socio-economic unit, and customary informal norms of land-use coordination re-emerged. As discussed previously, some of the consequences of these significant changes in patterns of pastureland use were: An increase in year-round and out of season grazing of areas previously used for emergency reserves or during only one or two seasons; the concentration of livestock near settlements and water points; and overall declines in mobility in terms of the number and distance of seasonal movements.

A number of laws and provisions regarding pastureland management have been enacted since transition. The Land Law, enacted in 1994 and amended in 1998 and 2002, is the present cornerstone of the legal framework governing pastureland. It makes a distinction between land use, possession and ownership, and allows for individual ownership of land in urban areas and small plots of 0.07 ha per person, and for collective possession of land for winter and spring camps. However, individual or collective ownership or possession of pastureland is forbidden.

Under the same law, pasture management responsibilities have devolved to aimag and soum governors, who, in coordination with ALAGC, are supposed to elaborate yearly pastureland management plans. This provision is hampered by implementation difficulties due to the insufficient fiscal resources of local governments and the lack of administrative capacity.

Pastureland use and management planning has been delegated to local-level institutions, but there is little horizontal coordination among them in terms of coordinating their planning activities and managing the common boundaries of emergency reserve areas. Although the Land Law urges soum and bag governors to consult with herders on the establishment of a yearly management plan, this is a discretionary prerogative and herders have no legal right to actively participate in this planning process. Despite the lack of a legal basis for participatory pasture 
management, donor projects are implementing participatory approaches to natural resource management, encouraging contract-based cooperation between soum governors and herder groups. However, there is a substantial amount of uncertainty in relation to that legal basis, which leads to projects sometimes moving ahead of it (Hannam, 2008).

\subsection{Different donor approaches}

Since 1999, Mongolia has become a de facto testing ground for community-based rangeland management, with the establishment of more than 2000 "herder groups" and "pasture-user groups" facilitated by more than 12 different donor and NGO-sponsored programs. Because there is no specific legal status for these groups, they either register as cooperatives (11\%), NGOs (18\%) or do not register at all (71\%) (Mau \& Chantsallkham, 2006).

The focus of these projects is on pasture-management improvement coupled with general livelihood improvement, capacity and skills-building in livestock husbandry and the value-chain enhancement of livestock products.

Three main approaches were taken by three donorfinanced herder-group projects. The first is the Sustainable Livelihood Project (SLP) financed by the World Bank, which is already in its second phase and is currently being extended nationwide. The SLP applies the methodologies and programs adopted by government: It produces maps for each soum and facilitates the preparation of pasturemanagement plans. These are participatory exercises led by the soum governments and bag governors, and are facilitated by soum land officers. Soum and bag governors thus take the lead in the implementation of the plans and hence the SLP has a capacitybuilding component for local governments and for herders. The SLP forms voluntaryherder groups to support the implementation of the pasture-management plans and its components, and for livelihood projects.

The second approach is Sustainable Land Management for Combating Desertification (SLMCD). This project formed voluntary herder groups organized primarily on the basis of a combination of kinship, the shared use of such key resources as wells and winter pastures, and a common interest in undertaking joint activities. These groups were usually fairly small, encompassing from eight to a maximum of 20 households. A significant potential weakness of this approach is that the member households are often spatially intermixed with non-member households, making it difficult to achieve a good match between social and spatial boundaries for resource management (Fernandez-Gimenez et al., 2008).

The third approach is the pasture-user group system (henceforth PUG-S), implemented by the SDC-funded Green Gold project. The GG approach began by supporting relatively small voluntary herder groups. Experience showed that these groups could take over incomegenerating activities and play other roles in the herding community. However, they are not suited for assuming a leading role in addressing the crucial issues of pasture management. Therefore, GG shifted to a territory-based approach in which all traditional users of a certain territory are organized in PUGs (Pasture-User Groups). According to this approach, an entire soum (except for reserved pastureland) is divided into tracts of pastureland that are allocated to PUGs. Pasture allocation and the definition of boundaries is a participatory process that involves herders, bag and soum authorities, professional organizations and project staff. Herders whose camps and pastures are 
located within a designated territory are automatically considered members of a respective PUG (statistics on PUGs can be found in Table 3.1).

The PUG-S is comprised of PUGs as core organizations, which then federate into PUG associations (APUGs) at the soum level. PUG members may form voluntary herder groups for specific activities, however the preparation of pasture-use plans is each PUG's task. Each PUG has a revolving fund, whose assets are managed via a savings and credits cooperative (SCC) at the soum level. PUGs take the initiative in the development of pasture-use and development plans. They are assisted by the APUG at the soum level and closely collaborate with soum and bag governments, assemblies and technicians. Pasture-management plans (PMP) regulate seasonal rotations, the resting of pastures and other technical means of pasture management. PUGs can negotiate and facilitate the seasonal and permanent movements of non-PUG members in and out of their area. APUGs are NGOs that on the one hand regroup the chairs of the individual PUGs, and on the other provide technical know-how for pasture management. An APUG has two permanent staff: a director and an administrative assistant. The APUG director receives training by the MSRM and in turn engages in the capacity-building of PUG chairs. The APUG director not only presides over the APUG, he/she is also the director of the savings cooperative that manages PUG revolving fund assets.

The main conceptual strength of the PUG-S is that membership is defined by locality of residence and resource use, facilitating a better match between the spatial and social boundaries of PUGs and resource units. The challenge of the PUG-S is the size of its groups (40-100 households). Members often do not have close kinship or other social ties, hence communication is more difficult and transaction costs are higher. Currently, ideas are being developed to address this problem, such as how interest or task-based herder groups of a smaller size can be formed and successfully execute their activities under the pasturemanagement umbrella of the PUG. GG also experienced difficulties in its initial stage with community-building. The process was very much leader-driven, with a lack of broad participation and poorly informed herders. However, increased conceptual clarity and the careful participatory introduction of this approach resulted in the astonishingly quick and smooth building of PUG-S in new target soums.

\subsection{Longer-term vision for the Pasture User Group System}

The long-term vision for the PUG-S is that PUGs will become the main planners and actors in sustainable pasture management and improvement. With the support of local authorities and technicians and with co-financing, they will be able to implement sustainable pasturemanagement practices and develop the productivity of the pastureland and their herds. More specifically, PUGs and APUGs will engage in the following tasks, receiving support through training and learning by doing, and with the creation of a more enabling legal environment and collaboration with local governments and service providers:

- Development of institutional capacity and social capital to undertake complex collective tasks for improving herder livelihoods.

- Management of pasture-use and possession rights.

- Regulation and facilitation of seasonal rotations and inter-annual movements.

- The use of various technical solutions for sustainable pasture management.

- Ensuring respect for reserve pastures (otor), agreed jointly with local governments.

- Fostering a gender balance and the equitable sharing of development benefits. 


\section{Chapter 3}

- Conflict prevention.

- Economic diversification and value-chain improvements.

- The regulation of stoking levels and, where necessary, the reduction of livestock numbers.

\subsection{Institution partners of the Pasture User Group System}

\subsubsection{Local government}

Close collaboration is needed between PUGs, APUGs and soum governments (land and extension officers, soum governors and soum khurals). While PUGs can reach agreements on the allocation of rights and pasture-user plans within and among themselves, they require official endorsement, and in the case of rights, they require official allocation. In the event that PUGs and APUGs are unable to reach agreement on boundaries and PMPs, the soum government can facilitate in achieving accord. They can also help negotiate movements inside and between soums, in conjunction with the protected area administration, and set aside otor reserve pastures. However, ultimately only the soum government can allocate rights, enforce their implementation, monitor compliance and sanction trespassing.

\subsubsection{The Ministry of Food, Agriculture and Light Industry}

The Ministry of Food, Agriculture and Light Industry (MOFALI) is a key stakeholder in the PUG-S, particularly in relation to planning, management and coordination of emergency pasture areas within and between aimags and soums. However, the MOFALI suffers from capacity limits and does not have enough personnel to ensure a strong presence at the field level. SDC through GG has supported the Pasture and Fodder Department of MOFALI, and as of last year initiated cooperation in the area of otor pasture management. GG also signed an agreement with the MOFALI concerning herder training, the expansion of extension services at the local level, the development of a national pasture-health monitoring system, and assistance with the drafting of pasture legislation.

\subsubsection{The Agency for Land Affairs, Geodesy and Cartography}

The Agency for Land Affairs, Geodesy and Cartography (ALAGC) is responsible for land allocations, and land officers at the soum level report to ALAGC's aimag agency. Thus, ALAGC is a key partner for any community-based pasture-management initiative. GG has supported and cooperated with ALAGC on several occasions: Firstly, a methodology for land and pasturemanagement plans was jointly elaborated; secondly, training for aimag and soum land managers was jointly organized; thirdly, GG provided capacity-building support to the Land Management Department of ALAGC by enabling 10 officers to attend English-language classes; and lastly, GG provided financial support for a pasture-management specialist position.

GG also provided support to ALAGC to strengthen its collaboration with the corresponding Inner Mongolian agency. ALAGC now exchanges specialists in pasture monitoring and evaluation with Inner Mongolia.

\subsubsection{The Mongolian Society for Range Management}

The Mongolian Society for Range Management (MSRM) coordinates the activities of herders, PUGs, APUGS, governmental organizations, NGOs, universities, research institutes and other stakeholders in the appropriate management of pastureland. The MSRM also initiates APUG NGOs 
at the soum level, which are the backbone of the PUG-S, and provides training and know-how. The MSRM was founded in 2007, partly as a result of GG project activities. In cooperation with GG, the MSRM actively participated in the organization of the "International Rangeland Congress" in 2008 that attracted 120 participants from 19 countries. During a field trip to Mongolia, conference participants visited GG field trial sites and were able to exchange views on pasture management. The MSRM also organized a joint workshop in conjunction with Colorado State University on "Community-based Pasture Management", which led to the development of a common research program on pasture-management issues, to be financed by the university. As well as organizing research events, the MSRM has also been active in knowledge dissemination. It has begun publishing the "Green Gold" newspaper, of which two issues have thus far been produced.

\subsubsection{Collaboration with the Research Institute of Animal Husbandry}

The development of the PUG-S has also benefited from GG's collaboration with the Research Institute of Animal Husbandry (RIAH). Based on mutual agreement, RIAH provided senior scientists as advisors for field research trials. Young GG field researchers have also been accommodated at RIAH, which has created opportunities for them to gain knowledge and experience in research design methodology and the interpretation of research results. SDC also provided financial support for the establishment of a feed evaluation laboratory at RIAH with a capacity to analyze 1000 samples a year. The laboratory has now been certified at the national level and international certification is pending.

\subsubsection{The Mongolian Forage Seed Producers' Association}

The Mongolian Forage Seed Producers' Association (MFSPA) was established as an NGO in 2004 with support from GG. The main goal of the MFSPA is to create seed reserves of perennials and annuals and provide companies, enterprises and herders with seed to increase forage production and rehabilitate degraded pastures and abandoned cropland. A second objective is to provide these groups with seed at affordable and stable prices. With financial support from GG, the MFSPA prepared 218.5 tonnes of forage seeds from 2005-2008 and distributed them to 348 companies, enterprises and herder families at a reduced cost, which enabled the production of 646.7 tonnes of green forage, 197.1 tonnes of hay and 1872 tons of silage.

The MFSPA has been responsible for field trials of the production of green forage, evaluation of perennial and annual species, seed production and the rehabilitation of degraded pastures and abandoned cropland. With support from GG, MFSPA fenced 107ha of land in Bornuur soum in Tuv aimag for the seeding of five species of plants on 59ha in 2008 and 48ha in 2009. The MFSPA will expand the seed multiplication of annuals and perennials on request from the MOFALI. The MFSPA will play a crucial role in the reestablishment of the forage-seed production system, the increase of forage production, the rehabilitation of degraded pastures and abandoned cropland, and the dissemination of knowledge and experience.

\subsubsection{The Mongolian Yak Society}

Given the necessity of improving cooperation with yak breeders, wool-processing factories and research organizations in the quest for possible value-added livestock products, GG supported the establishment of the Mongolian Yak Society in 2007. Through the implementation of a small "Yak Wool" project, the Society achieved a promising result in increasing the income of herders. With support from SDC and GG, the Society established a small-scale wool-processing factory and 
vocational training center in Ikh-tamir (the pilot soum) in Arkhangai aimag. After preparing the trainees, the Society organized training courses in wool-combing and wool-grading, in which 78 herders representing 651 herder families from 20 soums in four aimags participated. During a trade show organized in Ikh-tamir soum, herders sold 14.7t of yak wool to five wool-processing companies. One kilogram of first-grade wool was sold at MNT 3700-4000, secondgrade wool at MNT 2500-2700, third-grade wool at MNT 920-1500.

\subsection{Achievements of the Pasture User Group System}

According to the PUG-S approach, PUGs define the boundaries of pastures among themselves and develop rules based on traditional or newly negotiated arrangements that provide fair access for all members to the available pastureland. Enabling herders to define pasture boundaries is an important step towards reducing the detrimental impacts of open access. The early achievements of PUGs towards sustainable pasture management can already be observed.

The Green Gold project was involved in the development of a method to define the boundaries of pasture-use units with contributions from herders. This methodology, called the "Soum Annual Land-Management Plan", was officially adopted by ALAGC in 2006. The World Bank-financed SLP is now applying this methodology and is financing the production of maps and other technical inputs. Between 2007 and 2008, pasture-use plans for 15 aimags and 276 soums were developed using this methodology, dividing 64.9 million ha of pastureland into 2858 pasture-use units. Despite advances in the implementation of this methodology, questions remain about the degree of herder involvement in the process and the inadequacy of soum resources for implementation.

In the Green Gold project supported areas, different pasture-use unit demarcation practices have been developed, depending on the natural features of the environment and the traditions of a particular area: (1) Dividing pastures only in winter/ spring camp areas (63\%); (2) establishing boundaries according to summer/autumn grazing areas (9\%), and; (3) Creating pasture-use units that include all four seasonal rotation areas (24\%). Ninety percent of the PUGs established pasture-use unit boundaries within existing bag boundaries ${ }^{15}$. Herders living within the boundaries they defined are to become members of a PUG and no traditional local herder can be excluded from membership. This is an inevitable necessity in accepting the principle of community-based resource utilization.

Herder families who are organized into PUGs are bound by mutual obligations and are accountable to each other; unwritten rules imposed by kinship and by their traditional social norms, values and networks also bind them together in the form of a sub-group. In addition, most PUGs have operational rules related to the use of common places around rivers and water points. Violations of rules arise mainly as a result of water shortage as summer camps are established near water points and the movement of migrants takes place during winter to avoid harsh conditions.

At present, PUGs do not have the legal status and authority to make rules and apply sanctioning mechanisms to any individuals. Herders from some groups have surmised that if they register as an NGO or cooperative, they can act as a legal entity.

${ }^{15}$ The "Green Gold" Pasture Ecosystem Management Project Report, 2008 
"We think that if PUGs have the status of a legal entity, they have official rights and the legitimate authority to set rules for the use and management of pastures." - Herders from the Berkh PUG in Undurshireet soum, Tuv aimag"

The Green Gold project supported the establishment of PUG revolving funds to grant credit to members, to provide independence from bank loans, to increase responsibility and trust among herders, and to improve the self-financing capacity of PUGs. As a result, 3410 families from 84 PUGs are directly involved in savings and credit schemes, benefiting 2000 families who have received soft loans ${ }^{16}$. Half of the savings is provided as a matching fund as an incentive for wellestablished PUGs. As a result of this process of fund mobilization, group dynamics have been vibrant and herder families have increased their confidence, particularly given that banks are neither PUG-friendly nor readily accessible in times of immediate need. It has also encouraged saving, a concept previously not fully understood by herders. However, despite all the measures that have been undertaken, the beneficial effects of the revolving funds should be appraised with care. The project is still in in its initial starting phase, and too little time has passed to make meaningful observations about the adoption of new social practices. The visible impact of any significant change in the way livelihoods are earned from the loan that members have acquired is yet to be seen. Moreover, training on savings, credit, income-generation, business and marketing has not been adequate. Future project interventions should pay more attention to these aspects of fund mobilization.

Few PUGs have tried to collect grazing fees from outside herders who graze their livestock at an otor on PUG territory. The revenue collected goes directly into the revolving fund.

Co-funding from the Green Gold project and PUGs has enabled the successful realization of the construction of irrigation systems, the fencing of haymaking areas, the repairing of roads and the maintenance of wells. In Telmen soum (Zavkhan aimag), a base for technical cooperation to serve its members was established.

In most areas, PUGs have begun organizing themselves into APUGs as umbrella organizations. APUGs play an advocacy role in strengthening the position of the PUGs at the political level. They will also play a role in the coordination of movements across PUG, soum and aimag boundaries, and in preventing and resolving conflicts among herders. Another function of APUGs to be explored in the future is their role as service providers for member PUGs.

\subsection{Conclusions}

Donor agencies have utilized three main approaches to the introduction of community-based pasture management in Mongolia. The SLP and PUG-S rely on a territorial approach to rangeland management that has been endorsed by the ALAGC and is included in the draft of the Pasture Law. The SLP relies on the leadership and capacity of local governments to develop and implement pasturemanagement plans in participation with herder groups, while the PUG-S takes a more intensive bottom-up approach in which planning and implementation are led by PUGs and their federations, with support from local MSRMhired and trained NGOs and local governments. The SLMCD, on the other hand, is building on voluntary herder groups. While voluntary groups are

${ }^{16}$ PUG members receive loans from their fund at the rate of $2 \%$ per month for a maximum of three months, whereas bank interest rates vary from 2.8 to $3.5 \%$ per month (personal communication, NGO head, Ikh-tamir soum, Arkhangai aimag). 
likely to be closely integrated due to their small size and kinship base, it is unlikely that such a group model can tackle the open-access issue.

The key innovation of the PUG-S is the full organization of herders on a territorial basis, which is necessary for the transfer of the leadership role in pasture management from local governments to the herders themselves. Only if all the herders in a given territory belong to the same organization can they conclude agreements among themselves and with other PUGs on the management of resources, and in so doing bring the open-access issue under control. However, PUGs cannot perform these management functions on their own. They need support and collaboration from soum and aimag governments, which until now have had the authority to allocate pasture rights, and which must assist with the enforcement of the rules that are agreed upon within and among PUGs. In addition, the PUGs require strong technical support that is provided by the NGO staff of the APUG. The PUG-S is clearly a significantly more intensive organizational effort at the grassroots level than the systems used by the SLP and the SLMDC.

All three approaches function within a broader set of institutions in order to support herders. The Green Gold project is interacting intensively with many of these institutions and provides support to many of them. For example, the Green Gold project has supported the ALAGC in the development of a standard approach for pasture allocation to user groups. However, the definition of pasture boundaries varies in different regions, ranging from the allocation of winter and spring camps to the allocation of all pastureland. The definition of pasture boundaries and the allocation to PUGs remain delicate issues, and there are concerns that soum administrations lack the capacity to successfully oversee and assist in this process.

\section{Bibliography}

Avaadorj, D. (2000). The soil erosion of Mongolia and some methods to content with the erosion of soils in Central and Eastern European countries. In Lahmer, R. And Dosso, N., editors, The new independent states in Central Asia. European Soil Bureau.

Avaadorj, D. and Baasandorj, Y. (2006). Physical properties of soil. In Proceedings of 'Theoritical and Practical Conference on Issues and Challenges of Pasture Management', Ulaanbaatar.

Dash, D., Mandakh, D., and Hualenbek, A. (2006). Desertification map of Mongolia.

Dorligsuren, D. (2008). Changes in livestock number and pasture area of Mongolia. In XXI International grassland Congress, VIII International Rangeland Congress 2008, volume II, page 152.

Erdenetuya, D. (2006). Assessment of pasture land condition by NDVI. In Proceedings of 'Theoritical and Practical Conference on Issues and Challenges of Pasture Management', Ulaanbaatar.

Fernandez-Gimenez, M. (1999). Reconsidering the role of absentee herd owners: A view from Mongolia. Human Ecology, 27(1):1-27.

Fernandez-Gimenez, M. and Batbuyan, B. (2004). Law and disorder: Local implementation of Mongolia's Land Law. Development and Change, 35(1):141-165. 
Fernandez-Gimenez, M., Kamimura, A., and Batbuyan, B. (2008). Implementing Mongolia's Land Law: Progress and Issues. A research project of the Central Asian legal exchange. Nagoya University, Nagoya, Japan.

Fernandez-Gimenez, M. and Swift, D. M. (2003). Strategies for sustainable grazing management in the developing world. In Proceedings of the VIIth International

Rangelands Congress, pages 821-831, Durban. Fernandez-Gimenez, M. E. (2006). Land use and land tenure in Mongolia: A brief history and current issues. pages 30-36. U.S. Department of Agriculture, Forest Service, Fort Collins.

Gordon, H. S. (1954). The economic theory of a commonproperty resource: The fishery. Journal of Political Economy, 62(2):124-142.

Government of Mongolia (2003). State Policy of Food and Agriculture. Ulaanbaatar.

Government of Mongolia (2008a). Development Policy for Agriculture and Food Industry of Mongolia. Ulaanbaatar.

Government of Mongolia (2008b). Government Action Plan 2008-2012. Ulaanbaatar.

Hannam, I. (2008). Review of Draft Pastureland Law of Mongolia. UNDP Mongolia, Ulaanbaatar.

Hardin, G. (1968). The tragedy of the commons. Science, 162:1243-1248.

Himmelsbach, R. (2008). Collaborative pasture management, a solution for grassland degradation in Mongolia?

In Contemporary Mongolia Conference, Vancouver. University of British Columbia.

Lkhgvajav, N. (2006). Decrease of pasture land productivity. In Proceedings of 'Theoritical and Practical Conference on Issues and Challenges of Pasture Management', Ulaanbaatar.

Mau, G. and Chantsallkham, J. (2006). Herder Group Evaluation. UNDP Mongolia, Ulaanbaatar.

McLean, K. (2001). An assessment of decentralization in Mongolia. The World Bank, Washington, D.C.

Mearns, R. (2004). Decentralisation, rural livelihoods and pasture-land management in postsocialist Mongolia.

European Journal of Development Research, 16(1):p133- 152.

Ministry of Nature and Environment (2007). Bulletin of Ministry of Environment. Ulaanbaatar.

Myagmarsuren, D. and Enebish, D. (2008). Special Protected Areas of Mongolia. Ulaanbaatar.

National Center for Health Development (2008).

National Statistical Office (2008). Statistical Yearbook 2007. Ulaanbaatar. 
National Statistical Office (2009). Statistical Yearbook 2008. Ulaanbaatar.

National Statistical Office and ADB (2004). Labour Force Survey. Ulaanbaatar.

National Statistical Office and UNDP (2004). Mongolia

National Reproduction Health Survey 2003. Ulaanbaatar.

National Statistical Office and World Bank (2001). Poverty in Mongolia. Ulaanbaatar.

Natsagdorj, L. (2006). Assessment of impact of climatic factors on pasture degradation in Mongolia. In Proceedings of 'Theoritical and Practical Conference on Issues and Challenges of Pasture Management', Ulaanbaatar.

Nyamaa, N. (n.d.). Importance of cashmere in household income. Ulaanbaatar.

Open Society Forum (2004). The Future of Nomadic Pastoralism in Mongolia: Public percetion survey. Open Society Forum, Ulaanbaatar.

Ostrom, E. (1990). Governing the Commons: The Evolution of Institutions for Collective Action. Cambridge University Press, Cambridge; New York.

Ostrom, E. (2000). Private and common property rights. pages 332-379. Edward Elgar, Cheltenham, England.

Ostrom, E. (2009). Social-ecological systemsa general framework for analyzing sustainability of socialecological systems. Science, 325:419.

Oyuntsetseg, C. (2000). Methods of using some particular pastures in forest steppe zone. Ulaanbaatar. Population teaching and research center (2009). Mongolia: internal migration dynamics and its consequences. Bitpress, Ulaanbaatar.

Rossabi, M. (2005). Modern Mongolia : From Khans to Commissars to Capitalists. University of California Press.

Schmidt, S. (1995). Mongolia in Transition: The Impact of Privatization on Rural Life. Verlag für Entwicklungspolitik, Saarbrücken.

Shiirevdamba, T. (2000). Issues of human development. In Proceedings of International Congress 'Sustainable Ecological Development'.

Sneath, D. (2003). Land use, the environment and development in post-socialist Mongolia. Oxford Development Studies, 31(4):441-459.

UNDP (2007). Human Development Reports 1997-2007. Ulaanbaatar.

UNDP (2008). Strengthening the Disaster Mitigation and management system in Mongolia. Ulaanbaatar. 
UNDP and SIDA (2004). Bringing herders' assets into full economic and productive use. Ulaanbaatar.

Upton, C. (2005). Institutions in a pastoral society: Processes of formation and transformation in postsocialist Mongolia. Comparative Studies of South Asia, Africa and the Middle East, 25(3):584599.

World Bank (2002). Mongolia Public expenditure and financial management review, volume Report No 24439- MOG. World Bank, Washington, D.C.

World Bank (2006). Mongolia Poverty Assesment, volume Report No 35660-MN. Ulaanbaatar.

World Bank (2009). Poverty Pro国le in Mongolia. Ulaanbaatar. 



\section{Chapter 4}

Community development to improve rangeland management in Gobi region 


\title{
4. COMMUNITY DEVELOPMENT TO IMPROVE RANGELAND MANAGEMENT IN GOBI REGION*
}

\begin{abstract}
Several studies have been done and explained by changes and adoption of Mongolian pastoralism after 1990's socio-economics transition, including de-collectivization in the early, types of cooperation and collective actions among herders. This paper will focus on the best practices and challenges of pasture user groups in the Gobi region as represented by Ulziit soum of Dundgobi aimag. Herders' livelihood strategy and behavior are altered under socioeconomics as well as environmental changes to survive. Herders in the Gobi region temporarily migrate to other aimags, even other regions where demand for livestock products is high, or areas with less drought and dzud and have high pasture yields and adequate water supply. It is becoming common that herders move more than 200 kilometers to reach their target distance, which is not allowed or makes it difficult for them to go back and forth every year as an annual otor move. Pasture management activities are organized mostly by khot ail base; however, there are promising initiatives to support more organized institutional forms based on herders community which should be improved to the specification of Gobi region and would be supported by Government and donor organizations.
\end{abstract}

\section{Keywords}

Gobi, herders' livelihood, Mongolia, otor, pasture user group

\footnotetext{
* Paper by Tumur Erdenechuluun, published in Mongolian Journal of Agricultural Sciences, 2013, pp. 3440, Special issue dedicated for the international conference on 'Pasture and grazing management - 2013'
} 


\subsection{Introduction}

Mongolia is one of the sparsely populated countries, with an estimated 39.8 percent of its 2.7 million inhabitants are directly dependent on the livestock sector, which is based on pastureland. More than 70 percent of Mongolia's 156.4 thousand kilometers square area is classified as grassland. Pasturing livestock still plays an essential role in Mongolia's economy, employment, and export revenues. To date, the agricultural sector produced 18.8 percent of GDP, of which 87.9 percent accounts for livestock husbandry. Also, 36.0 percent of the country's total labor force is engaged in the agricultural sector and around 10 percent of total export income (NSOM, 2008). Therefore "livestock production has been and is the main source of income for Mongolia's rural population, and it does have the potential to provide a steady income for the rural population" (Enkh-Amgalan, 2008).

During the last two decades, herders of Mongolia having challenged and still are challenging how to secure their livelihood sources against socio-economical, environmental, and political changes. Poverty increased sharply after the transition, especially in rural areas. Household income and Expenditure Survey show that in 1998 the national poverty rate was slightly below 35 percent and increased to 36.1 percent in 2001-2002 due to the dzuds. From then to 2007, the poverty headcount has declined nationally by only 0.9 percent to 35.2 percent, which means that there has been no change in the poverty headcount over the last decade. More alarming is between 2002 and 2008, the headcount index increase by 7 percent from 42.7 to 49.7 in rural areas. That means half of the rural population is in poverty. What would be their participation in the goods and raw materials market without any knowledge and infrastructure on it? Why and how should they be responsible for keeping an ecological balance to secure their long-term sustainable livelihood, these are the real challenges for herders within the last two decades. Herders' reactions to those areas varies by region, although they all had the same strategy to increase the number of animals, smart to have free input from state owned open access rangeland.

\subsection{Rangeland management and herders' livelihood}

There is several scientists and scholars have studied lately in the area of rangeland management of Mongolia. Therefore, a general overview of the country will be discussed based on existing literature, while short information of the study area is pasted within body text as a box (Box 4.1; Bharat, 2009; Enkh-Amgalan.Ts., 2008; Dorligusren , 2006 \& 2008; Upton, 2005 \& 2008; Manon, 2006; Lise \& Byamba, 2006; Mau \& Chantsaldulam, 2006; Dietz et al., 2005; Enkh-Amgalan.A., et al., 2005; Fernandez-Gimenez, et al., 2004; Mearns, 1993 \& 2004).

As mentioned above, Mongolia's socio-political and environmental management systems have changed dramatically over the past century, undergoing many political and socio-economic transformations. The period of democratic transition of the last $15-18$ years has resulted in fundamental changes in animal husbandry and natural resources management policies and practices. In Mongolia, functional customary and formal institutions were replaced by the collective system in 1960, which provided formal institutions to guide pasture use and allocation. During the collectivization era in 1950-1990, pastoral land was used by collectives, and the national herd grazed the natural pastureland in an organized and controlled manner (FernandezGimenez, et al., 2004; Mearns, 1993 \& 2004). Water points were developed throughout the pasturelands at strategic locations to utilize better the pastures where water had not previously been available. Under this system, there was some degree of management of the two primary 
natural resources - pasture and water. Employees who were tending the livestock would be given clear instructions as to where the animals could be grazed and for how long in that location to provide full feed for the animals yet, at the same time, not degrade the pastures through overgrazing. Not only were livestock numbers and the herd size relatively stable (as was the species composition) mandated by the state as each collective had to generate certain production targets, but the grazing patterns developed did not place excessive demands on the pasture being grazed. State collective farms were major institutions that regulated pastoral movement to support extensive livestock production. Besides, state collectives were responsible for the wellbeing and development of rural communities and herders. The collectives played a significant role in allocating pastures and campsites and directing seasonal movements, often respecting pre-existing customary rights, but seasonal movements between soums and aimags were regulated and tightly controlled (Fernandez-Gimenez, 2001). Pastoral land-use practices remained mobile where herding families were generally supported by trucks and deliveries of hay and thus had a less dramatic impact on the landscape than at present.

Dismantling of collectives has left herding households without clear directions about their rights to use pastureland, resulting in decreased movements around seasonal pastures. In the central region closer to the central market system, competition for and conflict over grazing land has been increased, and to guard their winter-spring camps from trespassing, herders preferred staying there throughout the year without having seasonal movements to have only bi-seasonal rotations.

After the collapse of the socialist system, a number of detrimental impacts have been observed that resulted from the privatization process, including (i) the creation of a large number of small scale producers that have introduced significant marketing complications, (ii) significant levels of conflict (individualism and competition) between different users of pasture land, (iii) pasture degradation through overgrazing as the small herders did not want to undertake lengthy grazing routes far from the urban centers as they needed to supplement their incomes from nonherding activities, (iv) extensive destruction of water points throughout the pastoral areas - in the struggle of survival after the collapse of the socialist system and also through lack of any maintenance as there were no effective "owners," and (v) a significant void created for input supplies and access to technical

\section{Box 4.1. Brief introduction of target soum}

Ulziit soum: 2,600 people (in 699 families) live on 1.54 million hectares of land thus almost all soum territory classified as pasture land. Ulziit Soum located in the south part of the aimag and circle "A" of the Great Gobi region's northern hilly the Gobi. The Soum borders with Khuld, Luus, Saintsagaan, Gurvansaikhan, Undershil soums of Dundgobi aimag on the West and West-North; with Dornogobi and Umnogobi aimags on the East and East-South. The distance between the Soum center and Ulaanbaatar City is $358 \mathrm{~km}$, and it is isolated at $98 \mathrm{~km}$ from the aimag center. The soum is the biggest in terms of territory, but it is the rarest populated one in terms of citizens and animals. Here, low mountains, long hills, big flatlands, and spacious valleys represent $87 \%$ of its territory. Locally, a minimum herd of 200 animals is regarded as necessary for survival based on livestock subsistence production. According to the soums statistical report $2008,45 \%$ of all herding families (493 herding households) had less than 200 animals.

The main sector of the soum economy is livestock and, at the end of 2008, the soum had 132708 animals, including 5408 camels, 5530 horses, 888 cattle, 53211 sheep, and 67671 goats. $84.1 \%$ of the soum population is engaged in the livestock sector. Alternative income sources other than livestock are highly limited due to the harsh environmental conditions and low infrastructure development and institutions. As a result of pasture degradation (mainly lack of fodder availability) and poverty, herders continue migrating from more degraded land to better pastures and finally to urban areas, or they switch from herding to other occupations like artisanal mining. support services (ADB, 2005). 
Invulnerable communities where real ownership and management over the natural resources are lacking are free and uncontrolled access to natural resources. Together with the increase of herding households and economic shocks to the pastoral sector from privatization, this institutional void resulted in increasingly unsustainable land-use patterns among pastoralists as many failed to make traditional seasonal movements and occupied the same pastures year-long, in violation of custom.

Herders have unequal possibilities to invest in pasture improvement depending on their herd size. In general, they are not interested in investing in improved pasture land due to insecure use of rights. In recent years, herders who have experienced pasture shortages are trying to organize themselves, secure access rights, and invest in pasture improvement like digging manual wells, fencing woody grass, producing hay, etc.

\subsection{Uncertainty and risks in livestock sector}

There are many sources of risk and uncertainty in the Mongolian pastoral economy. The most important from the herders' point of view is natural hazards strongly affecting the livestock sector, such as dzud, drought, flood, strong wind, hail, thunderstorms, and rodents and grasshoppers. A combination of dzud and drought in the years 1945, 1968, 2000-2002 caused livestock losses between 10.4 and 15.7. The dzud that occurred in 1999-2000 and 2000-2001 caused 413.8 billion MNT (US\$ 369 million) worth of damage to the nation's economy (UNDP, 2008). In addition to natural risks, market risks are influenced by herders' livelihood in recent years. However, we will not go into detail on this aspect within our short paper.

Dzud can last from a few weeks to the entire winter season. In the best case, herders can respond by moving the herd to unaffected areas (winter otor). One of the only ways of ensuring a herd's survival when movement becomes impossible is to maintain a stock of fodder and hay in sufficient quantity to feed the entire herd. Warm and well-maintained winter shelters, corrals, and other facilities for keeping adult and newborn animals are decisive in helping herders cope with natural disasters. To decrease dzuds' effects, Mongolia's government is taking specific measures like operating a state emergency fodder fund, weather forecasting and early warning, livestock insurance. According to the World Bank news, 438.7 thousand livestock of 343 herder households from 3 aimags have been insured with World Bank funded Index-Based Livestock Insurance (IBLI-requires $2-4 \%$ of insurance payment of insured livestock's market price. If total percentage of soum livestock loss exceeds 6 or $10 \%$, herders will be compensated from insurance) covering $0.19 \%$ of national herder households and $1.02 \%$ of total livestock. Individual herders need to be responsible for securing their livelihood against dangers and risks with condition of improper and unclear institutional arrangements or lack of implementation in current regulations. 


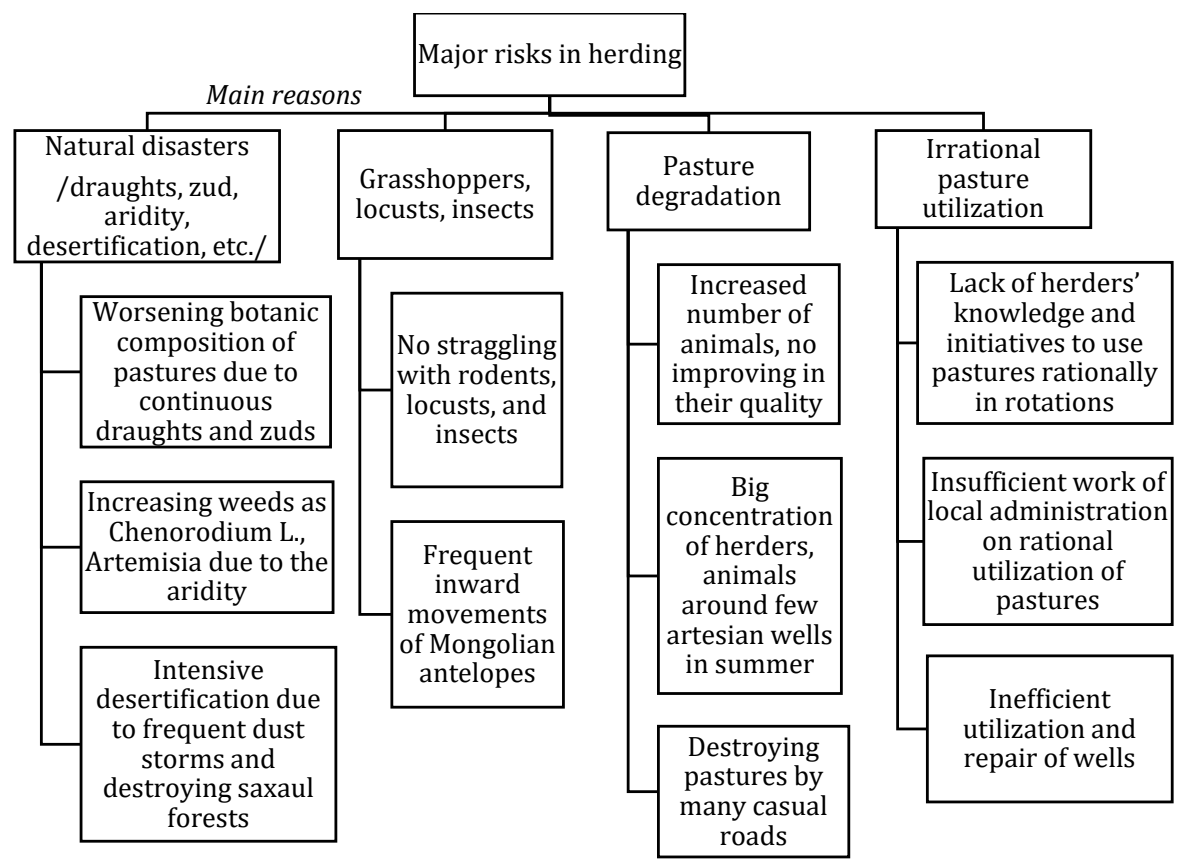

Figure 4.1. Major risk elements its causes identified by herders of Ulziit soum

Traditionally, herders believe that after bad years' good years come, they will be able to recover losses during the bad years. In other words, an increasing number of animals is a herders' strategy to recover natural disaster effects. This mentality persists to exist and appears to be a major psychological barrier preventing herders from preparing better for winter, and it cherishes the mentality to maximize animal numbers. According to our earlier game theory application, maximizing herd size equilibrium leads to the highest payoff. Hence there are viable institutional alternatives for herders to change their behavior from herd maximization to keeping the herd size constant (CPR \& PREM, 2003). This institution needs to compensate or secure for the loss of income due to keeping a small herd.

\subsection{The recent development of herders' community in the target area}

This part deal with the specific situation of Ulziit soum, Dundgobi aimag based on experiences having demonstrated from Green Gold Pasture Ecosystem Management Programme of Swiss Development Agency and its best practice and lessons learned/challenges as well.

In connection with a clear indication of lacking institutional arrangement, the Green Gold project initiated an approach where all traditional users of a particular territory are organized in pasture user groups (PUGs), which applies five target soums of Mongolia. Ulziit soum is one of the targets soums of the project. Defining pasture parcel boundaries by herders themselves made an essential step towards reducing the detrimental effect of open access. According to this approach, an entire soum pasture land (except reserved pasture land) is divided into pasture user parcels/units, using a participatory process that engaged herders, bag and soum authorities, professional organizations, and project staff. 

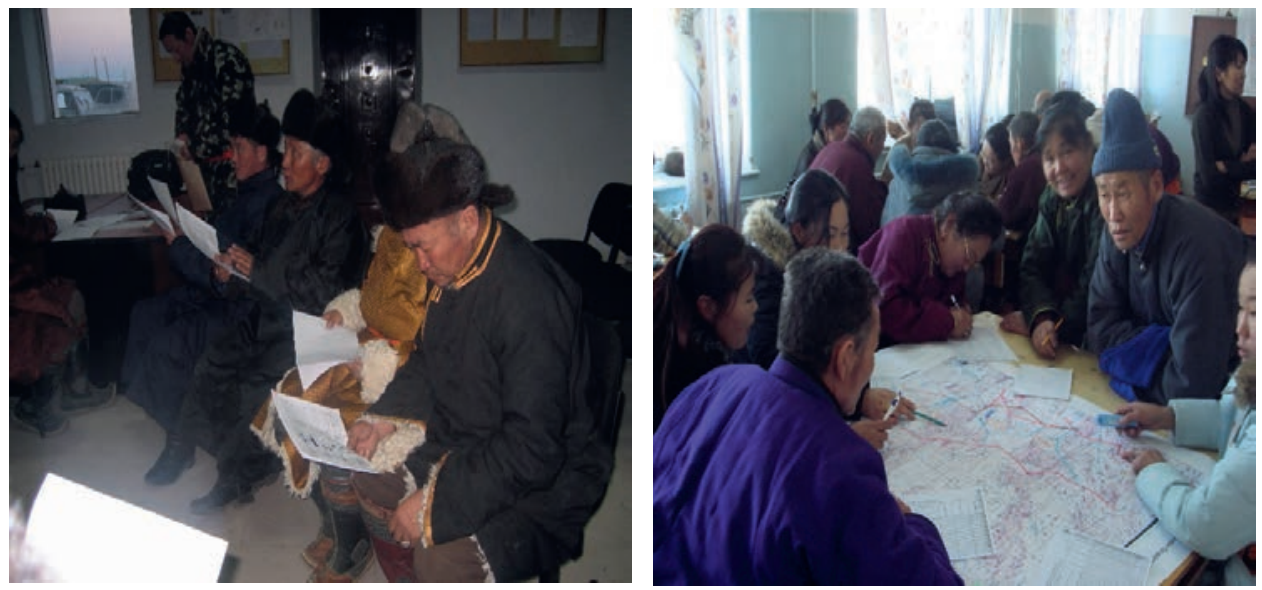

Figure 4.2. Stakeholders are discussing and debating to define PUGs boundaries, Photo by Erdenechuluun Tumur

Herders living within the boundaries defined themselves needs to be members of a Pasture User Group. All herders, who uses that certain parcels of common pasture needs to be asked as a member of PUG formed up in that certain area. This is an inevitable necessity to accept the principle of community-based resource utilization. Mutual obligations and accountabilities bound herder families organized in PUGs; unwritten rules imposed by kinship and by their traditional social norms, values, and networks also bind them together in the form of the subgroup.

Most PUGs have operational rules related to the use of common places around rivers and water points. In the case of Ulziit soum, 16 PUGs have been established according to defined boundaries as explained above. The number of households within PUG varies between 11 and 57, which is comparatively less than other soums (regions) of the project (Table 4.2).

Table 4.1. Statistical Information on PUGs in Ulziit soum

\begin{tabular}{|l|c|c|c|}
\hline \multicolumn{1}{|c|}{ Statements } & 2007 & 2008 & Average of targets soums \\
\hline Total number of herder households & 438 & 398 & 682 \\
\hline Number of PUGs & 16 & 16 & 67 \\
\hline PUG with the highest number of households & 57 & 41 & 41 \\
\hline PUG with an average number of households & 27 & 25 & 1229 \\
\hline PUG with the lowest number of households & 11 & 16 & 245 \\
\hline Pasture land per household (ha) & 3125 & 3439 & 87 \\
\hline $\begin{array}{l}\text { The average number of animals per households by } \\
\text { sheep unit }\end{array}$ & 314 & 293 & 49 \\
\hline Number of animals per 100 hectares by sheep unit & 10 & 12 & \\
\hline
\end{tabular}


Green Gold has been involved with other key organizations in developing a method to define the boundaries of pasture use units with the contribution of herders. This methodology, named "Soum Annual Land Management Plan," was officially introduced in 2006 by the Administration of Land Affairs, Geodesy, and Cartography. In 2007-2008, according to this methodology, the plans of 15 aimags and 276 soums were developed, 64.9 million ha of pasture land was divided into 2858 pasture use units. However, question marks about the herders' involvement in this process, and the soums do not have adequate resources to implement the plans.

GG project has a supporting package for PUGs. The package includes the facilitation of

Box 4.2. Main steps for developing PUG sketch map

A. Within the PUGs boundaries the herders jointly are to evaluate pasture carrying capacity and grazing pressure (degraded, not degraded etc.).

B. The issues related to seasonal rotation and resting of certain pasture (s), route (track) of movement and otor, improvement of pasture land and hay fields (fencing, fertilizing, rodent control, irrigation and road construction etc.), defining areas for intensive livestock husbandry and establishing new winter and spring camps are jointly discussed and reflected in the plan.

C. Based on information mentioned above the PUG sketch map should be developed. The sketch map should be clearly drawn and contain all information on the current situation and perspectives of the PUG's pasture(s).

developing pasture management plan (sketch mapping), providing technical assistance through soum service providing NGO, conducting training based on local demand, supporting and investing alternative income generation activities, and creating added value of animal-oriented products, providing seed money for PUG fund and animal productivity improvement.

Besides success stories, initiators face several problematic issues that need to develop a specific model or tools to use in the Gobi region that we should like to share here.

Major challenges implementing pasture management plan (part of the soum annual land management plan) specifically in Gobi region are long-distance otor movement and its increasing frequency. Thus, PUGs face difficulties rather than following agreed rules and implementing a pasture management plan and community activities. For instance, during the last two years, 63 percent of total herding households with long-distance otor move by carrying out more than 75 percent of the total number of animals in Ulziit soum. Most of the herders (74\%) moved to Umnugobi aimag, which raises several conflicts between local herders of host aimag. This huge moving is very much extracted PUGs and its activities mentioned above, e.g., herding households in one PUG is most likely separately organize otor movement into more than 2 locations with a distance of more than $200 \mathrm{~km}$.

The solution for this case is still not yet defined up to now; however, some people expect that there might be a possibility that recently developing inter aimag otor area arrangement is being enforced together with the implementation of soum annual land management plan. However, it will be a far way if expectation goes to something from the top or somewhere else, and only good initiative of local people with high support from stakeholders, i.e., governmental and nongovernmental, etc. would realize solutions faster and proper way.

Ulziit soum herders have started organizing themselves into umbrella organizations as the PUG association so-called Ulziit soums "Herder's Spirit" association. The association aims to play a role in inter PUG and inter Aimag movements and conflict management among PUGs and neighboring soums/aimags. It is workable within soum territory in recent cases but again, the case of otor movement conflicts with the approach's implementation. Therefore there are urgent needs to come up with specific models which adopt regional specification of Mongolia. 


\subsection{Findings and Conclusions}

Herders currently benefit from an increased number of animals; therefore, environmental degradation has not yet proved to be a sufficiently limiting factor in this regard for most herders. However, they are starting to understand that the increasing number of animals is not the best strategy to survive and leads to severe pasture degradation, so they are looking for alternative strategies.

A large majority of herders do not have enough animals to sustain themselves traditionally. They are neither forced to combine subsistence livestock-keeping with various other jobs, or they can choose to become more market-oriented herders. If they do this wisely, they can increase their incomes, improve their health, and maintain the pastures. However, this depends on renewed forms of land and water management institutions.

Establishing PUGs is recognized as an important tool to support herders' collective action not only in the GG target areas but also in other areas like their neighboring soums and otor arrangement. This system would be best introduced in conjunction with alternative income generation activities and economic support to compensate for losses associated with limiting herd sizes.

Following that, the descriptive analysis shows the importance of policy attention for the Gobi region's livestock sector. For instance, in addition to the PUGs approach, specific attention is still required for a large mobile community outside the boundaries of the PUGs and soum and aimag territory. Finding a solution for this phenomenon would highly support secure herders' livelihood in the Gobi region.

\section{References}

ADB (2005). Agricultural Sector Development Strategy 2006-2015, Asian Development Bank (ADB), Ulaanbaatar, Mongolia

Batima, P. \& D. Dagvadorj. (2000). Climate Change and its Impacts in Mongolia. Ulaanbaatar: National Agency for Meteorology, Hydrology and Environment Monitoring and JEMR Publishing.

Bedunah, D.J. \& S.M. Schmidt. (2004). Pastoralism and Protected Area Management in Mongolia's Gobi Gurvansaikhan National Park, Development and Change 35 (1): 167-191.

Caroline Upton. (2008). Social capital, collective action and group formation: Development trajectories in post socialist Mongolia, Human Ecology, 36:175-188

Caroline Upton. (2005). Institutions in pastoral society: process of formation and transformation in post socialist Mongolia, Duke University Press Vol. 25 No.3

CPR and PREM. (2003). Pastureland Degradation and Poverty among Herders in Mongolia, The unpublished project report, Poverty Reduction and Environmental Management (PREM), VU University Amsterdam, Centre for Policy Research (CPR), Ulaanbaatar, Mongolia 
Dorligsuren D. (2008) Changes in livestock number and pasture area of Mongolia XXI International grassland Congress, VIII International Rangeland Congress 2008 Volume II; p 152

Dorligsuren D. (2006) Issues of improved pasture management. Proceedings of "Theoritical and Practical Conference on Issues and Challenges of Pasture Management", Ulaanbaatar, Mongolia (in Mongolian)

Danker, Manon. (2004). Hörs-Gazar. Cry of a Woken Bull. Changes in Pastoral Life and Pastureland Management in Mongolia. Amsterdam: Vrije Universiteit (unpublished M.Sc Thesis, as part of PREM programme).

Elinar Ostrom at. al. (1999). Revisiting the commons: Local Lessons, Global Challenges, Science 284,278

Enkh-Amgalan.Ts., (2008) Mongolia's rangelands: is livestock production the key to the future?, The Ecological Society of America, TwoViews at www.frontiersinecology.org

Enkh-Amgalan A, Erdenechuluun.T, Byamba Purev at. el. (2005). Herder communities on Mongolia's free market era: Omproving livestock management and reducing pastureland degradation, PREM Policy brief - www.prem-online.org, Amsterdam, The Netherlands

GGPEMP. (2008). “Green Gold” Pasture Ecosystem Management Project (GGPEMP) Report, 2008 (in Mongolian)

Fernandez-Gimenez, M.E. \& B. Batbuyan. (2004). Law and Disorder: Local Implementation of Mongolia's Land Law, Development and Change 35 (1): 141-166.

Fernandez-Gimenez, M.E. (2001). The effects of livestock privatisation on pastoral land use and land tenure in post-socialist Mongolia, Nomadic Peoples New Series, Vol. 5, No. 2, Special Issue: Environment, Property Resources and the State (2001), pp. 49-66 (18 pages)

Gunther Mau, J Chantsallkham. (2006). Herder Group Evaluation , A study of herder groups, their present status, and future potential, UNDP, Mongolia

ALAGC. (2005). Information of Administration of Land Affairs, Geodesy and Cartography (ALAGC) for 1989-2004, in Mongolian

Jeremy J Swift. (2006). Case study Institutionalizing Pastoral Risk Management in Mongolia

Mearns, R. (1993). Territoriality and Land Tenure among Mongolian Pastoralists: Variation, Continuity and Change, Nomadic Peoples 33: 73-103.

Mearns, R. (2004). Sustaining Livelihoods on Mongolia's Pastoral Commons: Insights from a Participatory Poverty Assessment, Development and Change 35 (1): 107-140.

Bharat. (2009). Institutional and community development of pasture user groups and their enabling environment in Mongolia, Unpublished report, Ulaanbaatar

National Statistic Year book(s) (1990- 2008). National Statistical Office of Mongolia 
The World Bank. (2000). Participatory Living Standard Assessment 2000, Summary report prepared for the Donor Consultative Group Meeting

The World Bank. (2009). Poverty Profile in Mongolia, World Bank UB-2009, Mongolia

Ton Dietz, Enkh-Amgalan A, Tumur Erdenechuluun, Sebastiaan Hess (2005) Carrying capacity dynamics, livestock commercialisatioin, and land degradation in Mongolia's free market era, PREM Working paper 05/10, Amsterdam, The Netherlands

UNDP. (2008). Strengthening the Disaster Mitigation and management system in Mongolia, United Nations Development Programme (UNDP) in Mongolia, http://www.undp.mn/publications/Pr odoc_Disaster_III_final_070408.pdf) Retrieved August 8, 2008

UNEP (2008) Mongolia: State of the Environment. Nairobi: UNEP

Wietze Lise, Sebastiaan Hess, Byamba Purev (2006) Pasture degradation and poverty among herders in Mongolia: Data analyses and game estimation, Ecological Economics 58, 350-364 



\section{Chapter 5}

Sustainable Governance of Rangeland in Mongolia 


\title{
5. SUSTAINABLE GOVERNANCE OF RANGELAND IN MONGOLIA*
}

\begin{abstract}
Mongolia is suffering from increased degradation and desertification of its rangelands. One of the main causal factors is that rangeland has remained a common pool resource whereas livestock has been designated as private property of herders. In recent years, community-based rangeland management approaches such as Pasture User Groups (PUGs) have been introduced in selected regions of Mongolia in order to explore appropriate mechanisms for countering rangeland degradation. This study aims to analyse the performance of these newly introduced institutional arrangements, using data collected among 330 herding households living in three different ecological zones in Western Mongolia. The critical enabling conditions for sustainability of the commons concept forms the theoretical framework. The empirical results indicate that clear definitions of the boundaries of rangeland and its users are important preconditions for the sustainable governance of rangeland management. Inequality in herd sizes within a PUG negatively affects rangeland quality, the impact of group size resembles an inverted U-shaped relationship, thus intermediate group sizes therefore have the highest monitoring effort on rangeland management and lead to the best outcomes in terms of natural resource quality. PUGs with lower external financial aid have fewer opportunities to implement good rangeland management strategies. Based on these findings, we formulate a number of policy recommendations that are expected to further stimulate sustainable rangeland management by user groups.
\end{abstract}

\section{Keywords}

Common pool resources, collective action, Mongolia, pasture users groups, rangeland management

\footnotetext{
* Paper by Erdenechuluun Tumur, Wim J.M. Heijman, Nico Heerink, Agipar Bakey, published in Journal China Economic Review, 2018, https://doi.org/10.1016/j.chieco.2018.10.004
} 


\subsection{Introduction}

Common pool resources, such as forests, aquatic resources and rangelands, contribute significantly to rural livelihoods in many parts of the world (Fernandez-Gimenez 1999; 2002; Meinzen-Dick \& Mwangi, 2006; Mwangi \& Markelova 2009). Although humans have used rangelands for consumptive and non-consumptive purposes for centuries, it was only in the early 1900 s that researchers first began to study problems associated with sustainable management of rangelands. In this context, sustainable management of rangeland refers to "the manipulation of rangeland components to obtain the optimum combination of goods and services for society on a sustained basis" (Holechek, Pieper, \& Herbel, 2001).

Economic theory and observed practice across the world suggest that a variety of common pool resources (forests, rangeland, fisheries, water, air) are threatened by open access, which leads to a dissipation of the resource rents by overuse (Gordon, 1954). In economic terms, they are rival and non-excludable goods. While full privatisation is one way of eliminating open access (Hardin, 1968), it is often not feasible, and particularly not in the case of the Mongolian rangeland where mobility of animals both within and across years is required (Amgalan et al. 2010). Livestock grazing on rangeland in Mongolia can be considered a typical case of "resources that are highly mobile over large expanses of territory, or of those, such as irrigation water, which require a collective infrastructure to be exploited. In these peculiar circumstances, collective regulation under the common property regime is the only way to avoid the inefficient management and/or the degradation of the resource under conditions of open access" (Baland \& Platteau, 2003; p.138).

Sustainable rangeland management has received considerable attention amongst common pool resource scientists and scholars during the last two decades (Baland \& Platteau, 2003; Fratkin \& Mearns, 2003; Ho \& Azadi, 2010; Mau \& Chantsallkham, 2006; Mearns, 2004; Mwangi, 2007; Ykhanbai et al., 2011). Fratkin (1997) reviewed governance and development issues of pastoralism in different countries including Maasai pastoralists in East Africa, and pastoralists in India, Mongolia and China, and argued that the future of pastoralist populations is far from certain. Pastoral practices, including the tendency of individual herders to maximise their herds, coupled with increasing number of herders, are viewed as major factors promoting desertification. In Western China, rising livestock prices have contributed to a rapid increase in the number of livestock and a sharp decline in the available rangeland area per livestock unit, while in Northern China, rangeland degradation is caused by changing livestock demography, mushrooming permanent grazing encampments, year-round grazing, and an almost entirely new disaster preparation and response method (Cao, Yeh, Holden, Qin, \& Ren, 2013).

Mongolia is a country where almost 80 per cent of territory consists of rangeland; it ranks first in the world in terms of its share of rangelands. Rangeland is the basic natural resource of the Mongolian agricultural sector, which accounts for 18.8 per cent of the GDP of the country (NSO, 2011). The rapid rise of livestock numbers during the last two decades is favourable for the herding population and also benefits other sectors that use livestock as an input. However, the number of livestock has risen beyond a critical level in terms of the ecological potential of the rangeland in Mongolia (Erdenetuya, 2006). The open access system combined with rapidly rising livestock numbers has resulted in significant deterioration of rangeland; the institutions governing the herding system are therefore no longer considered as being suitable (Amgalan et 
al., 2010). Novel natural resource management institutions have been introduced in Mongolia since 1999. Thus, Mongolia has become a de facto testing ground for community-based rangeland management, with the establishment of herders' self-help groups facilitated by different donorand NGO-sponsored programs (Mau \& Chantsallkham 2006). Donor agencies have been using two main approaches to the introduction of community-based rangeland management in Mongolia (GGPEMP \& MSRM, 2010). These are: i) a territorial approach to rangeland management, where all traditional users of a certain territory are organised in Pasture User Groups (PUGs), ii) the formation of voluntary herder groups, which are organised primarily on the basis of a combination of kinships, shared use of key resources and common interest for joint activities. Little is known, however, about the impact of these community-based management institutions on the quality of rangeland.

The objective of this paper is to investigate the performance of community-based rangeland management institutions in Mongolia by analysing the specific characteristics of pasture user groups that affect rangeland quality. The primary interest of voluntary herders groups is the joint selling of animal-based products and small-scale seasonal products over relatively short periods of time. Their membership is not based on permanent pasture land boundaries. The focus of this study is therefore on PUGs rather than on voluntary herders' groups.

The conditions under which groups of users will self-organise and sustainably govern the resources upon which they depend is an important subject of research in the literature on common property resource management. Agrawal $(2001,2003)$ synthesises the factors affecting sustainable governance of the commons, as identified in three influential studies by Wade (1988), Ostrom (1990) and Baland and Platteau (1996), further extends the set of determining factors, and integrates them into a theoretical framework. We will use this integrated framework as the theoretical framework of our study.

The empirical analysis is based on survey data collected from 330 herding households, living in 7 aimags (provinces) in three different ecological regions in Western Mongolia. PUGs have been introduced by different donor projects in this region over the last decade. A mixed effect regression model will be used to identify the main characteristics of PUGs that influence rangeland quality.

This paper is structured as follows. Section 5.2 presents a literature review of rangeland management practices and livestock sector development in Mongolia. It includes information on trends in herd sizes, rangeland area and rangeland carrying capacity. In section 5.3, we discuss the implementation of the theoretical framework for the specific case of the surveyed pasture user groups in Mongolia. In section 5.4, the research methodology and hypotheses are presented. This section includes a discussion of the research area, the data collection method, and the model used for the regression analysis. It also presents hypotheses on the expected impact of different PUG characteristics on rangeland quality. The estimation results of the linear regression model are presented and discussed in Section 5.5. The final section summarises the main empirical findings and discusses their implications for the ongoing rangeland management initiatives in selected regions of Mongolia. 


\subsection{Rangeland management practices and livestock sector development in Mongolia}

During the collectivization era (1960-1990), management of natural resources like pastures and water was brought under state control and executed by the negdel (state collective). The state collectives played a significant role in allocating pastures and campsites and directing seasonal movements, often respecting pre-existing customary rights, but seasonal movements between soums (districts) and aimags were regulated and tightly controlled (Maria E. Fernandez-Gimenez, 2006).

The collapse of the socialist system had a huge impact on rural livelihoods. The collectives were disbanded and livestock ownership transferred to individual herders. Pasture management by the state virtually disappeared, rendering the herding system de facto open access. The dismantling of the collectives left a regulatory void in the area of pasture management and the services they once provided deteriorated or disappeared. Consequently, herders became responsible for all production inputs, risks and decisions. The hot ail reemerged as the smallest socioeconomic unit, and customary informal norms of land use coordination reemerged (GGPEMP \& MSRM, 2009).

Since 1999, Mongolia has become a de facto testing ground for community-based rangeland management, with the establishment of over 2000 "herder groups" and "pasture user groups" facilitated by over 12 different donor and NGO sponsored programs (Mau \& Chantsallkham, 2006). Donor agencies have been using three main approaches to the introduction of community based pasture management in Mongolia. The Sustainable Livelihood Project (SLP), financed by the World Bank, and the Green Gold Pasture Ecosystem Management Programe (GGPEMP), funded by the Swiss Agency for Development and Cooperation, both rely on a territorial approach to rangeland management, which has been endorsed by the Administration for Land Affairs, Geodesy and Cartography (ALAGC) in Mongolia. This approach is included in the draft law on pastureland. The SLP relies on the leadership and capacity of local governments to develop and implement pasture management plans in consultation with herder groups, while the GGPEMP uses a more intensive bottom up approach where planning as well as implementation is led by PUGs and their federations. The Sustainable Land Management for Combating Desertification (SLMCD) project of the UNDP, on the other hand, builds on voluntary herder groups, which are organized primarily on the basis of a combination of kinships, shared use of key resources and common interest for joint activities.

The extent to which these institutional arrangements will be able to promote sustainable rangeland management will depend to a large degree on prevailing local conditions in different parts of Mongolia. Rural Mongolia is characterized by a wide variety of agro-ecological zones, varying from equilibrium systems, with short and regular seasonal migration routes in the forest steppe, to disequilibrium systems, with very long and irregular seasonal and inter-annual movement in the desert steppe and the steppe. Pasture management systems must be adapted to the prevailing conditions in each zone, and institutional arrangements must be able to accommodate both seasonal and inter-annual movements, which differ in scope and frequency across the different agro-ecological zones. 
After the collapse of the socialist system, livestock enterprises expanded rapidly. This expansion was partly caused by relatively good weather conditions (except two large $d z u d^{17} s$ ), and partly by new entrants in the livestock economy after the privatisation of state-owned livestock and the de-industrialisation of the urban economy (Mearns, 2004).

Figure 5.1 shows the trend in livestock numbers and rangeland area in Mongolia since the end of the 1980s. Livestock numbers have increased by more than 50 percent during this period, while the area of rangeland has declined by more than 10 percent since the end of the 1990s. The main reason for the decrease of rangeland area is the growth of the mining sector. In addition, the expansion of tourism, farming and other sectors has reduced the amount of land available for grazing.

These recent trends raise the question as to what extent the carrying capacity of the rangeland has been exceeded. The carrying capacity is the stocking rate that can be sustained by a particular grazing unit during the grazing season without degrading the quality of the land, taking into account rangeland productivity. In accordance with recent government reports, the carrying capacity is measured according to the following formula (ALAGC, 2013; Tserendash \& Altanzul, 2013):

$C C=\frac{Y}{h * G D} \mathrm{Y}$

Where:

$\mathrm{CC}=$ carrying capacity (sheep units per $100 \mathrm{ha}$ )

$\mathrm{Y}=$ Annual forage production of rangeland (kg per $100 \mathrm{ha})$

$\mathrm{h}=$ Forage requirement $(\mathrm{kg}$ per sheep unit per day)

$\mathrm{Gd}=$ Annual number of grazing days (per sheep unit per $100 \mathrm{ha}$ )

The number of animals in the year 2010 was found to exceed the carrying capacity of rangeland by 32.5 percent, or by 16 million sheep units at the national level. Pasture carrying capacity varies greatly according to ecological zone. Figure 5.2 illustrates the variation by aimag in 2010 Only in three aimags, Dornod, Sukhbaatar, and Bayankhongor, is pasture utilisation below the carrying capacity (25.4 to 87.5 percent). In the remaining aimags, utilisation ranges from 100 to 300 percent of the carrying capacity. Utilisation was typically much higher around the large cities: 436 percent in Darkhan, 651 percent in Ulaanbaatar and 1,541 percent in Orkhon (Erdenet).

Although the total number of livestock in the country is increasing, its distribution over herding households varies greatly. As livestock is the main income source of herders, livestock herd sizes can be regarded as a good approximate measure of the wealth of herding households in Mongolia. According to studies done by researchers of the Mongolian State University of Agriculture and the Research Institute of Animal Husbandry, herding households with approximately 200 animals are at the poverty threshold level (Lkaghjav, 2006; Dorligsuren, 2008). Figure 5.3 shows the

$17 \quad$ Natural disaster during the winter period. 
distribution of herd sizes over herder households in the year 2010. It shows that more than 60 per cent of the herding households have herd sizes smaller than the poverty threshold.

\subsection{Theoretical framework}

Economic theory and observed practice across the world suggest that a variety of common pool resources (forests, pastures, fisheries, water, air) are threatened by open access. In economic terms, open access goods are rivalrous and non-exclusive goods. Increasing pressure on such resources leads to the dissipation of resource rents through overuse (Gordon, 1954). While full privatization is one way of eliminating open access (Hardin, 1968), it is often not feasible. In the case of the Mongolian pasture, where mobility of animals within years and across years is required, it is also inefficient. Common pool resources can often be sustainably managed by clearly defining resource boundaries, use rights, withdrawal quantities and monitoring rules that are implemented via collective management (Ostrom, 1990; 2009). In the case of rangeland management, defining rangeland boundaries and membership of user groups are considered important factors and essential prerequisites of secure tenure, and are therefore of crucial importance for successful common property rangeland management regimes (FernandezGimenez, 2002).

There are many examples of successfully managed common pool resources (Baland \& Francois, 2005; Baland \& Platteau, 1997, 1998; Fratkin \& Mearns, 2003; Hardin, 1968; Ho \& Azadi, 2010). Several of these examples have shown how to avoid a tragedy in a situation where the population is growing rapidly and the absolute number of people who live in poverty is steadily increasing (Fernandez-Gimenez \& Batbuyan, 2004; Heijman, 1991). What can we learn from these experiences in managing common pool resources, so that it can emerge as an institution on a larger scale? To address these kinds of questions, an analysis of their basic characteristics may help to understand why, how, and what kind of institutions can emerge at the community level to manage common pool resources (Hardin, 1968).

There is a considerable body of literature that tries to identify the set of conditions that are crucial for the sustainable governance of common pool resources. Agrawal $(2001,2003)$ summarises the conditions put forward in the influential works by Wade (1988), Ostrom (1990) and Baland and Platteau (1996), as well as extending the set of conditions distinguished in these studies further, and grouping them into six clusters: resource system characteristics, group characteristics, relationship between resource system characteristics and group characteristics, institutional arrangements, relationship between resource system and institutional arrangement, and external environment. In this study we apply Agrawal's framework to the case of rangeland resources in Mongolia. 


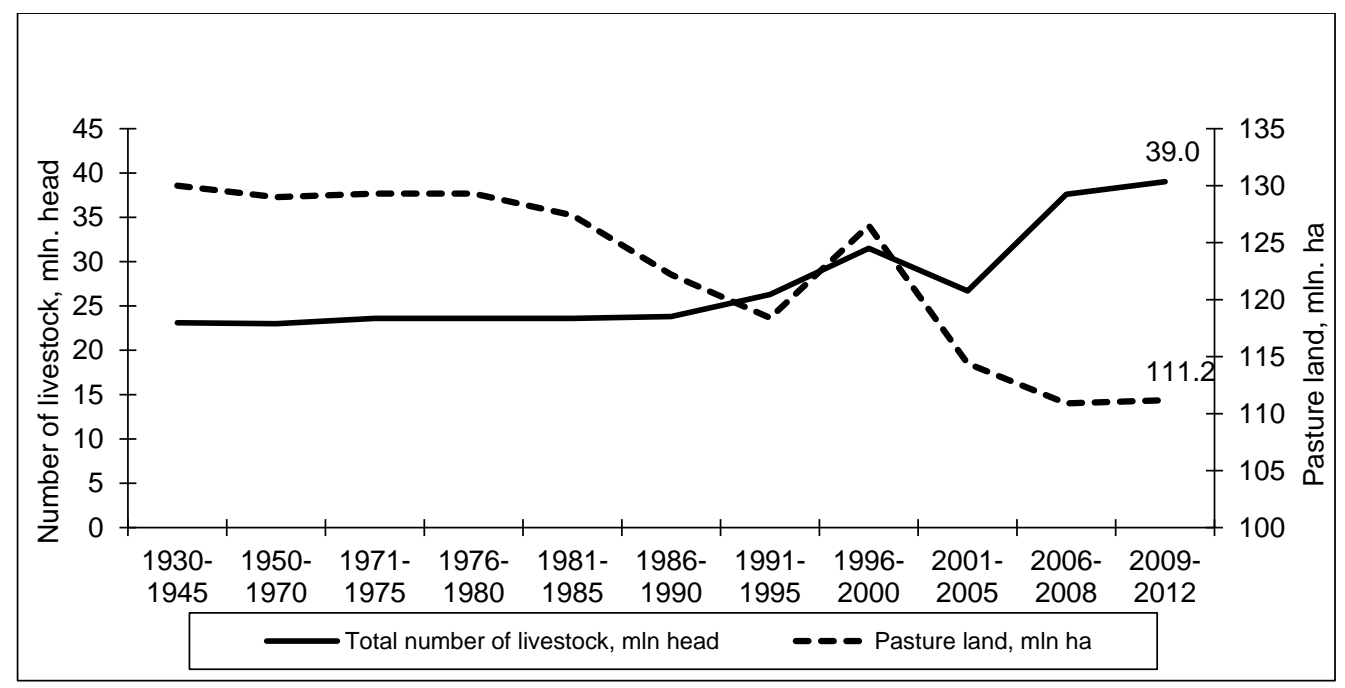

Figure 5.1. Livestock numbers and rangeland area in Mongolia, from 1986-1990 to 2009-2012 (NSO 1986-2012)

\subsection{Research methodology and hypotheses}

\subsubsection{Data collection}

The primary data used for the analyses was gathered through a herder household survey held in 2010, using a semi-structured questionnaire. A total of 330 herding households were interviewed. They were selected from PUGs in 7 aimags in Western Mongolia that cover three ecological regions, namely the High Mountain, Forest Steppe and Desert Steppe regions. The main reasons for the selection of the 7 Western aimags were i) the majority of animals and herding households can be found in these regions, ii) in contrast to other regions, the main source of livelihood in these regions is pastoral livestock, iii) the degradation level of the rangeland is comparatively high, and iv) these regions are the primary target areas of the collective action approach adopted by the government and donor agencies including Green Gold Project funded by the Swiss Agency for Development and Cooperation. Information collected for the national animal census count (a well-known census document called "A dans" in Mongolian) was used to select the households. The census data includes a list of herding households (as well as other households with animals) with their respective location, the number of animals by type and age, and other relevant information.

The 330 interviewed herders belong to 11 PUGs. The Green Gold project started with 5 soums located in North-Western Mongolia. PUGs were therefore selected from these soums, after our consideration of their performance based on soum government employees and herders' preferences. These preferences are connected to the leadership skills of the head of the PUG, his/her acceptance of fellow PUG members, and cooperation with local government and other PUGs. We selected the 11 PUG heads for the survey, while the other herding households were selected through (stratified) random sampling. The intention was that interviews should be conducted with 20 households from each PUG including the head of the PUG. According to the size of the PUG, however, 20 herding households was not always feasible. In cases in which a PUG 
had less than 20 members, all of the members were usually interviewed. When a PUG contained more than 20 households, we ensured that at least one household was selected from each of five different herd size groups $(0-50 ; 51-100 ; 101-200 ; 201-500 ; 501$-and over) when possible. The herding households were randomly selected from these five herd size groups using a list of herding households obtained through the livestock census and kept in the soum governor's office. In our sample, 26.7 percent of the interviewed households were above the poverty threshold line of 200 animals, while 73.3 percent were below the threshold. The share of herder households below the poverty threshold is therefore lower than the national average of 60 percent (see Section 5.2).

\subsubsection{Model specification}

Using the dataset described in the previous section, the following relationship is estimated:

$R Q_{i j}=f\left(A_{j}, B_{i j}, C_{j}\right)+\varepsilon_{i j}$, for $i=1, \ldots 330 \wedge j=1, \ldots 11$

Where:

$R Q_{i j}=$ Rangeland quality perception of interviewed household $\mathrm{i}$ in PUG $\mathrm{j} ; 1=$ improvement in quality over the last five years,

$0=$ decrease in quality over the last five years

$A_{j}=$ Set of PUG characteristics for PUG $j$;

$B_{i j}=$ Set of control variables for household i in PUG $j ; C_{j}=$ Set of ecological zone dummies for PUG j;

$\varepsilon_{i j}=$ Error terms with standard properties.

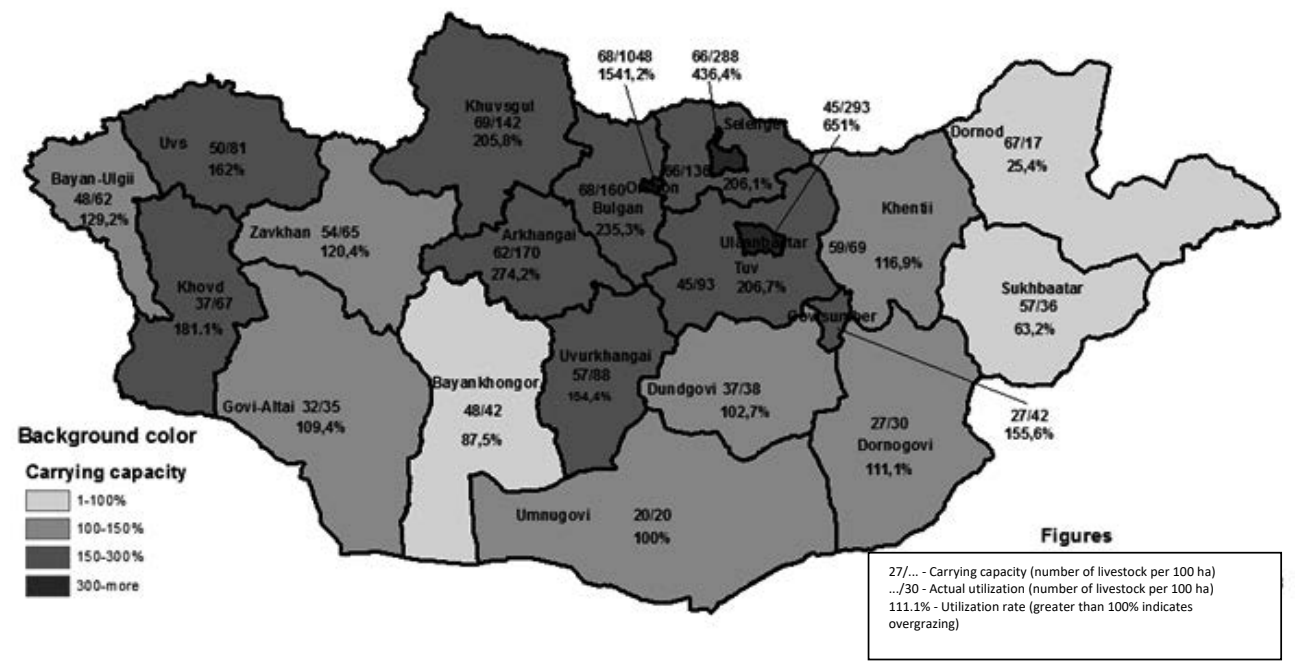

Figure 5.2. Carrying capacity, actual utilization and grazing pressure by aimags, 2010 (ALAGC, 2013). 


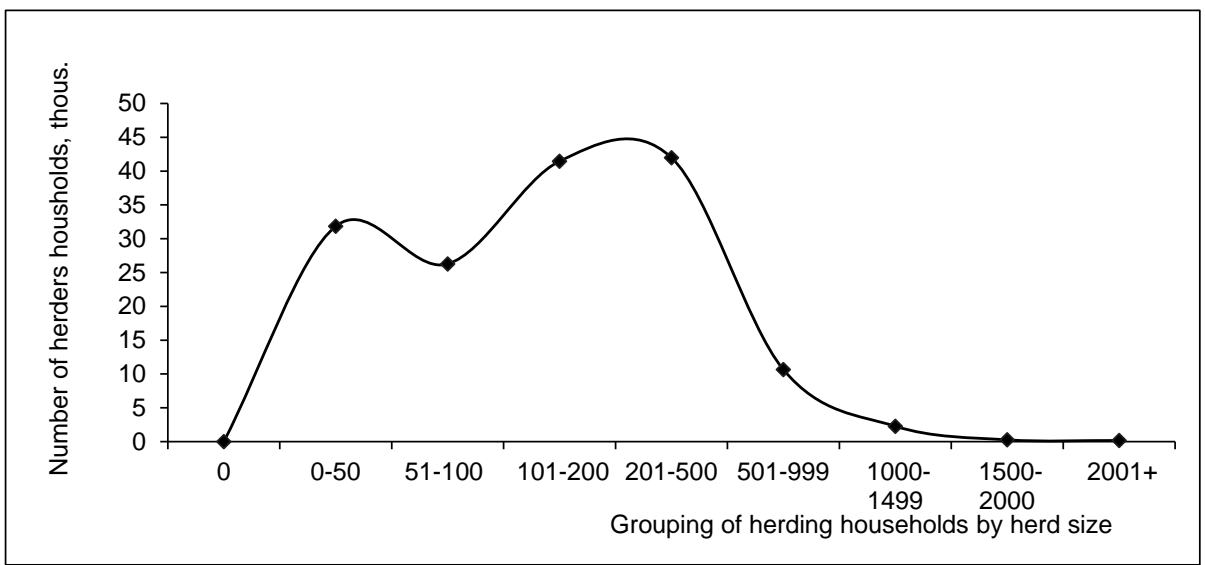

Figure 5.3. Distribution of livestock by herding households, 2010 (NSO, 2011)

The quality of the rangeland, as perceived by herder households, is used as the dependent variable. It is measured through the answer to the question concerning perceived changes in quality of the rangeland. Current data on rangeland quality is only available at the soum level where soum territory consists of more than 8 pasture user groups and therefore could not be used for our purpose. Herders are usually well-informed about rangeland quality and its changes, since they seek to move into good quality rangeland all year round. Herders' moving decisions only depend on the (expected) quality of rangeland; therefore, herders remember well how quality of rangeland changes over years.

Perceived changes in the quality of rangeland are explained by group characteristics, resource characteristics, institutional arrangements and the external environment. The choice of these explanatory variables is based on Agrawal $(2001,2003)$, but is limited to those characteristics for which information is available in our data set and which show sufficient variation among the PUGs and/or herder households that we selected. Household-level data are obtained from the herder household survey (see Section 5.4.1). PUG characteristics have been obtained from soum level secondary data or estimated from household answers. These estimates have been crosschecked during interviews with PUG heads and other local government officials like statistical officers and land managers. Table 5.1 provides the definitions of the variables that are included in the model and shows the expected sign of each explanatory variable.

\section{(1) Group characteristics}

The first group characteristic that we include in our analysis is the heterogeneity of endowments, as measured by the Gini coefficient of inequality in herd sizes. The degree of inequality in herd sizes varies greatly for the PUGs in our sample, as the Gini coefficient ranges from 0.28 to 0.61 , with a mean value of 0.51 . This is expected to have a positive effect on rangeland quality, through enhancing the likelihood of collective action (Baland \& Platteau, 1996). The underlying argument is that wealthy elites who have a relatively large economic interest in a resource can afford to invest extra effort in initiating and maintaining collective action as they will benefit most from sustainable resource management (Nagendra, 2011). 
PUG size is measured by the number of herder households. Group size serves as an indicator of user boundaries according to Ostrom's design principles (Ostrom, 2008). The PUG size varies from 14 to 55 in our data set, with an average size of 39 households (see Table 5.2). A smaller group size is easier to manage and is expected to cause less free riding behaviour (Zhang, Heerink, Dries, \& Shi, 2013) which leads to an efficient use of rangeland and therefore to better rangeland quality. On the other hand, small groups often possess fewer resources for monitoring and punishing free riders. The recent literature therefore suggests an inverted U-shaped relationship between user group size and resource quality, with intermediate group sizes necessitating the greatest monitoring efforts and having the best natural resource quality outcomes (Yang et al., 2013). The impact of group size can therefore be positive as well as negative.

Poor households are expected to be more interested in achieving individual goals than common goals. We use the share of households with a herd size of less than 200 as a measure of poverty in the PUG. Its value ranges from 0.54 to 0.88 , with a mean value of 0.72 for the nine PUGs in our sample. PUGs with low levels of poverty are expected to have more opportunities to use rangeland sustainably in terms of rotational grazing and resting of rangeland (Lise, Hess, \& Purev, 2006). The expected sign of this variable is therefore negative.

\section{(2) Resource characteristics}

Well-defined Well-defined resource boundaries allow the exclusion of outsiders from using the resource and the successful implementation of a resource management plan. According to current regulations in Mongolia, every soum is obliged to develop an annual land management plan. A rangeland management plan is a major part of the soum annual land management plan. Within the framework of this regulation, the soum territory is divided into different rangeland areas for the PUGs within a soum. According to the PUG approach,

Table 5.1. Operationalization and expected effects of explanatory variables

\begin{tabular}{|c|c|c|c|c|}
\hline & $\begin{array}{l}\text { Variable (based on } \\
\text { Agrawal 2003) }\end{array}$ & $\begin{array}{l}\text { Expected } \\
\text { Effect }\end{array}$ & Operationalization & Level $^{1}$ \\
\hline \multicolumn{5}{|c|}{ Group characteristics } \\
\hline Gini & $\begin{array}{l}\text { Heterogeneity of } \\
\text { endowments }\end{array}$ & + & $\begin{array}{l}\text { Gini coefficient of inequality in } \\
\text { herd sizes within PUG }\end{array}$ & $\mathrm{P}$ \\
\hline Number_HHs & Group size & $+/-$ & Number of households in PUG & $\mathrm{P}$ \\
\hline Poverty & Level of poverty & - & $\begin{array}{l}\text { Share of poor households in the } \\
\text { group }\end{array}$ & $\mathrm{P}$ \\
\hline \multicolumn{5}{|c|}{ Resource system characteristics } \\
\hline PUG_Boundary & $\begin{array}{l}\text { Well-defined } \\
\text { boundaries }\end{array}$ & + & $\begin{array}{l}\text { PUG members mutually agreed on } \\
\text { the rangeland boundaries and } \\
\text { showed their approval by signing } \\
\text { on a map }\end{array}$ & $\mathrm{P}$ \\
\hline DistanceMove & Resource mobility & - & $\begin{array}{l}\text { Movement distance of the } \\
\text { household }\end{array}$ & $\mathrm{H}$ \\
\hline OtorMove & Resource mobility & + & Long distance move arrangement & $\mathrm{H}$ \\
\hline PastureAvailability & $\begin{array}{l}\text { Reserve resource } \\
\text { availability }\end{array}$ & + & Reserve rangeland available & $\mathrm{H}$ \\
\hline AV_Move_PUG & & + & $\begin{array}{l}\text { Average distance of annual move } \\
\text { of PUG member HHs excluding } \\
\text { the household itself (in km) }\end{array}$ & $\mathrm{H}$ \\
\hline
\end{tabular}




\begin{tabular}{|c|c|c|c|c|}
\hline PUG_LandSize & Land size & - & PUG area (in 1,000 hectares) & $\mathrm{P}$ \\
\hline \multicolumn{5}{|c|}{ Relationship between resource and group characteristics } \\
\hline LivelihoodChange & $\begin{array}{l}\text { Dependence by group } \\
\text { members on resource } \\
\text { system }\end{array}$ & + & $\begin{array}{l}\text { Change in livelihood level as } \\
\text { compared to two years ago }\end{array}$ & $\mathrm{H}$ \\
\hline \multicolumn{5}{|c|}{ Institutional arrangements } \\
\hline Participation & $\begin{array}{l}\text { Availability of low- } \\
\text { cost adjudication }\end{array}$ & + & $\begin{array}{l}\text { Participation in PUG meetings in } \\
2010\end{array}$ & $\mathrm{H}$ \\
\hline EaseEnfRules & $\begin{array}{l}\text { Ease in enforcement } \\
\text { of rules }\end{array}$ & + & $\begin{array}{l}\text { All PUG members discuss when } \\
\text { problematic issues arise (scale } 1 \text { - } \\
\text { 7) }\end{array}$ & $\mathrm{H}$ \\
\hline \multicolumn{5}{|c|}{ Relationship between resource system and institutional arrangements } \\
\hline Challenge & & - & $\begin{array}{l}\text { Number of challenges when } \\
\text { aiming to improve rangeland }{ }^{2}\end{array}$ & $\mathrm{H}$ \\
\hline \multicolumn{5}{|c|}{ External environment } \\
\hline External aid & $\begin{array}{l}\text { Level of external aid } \\
\text { to compensate users } \\
\text { for conservation } \\
\text { activities }\end{array}$ & + & $\begin{array}{l}\text { PUG obtained external aid in } \\
2010\end{array}$ & $\mathrm{H}$ \\
\hline Aid sources & $\begin{array}{l}\text { Level of external aid } \\
\text { to compensate users } \\
\text { for conservation } \\
\text { activities }\end{array}$ & - & Number of sources of external aid & $\mathrm{H}$ \\
\hline GetLoan & $\begin{array}{l}\text { Level of articulation } \\
\text { with external markets }\end{array}$ & - & Obtained loan in 2010 & $\mathrm{H}$ \\
\hline StateRegulation & $\begin{array}{l}\text { Central government } \\
\text { should not undermine } \\
\text { local authority }\end{array}$ & + & $\begin{array}{l}\text { PUG's rangeland plan is part of a } \\
\text { soum-level land management plan }\end{array}$ & $\mathrm{H}$ \\
\hline \multicolumn{5}{|c|}{ Household characteristics } \\
\hline HerdingExperience & & + & Age of household's head & $\mathrm{H}$ \\
\hline FamilySize & & + & Number of family members & $\mathrm{H}$ \\
\hline \multicolumn{5}{|l|}{ Ecological zones } \\
\hline eco_z3 & & + & Desert steppe ecological zone & $\mathrm{P}$ \\
\hline eco_z2 & & + & Forest steppe ecological zone & $\mathrm{P}$ \\
\hline
\end{tabular}

Note: +/- means undetermined effect

1: $\mathrm{P}=\mathrm{PUG}, \mathrm{H}=$ Herder household

2: Herders were asked about the following potential challenges they face regarding investing in rangeland improvement and management:

- Not enough pasture land to rotate

- Lack of water source

- Lack of cooperation amongst members

- Lack of finance

- Lack of transportation

- Free riding problem

- Other

PUGs define the boundaries of pastures among themselves and develop rules based on traditional or newly negotiated arrangements that provide fair access for all members to the available pastureland. Enabling herders to define pasture boundaries is considered an important step towards reducing the detrimental impacts of open access. Out of the 330 herder households that 
we interviewed, 64 percent of the respondents indicated that the PUG members mutually agreed on the rangeland boundaries and showed their approval by signing on a map. We use a dummy variable that indicates the presence of such agreements as an explanatory variable in the model, and expect that it will have a positive effect on rangeland quality.

The level of mobility is expected to affect resource management as greater mobility makes management more difficult for users because of problems associated with the reliability and cost of information (Agrawal, 2003, p. 249). We include the movement distance as indicator of livestock mobility in our model. The movement distance varies from 0 to $244 \mathrm{~km}$, with a mean value of $78.7 \mathrm{~km}$, for the herders in our sample. This variable cannot be considered as exogenous, because herders are likely to move longer distances when the quality of rangeland is perceived as poor. To deal with this problem, the average value of this variable for the other interviewed households in the same PUG is used in the model. The movement distance is expected to have a negative effect.

Herders may also do otor movement, i.e. herd movement for the purpose of resting the permanent grazing land and fattening the

Table 5. 2. Descriptive statistics

\begin{tabular}{|c|c|c|c|c|c|c|}
\hline & $\begin{array}{l}\text { Level of the } \\
\text { variable }\end{array}$ & Unit & Mean & $\begin{array}{c}\text { Std. } \\
\text { Deviation }\end{array}$ & Min. & Max. \\
\hline Rangeland quality & Household & 1 or 0 & 0.54 & 0.50 & 0 & 1 \\
\hline Gini & PUG & Percentage & 0.51 & 0.09 & 0.28 & 0.61 \\
\hline Number_HHs & PUG & Integer & 38.97 & 12.60 & 14 & 55 \\
\hline (Number_HHs)^2 & PUG & Integer & 1677.06 & 904.705 & 196 & 3025 \\
\hline Poverty & PUG & Percentage & 0.72 & 0.11 & 0.54 & 0.88 \\
\hline PUG_Boundary & PUG & 1 or 0 & 0.64 & 0.48 & 0.00 & 1.00 \\
\hline DistanceMove & Household & Integer & 78.72 & 46.34 & 0.00 & 244.00 \\
\hline OtorMove & & $\mathrm{Km}$ & 0.52 & 0.50 & 0.00 & 1.00 \\
\hline PastureAvailability & Household & Integer & 0.28 & 0.45 & 0.00 & 1.00 \\
\hline AV_Move_PUGkm & Household & Integer & 78.73 & 17.84 & 37.00 & 118.61 \\
\hline PUG_LandSizeHa & PUG & 1,000 ha & 16.78 & 10.16 & 8.10 & 43.60 \\
\hline LivelihoodChange & Household & Integer & 2.54 & 0.97 & 1.00 & 5.00 \\
\hline Participation & Household & Integer & 0.68 & 0.74 & 0.00 & 3.00 \\
\hline EaseEnfRules & Household & Integer & 5.90 & 1.37 & 1.00 & 7.00 \\
\hline Challenge & Households & Integer & 1.76 & 1.08 & 0.00 & 6.00 \\
\hline Aid_YN & Households & 1 or 0 & 0.88 & 0.32 & 0.00 & 1.00 \\
\hline ExternalAid & Households & Integer & 1.17 & 0.99 & 0.00 & 6.00 \\
\hline GetLoan & Households & 1 or 0 & 0.46 & 0.50 & 0.00 & 1.00 \\
\hline StateRegulation & Households & 1 or 0 & 0.29 & 0.45 & 0.00 & 1.00 \\
\hline HerdingExperience & Household & Integer & 42.97 & 12.32 & 21.00 & 78.00 \\
\hline FamilySize & Household & Integer & 4.64 & 1.83 & 1.00 & 12.00 \\
\hline eco_z3 & PUG & 1 or 0 & 0.30 & 0.46 & 0.00 & 1.00 \\
\hline eco_z2 & PUG & 1 or 0 & 0.21 & 0.41 & 0.00 & 1.00 \\
\hline
\end{tabular}


animals. Different from seasonal move, otor represents moving a comparatively long distance one time a year. Otor areas are also used as reserve grazing land when permanent grazing land faces shortage of forage due to a natural disaster. Resting their pasture is a beneficial practice for nomadic people, therefore the expected effect of this variable is positive. In our survey, herders were asked whether or not they do annual otor move. Out of the 330 interviewed herder households, 52 percent answered that they do organize otor annual herd movement.

In addition to the aforementioned resource system indicators listed by Agrawal $(2001,2003)$, we added an indicator of reserve resource availability to the model. PUGs with reserve rangeland have more opportunities to introduce different grazing schemes and protect vulnerable areas from overgrazing. Establishing reserve rangelands cannot be implemented without a collective decision-making process that involves all herders who would benefit from that reserve area. Reserve rangeland is available for 28 percent of the herder households in our sample (see Table $5.2)$.

One important element of rangeland management plans at the PUG level is the seasonal herd move of PUG members. Every PUG develops its annual rangeland management plan which is approved by all members in a meeting. The average distance for a seasonal move is measured in $\mathrm{km}$ in our model. Its expected effect is positive, because longer distance moves mean the implementation of better inter-season rotational grazing. On average, the PUG seasonal move distance was $78.7 \mathrm{~km}$ for the interviewed herders; it varied between 18 and $119 \mathrm{~km}$.

PUG land size is measured in 1,000 hectares. In the beginning of PUG formation, all herder households discuss and draw their sketch maps to settle the PUG's physical boundary. This results in time-consuming long-term debates and discussions amongst herders within a soum and neighbouring soums. Once all herders agree and a PUG boundary is fixed, a soum land manager specifies the boundaries on the soum map, and calculates the sizes of the PUG land. In our sample, an average land size of a PUG is 16,780 hectares while the largest territory is 43,600 hectares and the smallest territory is 8,100 hectares. We expect that the effect of PUG land size is negative, because use and misuse of rangeland is easier to monitor when land size is relatively small.

(1 and 2) Relationship between resource system characteristics and group characteristics

Since livestock is the main livelihood asset, PUG members are highly dependent on rangeland quality and availability for their livelihoods. The change in livelihood is therefore used to indicate the relation between rangeland characteristics and group characteristics. It is measured by the answers of herders to the survey question 'Change in livelihood level as compared to two years ago'. Responses were ranked on a scale from 1 to 5 , with 3 indicating no change, greater than 3 indicating an improvement of livelihood, and smaller than 3 indicating a worsening of livelihood. It is expected that herders with positive recent livelihood changes are more dependent on rangeland and therefore more positive about recent changes in the quality of the rangeland.

(3) Institutional arrangements

Ease in enforcement of rules is expected to contribute to better resource quality. In our dataset we have information about the degree of agreement of all PUG members discussing when 
problematic issues raised, measured on a scale from 1 (= fully disagree) to 7 (= fully agree). In general, the degree of agreement is high, since the mean value for this variable is ' 5.9 '. It is expected that the quality of the rangeland is positively affected by the extent to which member herders agree with the group decision.

Member herders' participation in PUG meetings is likely to reduce conflicts within the group and to contribute to a common understanding of issues related to the group, its resources and external factors. Active participation of group members is therefore expected to have a positive impact on "availability of low cost adjudication" and as a result on rangeland quality. On average, herders in our sample participated 0.68 times in PUG meetings in 2010. The largest number of meetings in which a herder household participated was 3.

(1 and 3) Relationship between resource system and institutional arrangements

Currently rangeland is an open access resource and under government control while livestock is private property in Mongolia. Therefore, the strategy of herders is usually to benefit from rangeland as much as possible before other herders use it when there is no institutional arrangement like a PUG. Since PUGs do not have a formal legal status, it is challenging to manage its members and to stimulate them to invest in rangeland improvement. The level of challenges that PUGs face in rangeland improvement is expected to have a negative effect on rangeland quality. The variable Challenge is measured by the number of challenges herder households face when they intend to invest in rangeland improvement and management. The larger the number of challenges perceived by PUG members, the lower the quality of the rangeland is expected to be. The number of challenges mentioned by the interviewed herders ranges from zero to six, and equals 1.76 on average (see Table 5.2).

(4) External environment

Factors outside the group managing a resource or outside the resource system may also play an important role in the sustainable management of such resources. Levels of external aid to compensate local users for conservation activities can play an important role in forming PUGs and in managing rangeland-related activities. Two questions were asked for this purpose: a) whether or not a PUG received any external aid, b) if yes, the number of external aid sources. Most households, namely 88\%, indicated that their PUG received external aid in 2010. The number of sources ranged from 0 to 6 , with a mean value of 1.17 . Receiving external aid is expected to have a positive impact on rangeland quality. The number of sources is expected to have a negative impact, as requirements for obtaining aid usually differs between different agencies.

The level of articulation with external markets is a major external factor identified in the common pool resource management literature. A high degree of involvement in external markets may act as a stress factor that contributes to resource degradation. We do not have information on the degree of involvement in output or input markets. Instead, we use getting bank loans (a dummy variable) as an indicator of the level of articulation with external markets. The majority of basic needs of herder households are usually covered by the income obtained from animal products and crop production. Herders in Mongolia tend to use loans for making investments in animal husbandry and in market activities. Obtaining bank loans is therefore expected to have a negative impact on resource quality. Out of the interviewed herders, $46 \%$ indicated that they obtained a loan in 2010. 
According to the current legislation in Mongolia, local governments must support initiatives by herders' organisations for sustainable rangeland management. Approval of the soum-level annual land management plan depends on the outcome of the representatives' meetings held by the inhabitants of the soum. These representatives are responsible for monitoring the implementation of the plan. PUGs are expected to have fewer difficulties in implementing their rangeland use plan when it is part of an approved soum annual land management plan that regulates livestock transit, rangeland rest, reserve rangeland, and so on. Despite the current legislation on soum-level approval of land management plans, only 29 percent of the interviewed herder households indicate that their PUG's rangeland plan is part of a soum-level land management plan that needs to be approved at a soum citizen's representatives' meeting each year (see Table 5.2).

In addition to the aforementioned variables, two household characteristics reflecting human capital are included in the model as control variables. Herding experience, as measured by the age of the head of the household, is assumed to be favourable for sustainable rangeland management. A large family size usually implies more laborers, and hence is also expected to have a positive impact on sustainable rangeland management. The average age of interviewed herders is 43.0 years, while the average family size is 4.6 . Both variables show considerable variation across interviewed herders. Finally, two dummy variables are included in the model to control for differences between the three ecological zones. Almost $50 \%$ of the interviewed herders' lives in the high mountain zone, while $30 \%$ lives in the desert steppe zone and $21 \%$ in the forest steppe zone. Because of the geological position and availability of summer grazing land, herders in the two steppe zones are expected to manage their rangelands in a relatively more sustainable way than herders in the high mountain zone. Herder household density in summer pastures is very high in the high mountain region, which is expected to complicate the functioning of PUGs. 


\subsection{Estimation results}

The model presented in the previous section explains a binary variable from a number of explanatory variables at two different levels, the PUG level and the household level. An appropriate method for estimating such a model is the multilevel mixed effects logistic regression approach (Cameron \& Trivedi, 2009). Estimation techniques applied before in similar studies include logit regression and the analytical hierarchy logistic model. The selected method is considered more suitable for our study because it allows to distinguish the impact of nested institutions, i.e. herders' households within PUGs.

The regression results of applying the multilevel mixed effect logistic regression model, with random effects at the PUG level, to

Table 5. 3. Regression results for rangeland quality

\begin{tabular}{lrrr}
\hline Variables & & & \\
Dependent variable: (RQ Rangeland Quality) & \multicolumn{1}{c}{ Coefficient } & Odds Ratio & \\
\hline Gini & $-10.574^{* *}$ & 0.000 & -2.250 \\
Number_HHs & $0.647^{* * *}$ & 1.090 & 11.660 \\
(Number_HHs)^2 & $-0.00752^{* * *}$ & & -9.200 \\
Poverty & $-3.310^{*}$ & 0.034 & -1.590 \\
\hline PUG_Boundary & $0.915^{* * *}$ & 2.510 & 2.720 \\
DistanceMove & $-0.010^{* * *}$ & 0.991 & -2.660 \\
OtorMove & $0.530^{* *}$ & 1.706 & 1.910 \\
PastureAvailability & 0.178 & 1.198 & 1.390 \\
AV_Move_PUGkm & $0.018^{*}$ & 1.019 & 1.640 \\
PUG_LandSizeHa & -0.026 & 0.975 & -1.120 \\
\hline LivelihoodChange & 0.029 & 1.028 & 0.180 \\
\hline Participation & 0.170 & 1.217 & 0.680 \\
EaseEnfRules & $0.214^{* *}$ & 1.248 & 1.860 \\
\hline Challenge & $-0.440^{* *}$ & 0.647 & -2.540 \\
\hline Aid_YN & $1.126^{* *}$ & 3.081 & 1.840 \\
ExternalAid & $-0.472^{* *}$ & 0.615 & -2.400 \\
GetLoan & $-0.658^{* *}$ & 0.520 & -2.420 \\
StateRegulation & $-1.284^{* * *}$ & 0.281 & -3.730 \\
\hline HerdingExperience & $0.025^{* *}$ & 1.026 & 2.120 \\
FamilySize & 0.079 & 1.085 & 1.040 \\
eco_z3 & $1.242^{* *}$ & 3.503 & 2.150 \\
eco_z2 & $1.619^{* * *}$ & 5.250 & 2.570 \\
\hline cons & 0.514 & 1.674 & 0.280 \\
\hline Wald chi2(22) & 57.25 & & Prob>chi2 \\
\hline Notes: & 0.0001 \\
\hline
\end{tabular}

Notes: $*, * *, * * *$ indicate significant at $10 \%, 5 \%$, and $1 \%$ level respectively.

our dataset are presented in Table 5.3. We find that inequality in herd sizes exerts a significant negative impact on sustainable rangeland management. This finding indicates that, in the case of Mongolian rangelands, successful collective action is more likely when differences in herd sizes are small, and thereby contradicts previous research stressing the importance of endowments inequality in promoting collective action (Baland \& Platteau, 1996; Nagendra, 2011). We 
observed in the field that households with large herds are often reluctant to join a PUG. They tend to live alone in a remote area in order to not mix their herds with other households, and often do not trust PUG members with much smaller herds. The result for the inequality in herd sizes indicator suggests that when they do join a PUG, they do not invest extra effort in maintaining collective action. PUG size has a significant positive impact on rangeland quality, while PUG size squared has a significant negative impact. These findings support our expectation of an inverted U-shaped relationship between user group size and resource quality, with intermediate group sizes contributing the greatest monitoring effort and having the best natural resource quality outcomes (Yang et al., 2013). The estimated coefficients suggest that maximum rangeland quality is obtained at a group size of 43 herder households. It slightly exceeds the mean group size of 39 for the PUGs that we examine. The share of poor households in a PUG has a negative impact on rangeland quality, as expected; it supports the proposition that PUGs consisting of many poor households have fewer opportunities to implement a good rangeland management strategy.

Concerning the resource characteristics, we find that well-defined pastureland boundaries of the PUG have a significant positive effect on perceived rangeland quality. This finding supports the premise that well-defined boundaries enable the exclusion of outsiders and successful implementation of rangeland management plans. Average movement distance has a significant negative association with rangeland quality. This result supports the presumption that greater mobility makes management more difficult for users because of problems associated with the reliability and cost of information. Annual otor moves are found to have a positive impact on rangeland quality. By making otor, permanent grazing land is allowed to rests and is conserved, positively affecting the quality of rangeland. The average distance of the annual move of all herders in a PUG, excluding the household itself, is found to have a significant positive impact on rangeland quality. This finding support the proposition that longer distance moves by PUG members, as specified in the approved rangeland management plan, imply the implementation of better inter-season rotational grazing and thereby contribute to more sustainable rangeland management. Contrary to our expectations, the availability of reserve rangeland and the size of the land area managed by a PUG do not have significant effects on the quality of the rangeland. Agro-climatic differences between the regions in which PUGs are active may obscure these relationships.

The estimated coefficient for the variable reflecting the relationship between resource and group characteristics, changes in livelihood level over the last two years, does not differ significantly from zero. In other words, perceived changes in rangeland quality are not significantly related to recent changes in livelihood levels even though rangeland is the main livelihood asset for most interviewed herders.

With regard to institutional arrangements, we find that the extent to which member herders agree with group decisions has a positive impact on rangeland quality. This finding supports the premise that the ease with which a PUG enforces its rules positively affects rangeland quality. On the other hand, the number of times that a herder participated in a PUG meeting does not have a significant impact. Participation in meetings may not only reflect active participation of group members, but may also signal the existence of major problems in group decision making.

Challenges experienced when aiming to improve rangeland quality is used in the model to reflect the relationship between the resource system and institutional arrangements. Its estimated 
coefficient is significantly different from zero with a negative sign, as expected from theory. The more hurdles herders face in improving rangeland quality, the lower the observed quality of the rangeland.

The external environmental is also found to significantly affect rangeland quality. As expected, receiving external aid positively affects rangeland quality, as it can serve as a catalyst in forming PUGs and in managing rangeland-related activities. But the number of external aid sources is found to have a negative impact, possibly due to differences between donor agencies in conditions that need to be met for obtaining aid. The indicator of articulation with external markets in our model, whether herder households obtained a loan in 2010, has a significant negative effect on rangeland quality. This finding provides support for the proposition that involvement in external markets may act as a stress factor that contributes to resource degradation. Finally, heavy government involvement in rangeland management decisions has a significant negative effect on rangeland quality. This finding suggests that central government involvement undermines local authority.

Out of the two human capital variables that are included as control variables in the model, only the age of the household head is found to exert a significant effect on rangeland quality. Its positive sign confirms that herding experience may play an important role in sustainable rangeland management. The size of a household does not have a significant impact on rangeland quality, probably because larger households do not only have more laborers but also demand more resources for their livelihoods.

The estimated coefficients of the two ecological zone dummy variables are both positive and significantly different from zero. Hence, controlling for the other factors that are included in the model, rangeland quality of the high-mountain zone is lower than rangeland quality in the desert and forest steppe zones. This finding confirms that herders in the two steppe zones are expected to manage their rangelands in a relatively more sustainable way than herders in the high mountain zone.

\subsection{Conclusion}

Rangelands are of crucial importance for the livelihoods of Mongolian herders. They are the basic natural resource base of the agricultural sector, which constitutes a key sector in the Mongolian national economy. Pasture Users Groups (PUGs) and other community-based rangeland management institutions have been created in recent years, in an effort to address the increased degradation and desertification of rangelands. Little is known about the impact of these newly created institutions on the management of rangeland. The objective of this paper is to investigate the performance of community-based rangeland management institutions in Mongolia by analysing specific characteristics of pasture user groups that affect rangeland quality. We use the integrated framework of factors affecting sustainable governance of the commons developed by Agrawal $(2001,2003)$ to guide the specification of the empirical model. A multilevel mixed effects logistic regression model was applied to data at the herders and PUGs level to explain herders' perceptions of the change in rangeland quality during the last five years.

The estimation results show that selected characteristics of PUGs have significant impacts on rangeland quality. A well-defined rangeland boundary is key in supporting rangeland quality, which is in line with the current government policy to enable the delineation of rangeland 
boundaries by user groups within the framework of an annual land management planning scheme. We further found an inverted U-shaped relationship between user group size and resource quality, with the optimal group size slightly exceeding the mean group size observed in our sample. The share of poor households in a PUG has a negative impact on rangeland quality, confirming that poorer households have fewer resources to implement good rangeland management strategies. Inequality in herd sizes has a negative impact on rangeland quality. Hence, in the case of Mongolian rangelands endowments equality instead of inequality is important for successful collective action. Resting of rangeland, seasonal movement of households and successful implementation of rotational grazing management schemes are also important for maintaining rangeland quality.

Once a PUG has been established by using a bottom-up approach and all members have discussed problematic issues openly, it is easier to enforce PUG bylaws and other rules to manage rangeland. It is expected that this will overcome challenges and difficulties in improving rangeland quality, and thereby positively affect sustainable rangeland management.

External aid is necessary and is an important factor for rangeland management, as our empirical results confirm. The number of sources providing external aid, however, has a negative impact on rangeland quality. In order to increase their impact on sustainable rangeland management, the government and donor organizations should therefore concentrate their support to specific user groups and spend more effort on coordinating their activities. We hope that our findings on the importance of well-defined boundaries, group size, herd size inequality and other factors will help the Mongolian government as well as donor agencies in further shaping the policy environment and the assistance provided to joint action in rangeland management as this seems an important pathway towards sustainable rangeland management.

\section{Acknowledgments}

The data collection and survey within this research is supported by the Green Gold Pasture Ecosystem Management Programme by Swiss Cooperation and the Development Agency in Mongolia. The authors would like to thank to Dr. Ts.Enkh-Amgalan and all Green Gold project team members.

\section{References}

Agrawal, A. (2001). Common property institutions and sustainable governance of resources. World Development, 29(10), 1649-1672.

Agrawal, A. (2003). Sustainable governance of common-pool resources: Context, methods, and politics. Annual Review of Anthropology, 32, 243-262.

ALAGC (2013). Grazing pressure and stocking rates by aimags. Retrieved June 17, 2013, from http://www.gazar.gov.mn.

Amgalan, O., Avaadorj, D., Batbuyan, B., Batmandakh, A., Binswanger, M. H., Bolormaa, B., ... Zagdsuren, Y. (2010). Livelihood study of herders in Mongolia. 
Ulaanbaatar Mongolia: Selengepress Co.Ltd.

Baland, J. M., \& Francois, P. (2005). Commons as insurance and the welfare impact of privatization. Journal of Public Economics, 89(2-3), 211-231.

Baland, J. M., \& Platteau, J. P. (1997). Wealth inequality and efficiency in the commons.1. The unregulated case. Oxford Economic Papers-New Series, 49(4), 451-482.

Baland, J. M., \& Platteau, J. P. (1998). Wealth inequality and efficiency in the Commons, part II: The regulated case. Oxford Economic Papers-New Series, 50(1), 1-22.

Baland, J.-M., \& Platteau, J. P. (1996). Halting degradation of natural resources. Oxford, Food and Agriculture Organization of the United Nations. Clarendon Press.

Baland, J.-M., \& Platteau, J.-P. (2003). Chapter 4: Economics of common property management regimes. In K. G. Maler, \& J. R. Vincent (Vol. Eds.), Handbook of

environmental economics. Vol. 1. Amsterdam: Elsevier.

Cameron, A. C., \& Trivedi, P. K. (2009). Microeconometrics using Stata. College Station: Stata Press.

Cao J., T., E.T. Yeh, N. M. Holden, Y. Qin and Z. Ren (2013). "The roles of overgrazing, climate change and policy as drivers of degradation of China's grasslands."

Nomadic Peoples 17(2): 82-101.

Dorligsuren, D. (2008). Changes in livestock number and pasture area of Mongolia. Paper presented at XXI International Grassland Congress \& VIII International Rangeland

Congress, Hohhot, P.R. China, 29th June - 5th July, 2008.

Fernandez-Gimenez, M. E. (1999). Sustaining the steppes: A geographical history of pastoral land use in Mongolia. Geographical Review, 89(3), 315-342.

Fernandez-Gimenez, M. E. (2002). Spatial and social boundaries and the paradox of pastoral land tenure: A case study from post socialist Mongolia. Human Ecology,

30(1), 49-78.

Fernandez-Gimenez, Maria E. (2006). Land Use and Land Tenure in Mongolia: A Brief History and Current Issues. 2004 January 27; Salt Lake City, UT. Proceeding

RMRS-P-39 In Bedunah, Donald J., E. Durant McArthur, \& Maria Fernandez-Gimenez (Eds.). Rangelands of Central Asia: Proceedings of the Conference on

Transformations, Issues, and Future Challenges (pp. 30-36). Fort Collins, CO: U.S. Department of Agriculture, Forest Service, Rocky Mountain Research Station.

Fernandez-Gimenez, M. E., \& Batbuyan, B. (2004). Law and disorder: Local implementation of Mongolia's Land Law. Development and Change, 35(1), 141-165. 
Fratkin, E. (1997). Pastoralism: Governance and development issues. Annual Review Anthropology, 26, 235-261.

Fratkin, E., \& Mearns, R. (2003). Sustainability and pastoral livelihoods: Lessons from East African Maasai and Mongolia. Human Organization, 62(2), 112-122.

GGPEMP, \& MSRM (2010). Livelihood study of herders in Mongolia. Ulaanbaatar Mongolia: Green Gold Pasture Ecosystem Management Programme (GGPEMP) and

Mongolian Society for Range Management (MSRM).

Gordon, H. S. (1954). The economic theory of a common-property resource: The fishery. Journal of Political Economy, 62(2), 22.

Hardin, G. (1968). The Tragedy of the Commons. Science, 162(3859), 1243-1248.

Heijman, W. J. M. (1991). Depletable resources and the economy. Department of General Economics. Wageningen, Wageningen Agricultural University (PhD thesis).

Ho, P., \& Azadi, H. (2010). Rangeland degradation in North China: Perceptions of pastoralists. Environmental Research, 110(3), 302-307.

Holechek, J. L., Pieper, R. D., \& Herbel, C. H. (2001). Range management principles and practices. Upper Saddle River NJ: Prentice-Hall.

Lise, W., Hess, S., \& Purev, B. (2006). Rangeland degradation and poverty among herders in Mongolia: Data analysis and game estimation. Ecological Economics, 58(2),

$350-364$.

Lkaghjav, N. (2006). Decrease of pasture land productivity. Theoretical and practical conference on issues and challenges of pasture management (Ulaanbaatar, Mongolia,

Admon).

Mau, G., \& Chantsallkham, J. (2006). Herder group evaluation. Ulaanbaatar: United Nations Development Program (UNDP) Mongolia.

Mearns, R. (2004). Sustaining livelihoods on Mongolia's pastoral commons: Insights from a participatory poverty assessment. Development and Change, 35(1), 107-139.

Meinzen-Dick, R., E. Mwangi and D. S (2006). "Securing the commons." Policy Brief no. 4 CGIAR Systemwide programme on collective action and poverty rights.

Washington, D.C., IFPRI.

Mwangi, E. (2007). Subdividing the commons: Distributional conflict in the transition from collective to individual property rights in Kenya's Maasailand. World

Development, 35, 815-834. 
Mwangi, E., \& Markelova, H. (2009). Collective action and property rights for poverty reduction: A review of methods and approaches. Development Policy Review,

$27(3), 307-331$.

Nagendra, H. (2011). Heterogeneity and collective action for forest management. Human development research paper 2011/2. New York: UNDP.

NSO (2011). Statistical Yearbook of Mongolia. Ulaanbaatar: Soyombo Printing.

Ostrom, E. (1990). Governing the Commons: The Evolution of Institutions for Collective Action.

Ostrom, E. (2008). The challenge of common-pool resources. Environment, 50(4), 8-20.

Tserendash, S., \& Altanzul, T. (2013). Handbook for pasture management. (Ulaanbaatar, Mongolia).

Wade, R. (1988). Village republics : economic conditions for collective action in South India. Cambridge: Cambridge University Press.

Yang, W., Liu, W., Vina, A., Tuanmu, M.-N., He, G., Dietz, T., \& Liu, J. (2013). Nonlinear effects of group size on collective action and resource outcomes. PNAS,

110(27), 10916-10921.

Ykhanbai, H., Narantungalag, B., Tserendash, S., Saipolda, T., Beket, U., Tsogt, Z., ... Baatarbileg, N. (2011). Community based co-management of natural resources in

Mongolia. Ulaanbaatar: ADMON.

Zhang, L., Heerink, N., Dries, L., \& Shi, X. (2013). Water users associations and irrigation water productivity in northern China. Ecological Economics, 95, 128-136. 



\section{Chapter 6}

\section{Options for Increasing Mongolia's \\ Livestock Sector Exports A Revealed Comparative Advantage Analysis}




\title{
6. OPTIONS FOR INCREASING MONGOLIA'S LIVESTOCK SECTOR EXPORTS - A REVEALED COMPARATIVE ADVANTAGE ANALYSIS*
}

\begin{abstract}
Mongolia is a country with rich natural resources, including more than 70 million domesticated animals. The livestock sector is the traditional economic sector of Mongolia, and it is a major food source of the nation. Currently, the country faces an overgrazing problem caused by an increase in the number of animals whereas rangeland carrying capacity is limited. Exporting more meat and other products of animal origin has the potential to reduce the livestock population to sustainable levels, reduce overgrazing pressure, and increase the country's export income. Policies aimed at promoting animal product exports should take the comparative advantages of different types of products of animal origin into account in order to maximize their impact. This paper aims to provide science-based evidence to support such policies by investigating the comparative advantage of meat and other selected products of animal-origin using the revealed comparative advantage index. Official statistics for 81 products over nine years were used for the data analysis. The results suggest that Mongolia's meat export policy should focus on large volumes and relatively lower processing level products in the short run and should shift to differentiated value-added products in the long run. We recommend that the Government of Mongolia improves its meat sector's regulation and develops formal supply chains in order to effectively monitor food safety and create high-quality Mongolian brand products of animal origin.
\end{abstract}

\section{Keywords}

Comparative advantage, meat export, trade analysis, value chains

\footnotetext{
* Paper by Erdenechuluun Tumur, Wim Heijman, Enkh-Amgalan Gurjav, Bakey Agipar, and Nico Heerink, submitted to Mongolian Journal of Agricultural Sciences, 2020, ISSN 2310-6212 eISSN 2524-0722
} 


\subsection{Introduction}

The livestock sector of Mongolia was among the top three highest growing sectors in the country between 2000 and 2019. About 170,000 herding households are working in the livestock sector and are responsible for herding more than 70 million open-range pastoral livestock; the sector produces $90 \%$ of the total agricultural production (National Statistical Office (NSO), 2019). Rangeland degradation caused by overgrazing is one of the greatest environmental problems that Mongolia is facing, in large part caused by the tripling of the livestock population from 1990 to 2019 (National Statistical Office (NSO), 2019). According to various scientific studies, the livestock population is overstocked by more than 30 million heads compared to the carrying capacity of the rangeland (Ministry of Food Agriculture and Light Industry (MoFALI), 2018; National Statistical Office (NSO), 2018; Swiss Agency for Development and Cooperation (SDC), 2015; Densambuu, Sainnemekh, Bestelmeyer, \& Budbaatar, 2018). A recent study indicates that the rational number of livestock that would not degrade the rangelands given their carrying capacities is between 32.8 - 46.7 million livestock heads depending on the season (Agipar \& Byambaa, 2019). Exceeding the carrying capacity of the pastureland causes scarcer fodder resources in the grassland and increased vulnerability to drought and dzud (Dzud refers to a high winter/spring mortality of livestock caused by drought-induced poor rangeland conditions followed by cold winter conditions. Animals basically starve or succumb to disease) natural disasters, which can cause the death of millions of livestock in a short period.

According to the National Rangeland Health Report published in 2015 and 2018, the percentage of degraded rangelands has declined from $65 \%$ in 2014 to $57 \%$ in 2017 . However, compared with conditions in 2014, the degradation degree had increased. In 2017, $13.5 \%$ of the rangeland was slightly degraded, $21.1 \%$ was moderately degraded, $12.8 \%$ was heavily degraded, and $10.3 \%$ was completely degraded. The proportion of areas that were not degraded to slightly degraded rose by up to $10 \%$, but the proportion of areas classified as heavily or completely degraded rose by 4.3 - 5.9\% (Densambuu, Sainnemekh, Bestelmeyer, \& Budbaatar, 2018; Swiss Agency for Development and Cooperation (SDC), 2015).

No serious action has been undertaken so far by the Government of Mongolia to limit the growth of livestock in order to counteract the rangeland degradation caused by overgrazing (International Monetary Fund (IMF), 2019). The decline in rangeland health is the central challenge to sustainability of the livestock sector in Mongolia, and the control of livestock numbers is a fundamental pre-condition for effective rangeland management' (Densambuu, Sainnemekh, Bestelmeyer, \& Budbaatar, 2018). It is clear that the number of animals cannot grow permanently given the present rangeland carrying capacity in Mongolia. Uncoordinated expansion of herd sizes will lead to deterioration in the welfare of the community of herders (Swiss Agency for Development and Cooperation (SDC), 2015).

One of the main causes of the increase of livestock numbers and the concomitant overgrazing is the lack of markets to harvest annual natural increases in livestock population (International Monetary Fund (IMF), 2019; National Statistical Office (NSO), 1990-2018; Bakey, 2016). The growth of the domestic meat market demand lags behind the growth in livestock numbers. Mongolia annually slaughters nearly ten million animals for domestic meat consumption. The current stock's reproductive capacity of livestock is nearly three times the domestic demand (National Statistical Office (NSO), 2018). 
One important option to reduce the pressure on the rangelands is the export of products of animal origin. During the socialist period before 1990, Mongolia annually exported ten million live animals to the Soviet Union in addition to products of animal-origin. This market closed after 1990 , resulting in only a small export volume of live animals and animal originated products. This situation remained the same in recent years.

Mongolia should have a high potential for the export of products of animal origin because the country has a high number of open-range pastoral livestock and a vast territory to develop agribusiness. Such exports could increase the value-added of the livestock sector by gradually shifting the focus from quantity to quality and would be a win-win situation for both the Mongolian livestock sector and the natural environment. Currently, the main export products of the livestock sector in Mongolia are meat, cashmere, and hides and skins (Mongolian Customs, 2020). The total export of the livestock sector was 561.5 million US dollars in 2018, which accounted for $8.0 \%$ of the total export of the country (International Trade Center (ITC), 2020).

This study considers exports of meat and its byproducts and excludes cashmere and other fibers exports. The reason for this choice is that exports of meat and its byproducts contribute to a decrease in the number of livestock in the short run.

Meat export of Mongolia has been increasing rapidly since 2014. Meat is the second important export item after cashmere in terms of products of livestock origin in Mongolia. Meat export has increased from 2.8 thousand tons in 2015 to 70.0 thousand tons in 2018. Meat exports had a value of 160 million USD in 2018, i.e 28.5 percent of the total export value of livestock output. In terms of live animals, 4 - 5 million animals were slaughtered for export purposes in 2018 (Ministry of Food Agriculture and Light Industry (MoFALI), 2019). According to earlier research done by the Asian Development Bank, in which suitable herd sizes and herd structures aligned with each aimag's (Aimag is the largest administrative unit in Mongolia equivalent as province) available rangeland carrying capacity was calculated, Mongolia should be able to produce 318,800 tons of meat (beef, horse, camel, sheep and goat meat) per year on average if herd sizes and herd structures would be aligned with the available rangeland reserves (Asian Development Bank (ADB), 2014). The number of livestock in 2018 was 1.6 times larger compared with that of 2012 when the research for this ADB study took place (Asian Development Bank (ADB), 2014). Therefore, the export potential of meat would have also increased by a similar ratio. The difference between the current export data and the potential export volume shows that there is an excellent opportunity to increase the export income of meat in Mongolia.

Boosting meat exports in the short run would contribute to reaching a level of sustainable production. Considering the biological reproductivity rate, the Government of Mongolia has imposed export quota for beef and horse meat, while sheep and goat meat do not have any quotas (Government of Mongolia, 2019). Mongolia is uniquely located between two large markets, i.e. Russia and China. It has significant opportunities to expand meat export to these two countries and to other countries that eat substantial amounts of sheep and goat. The Government of Mongolia does have several policies to promote animal product export, but these policies make limited use of science-based evidence. In particular, research on comparative advantages could be used to identify the most promising products of animal origin for exports and the export partner countries.

The objective of this study is to investigate the possibilities of increasing the export of Mongolia's livestock sector by investigating the comparative advantages of different animal products. In order to fulfill the research objective, the comparative advantages of animal products in Mongolia 
are compared with international levels. The concept of comparative advantage refers to the ability of a country to produce some good or service not only with higher productivity, as initially proposed by Ricardo (1817), but also with higher product differentiation than other countries in a given trade area (Lafay, 1987) (Ricardo, On the Principles of Political Economy and Taxation, 1817; Lafay, Avantage comparatif et compétitivité, 1987). International trade is an essential source of wealth generation and an essential way to self-sustained growth and poverty reduction, particularly in low-income countries with small domestic markets like Mongolia (Higgins \& Prowse, 2010; Lang N. T., 2011).

Since the pioneering work of Balassa (1965), the standard method for the measurement of comparative advantages is the calculation of a revealed comparative advantage (RCA) index on the basis of trade flows (Balassa B. , 1965). In this research, Balassa's measure of the revealed comparative advantage is applied to answer the research question 'Which types of animaloriginated products of Mongolia are competitive in the world market?'. Time series and crosssection data for 81 products over 9 years was used for the data analyses. Data was gathered from the International Trade Centre, the National Statistical Office of Mongolia, and the Customs Office of Mongolia.

The remainder of the paper consists of four sections. Section 6.2 presents information on Mongolia's livestock sector and the export of animal products. The materials and methods of the study are presented in section 3 . Section 4 presents and discusses the results of the data analyses, while the fifth section of the paper presents conclusions.

\subsection{The Livestock Sector and its Exports}

The livestock number of Mongolia has been increasing since 2010 and has doubled within the last eight years. In terms of the composition, sheep account for 45.5 percent in the total number of livestock in 2019, with goats accounting for 41.2 percent, cattle for 6.7 percent, horses for 5.9 percent, and camels for 0.7 percent (Figure 6.1). The proportion of large animals (such as cattle, horses, and camels) has rapidly declined, while the proportion of goats and sheep have increased. These changes in herd composition reflect market conditions. The impact of extreme weather conditions, which have the greatest impact on small ruminants, has been less significant over the past decade. Thus scientists warn that the appropriate ratio between sheep and goat (75:25) has been still lost with a ratio of 53:47 in 2019 (Agipar \& Byambaa, 2019). The high number of goats brings more cash income to the herders from its cashmere, but it causes negative impacts on environmental sustainability. 


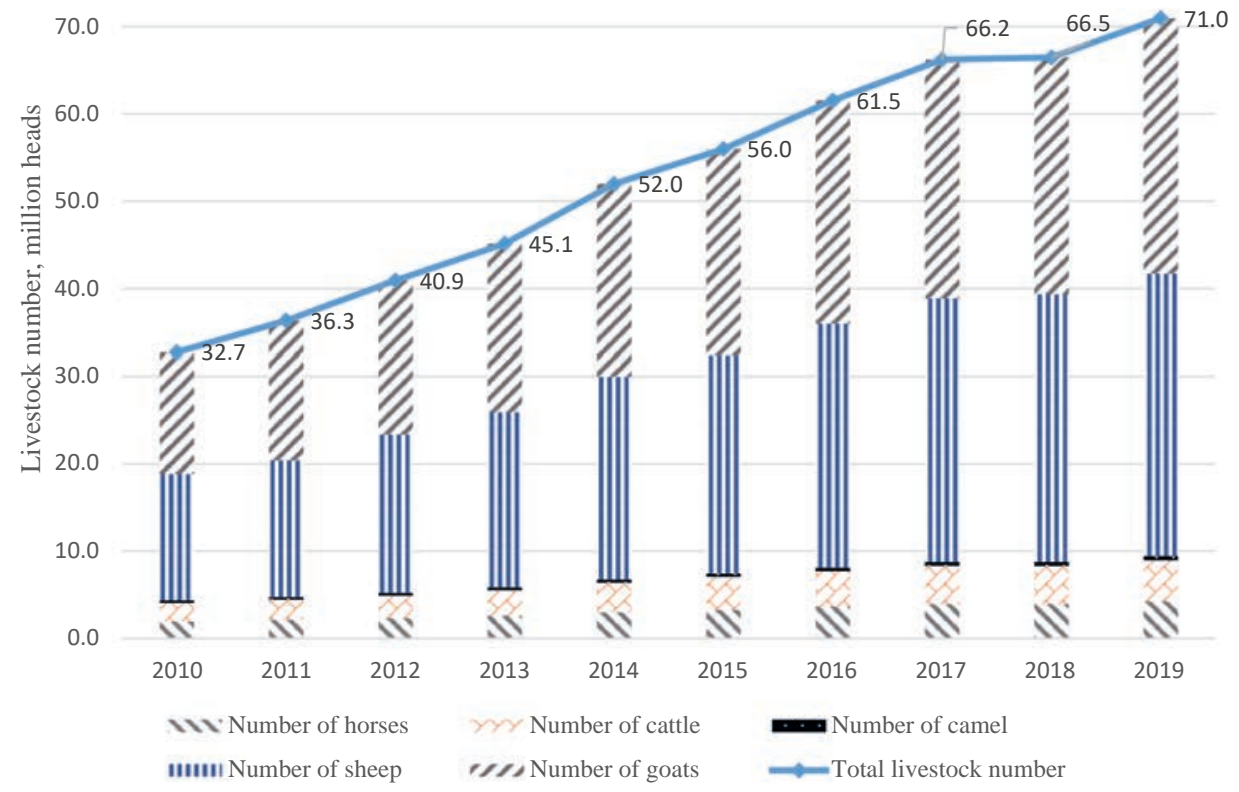

Figure 6.1. Trends in livestock numbers, source: NSO data (National Statistical Office (NSO), 1990-2018)

Animals provide a variety of products. There is a trade-off in terms of use of animals between animal's use for a continuous stream of earnings from products of animal origin and the sale of the live animals. Mongolian herders select the species of animals depending on both income requirements and the local environment (Food and Agriculture Organization of the United Nations, 2019). In 2019, the sector produced 554 thousand tons of meat, 1074 million liters of milk, and 10 thousand tons of cashmere. All products of animal origin have registered steady growth since 2010, with the growth in output of livestock products primarily driven by the number of livestock rather than productivity (National Statistical Office (NSO), 2019). Overall, the livestock sector remains characterized by low productivity due to underdeveloped animal health and breeding systems, high incidence of production- and trade-limiting animal diseases, lack of proper management of pastureland, and insufficient fodder and water supply. All these factors have substantially increased risk to herders' households, the quality of Mongolian livestock, and the health of the livestock industry. 
Options for Increasing Mongolia's Livestock Sector Exports

Table 6.1. Export of Products of Animal Origin from Mongolia, thousand US Dollar

\begin{tabular}{llrrrrrrrrrr}
\hline $\begin{array}{l}\text { HS } \\
\text { Code }\end{array}$ & Product label & 2010 & 2011 & 2012 & 2013 & 2014 & 2015 & 2016 & 2017 & 2018 \\
\hline 01 & Live animals* & 1412 & 56 & 36 & 33 & 38 & 3009 & 1539 & 110 & 221 \\
\hline 02 & $\begin{array}{l}\text { Meat and } \\
\text { edible meat } \\
\text { offal }\end{array}$ & 54385 & 24112 & 10355 & 11104 & 6802 & 10166 & 16406 & 54631 & 86027 \\
\hline 05 & $\begin{array}{l}\text { Other } \\
\text { products of } \\
\text { animal origin }\end{array}$ & 8940 & 12221 & 11031 & 11719 & 8051 & 8880 & 6961 & 6738 & 9644 \\
\hline 15 & $\begin{array}{l}\text { Animal fats } \\
\text { and oils ... }\end{array}$ & 1 & 11 & 17 & 1 & 0 & 1 & 149 & 20 & 1 \\
\hline 16 & $\begin{array}{l}\text { Preparations } \\
\text { of meat ... }\end{array}$ & 282 & 309 & 138 & 2 & 124 & 614 & 1589 & 8628 & 79658 \\
\hline 41 & $\begin{array}{l}\text { Raw hides } \\
\text { and skins ... }\end{array}$ & 31745 & 50761 & 30183 & 34827 & 35514 & 32779 & 24157 & 22662 & 16664 \\
\hline 42 & $\begin{array}{l}\text { Leather: } \\
\text { "travel goods, } \\
\text { handbags, and } \\
\text { similar } \\
\text { containers; } \\
\text { articles" }\end{array}$ & 751 & 290 & 232 & 338 & 192 & 886 & 5864 & 770 & 211 \\
\hline 64 & $\begin{array}{l}\text { Leather: } \\
\text { "Sports } \\
\text { footwear, } \\
\text { footwear, } \\
\text { parts of } \\
\text { footwear" }\end{array}$ & 549 & 1756 & 1001 & 771 & 655 & 860 & 1363 & 1593 & 1359 \\
\hline
\end{tabular}

Source: International Trade Centre (ITC) www.intracen.org

Note: *The Government of Mongolia banned live animals exports since July 3, 2019

Due to improved animal health and lower occurrence of animal diseases, the export value of meat and other products of animal origin has increased the last three years (Table 6.1). The large difference between the current and potential export volumes (see Section 1) indicates that there is a great opportunity to increase the meat export income in Mongolia. The export dynamics of meat and meat products of Mongolia are closely related to the production technology used in animal husbandry. The meat of Mongolian animals is considered a pure and natural 'open range' product. As such it does not always meet international trade partners' requirements for veterinary medicine and food hygiene and quality. Increasing meat exports thus requires improvements in the health status and traceability of livestock. One of the major barriers to meat exports from Mongolia connects to foot-and-mouth disease (FMD) occurrence. According to the infectious nature of FMD and its occurrences in Mongolia, trade partner countries have implemented import bans on meat from Mongolia. Achieving FMD-free status from the World Organization for Animal Health (OIE) is a critical step, as all major international suppliers of meat to China have attained this status (Food and Agriculture Organization of the United Nations, 2019).

Mongolia has no registration or information system for approving or submitting the percentage of healthy livestock and the percentage of meat produced in disease-free regions. This lack has diminished the opportunities for expansion of the Mongolian meat export industry (Mongolian Meat Association (MMM), 2018). Currently, the cost of diagnosing animal diseases and taking preventive measures against animal disease is financed by the herders themselves instead of public agencies, which contributes to the spread of diseases and enables an environment for infection. The current state policy (and finance) of veterinary services focuses on post-disease treatment activities, disinfections, and cutting the spread of diseases rather than pre-disease 


\section{Chapter 6}

control, early diagnosis, and preventive measures. This choice can be explained by the low veterinary budget per livestock unit. In order to resolve the problem, the Parliament of Mongolia approved the "Law on Protection of Livestock Health" and the "Law on Genetic Fund of Livestock" in 2017. The Government of Mongolia re-structured veterinary and animal health institutions and established the General Agency for Veterinary Services (GAVS) of Mongolia in 2018. The occurrences of major animal diseases have dramatically decreased in the last four years (Table $6.2)$.

Table 6.2. The occurrences of 'A-level' animal diseases in Mongolia

\begin{tabular}{|l|c|c|c|c|}
\hline Diseases & 2016 & 2017 & 2018 & 2019 \\
\hline Foot-and-mouth disease & 4 & 67 & 61 & 0 \\
\hline Peste des petitis & 11 & 15 & 5 & 0 \\
\hline Sheep Pox & 53 & 37 & 1 & 0 \\
\hline Total & 68 & 119 & 67 & 0 \\
\hline
\end{tabular}

Source: General Authority for Veterinary Services, 2020

The areas of animal diseases narrowed in terms of geographical distribution during the last four years (Figure 6.2). In 2019 Mongolia was FMD-free while its two neighboring countries, the People's Republic of China and the Russian Federation, recorded occurrences of FMD (Mongolian General Authority for Veterinarian Services (GAVS), 2020).

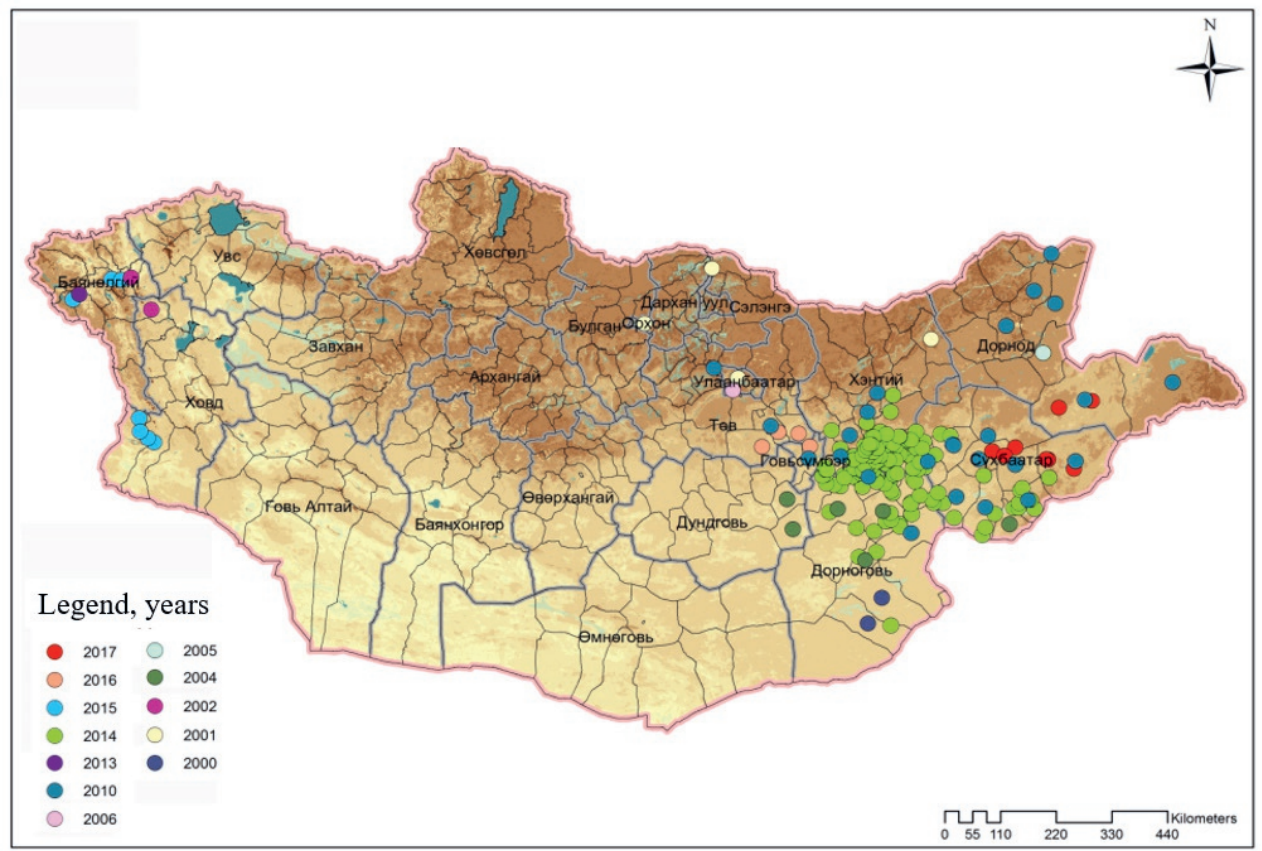

Figure 6.2. The occurrences of the foot-and-mouth disease by location between 2000 and 2017 Source: GAVS, 2020

\subsection{Materials and Methods}

\subsubsection{Data}

The study uses data for 81 products over the years 2010-2018. The main data source was the International Trade Centre database of the National Statistical Office of Mongolia and the Customs 
Office of Mongolia. The selected date is only for products of animal origin (excluding any fibers) and uses the six-digit code Harmonized Commodity Description and Coding System (HS) for the product classification. The data show that Mongolia exported goods to 56 countries during this period. The main export partners were only seven countries, while each of the other countries accounted for less than $1 \%$ of the export share (Figure 6.3). The largest share by far was exported to the People's Republic of China (60.4\%), followed by the Russian Federation (11.8\%) and Italy (8.1\%).
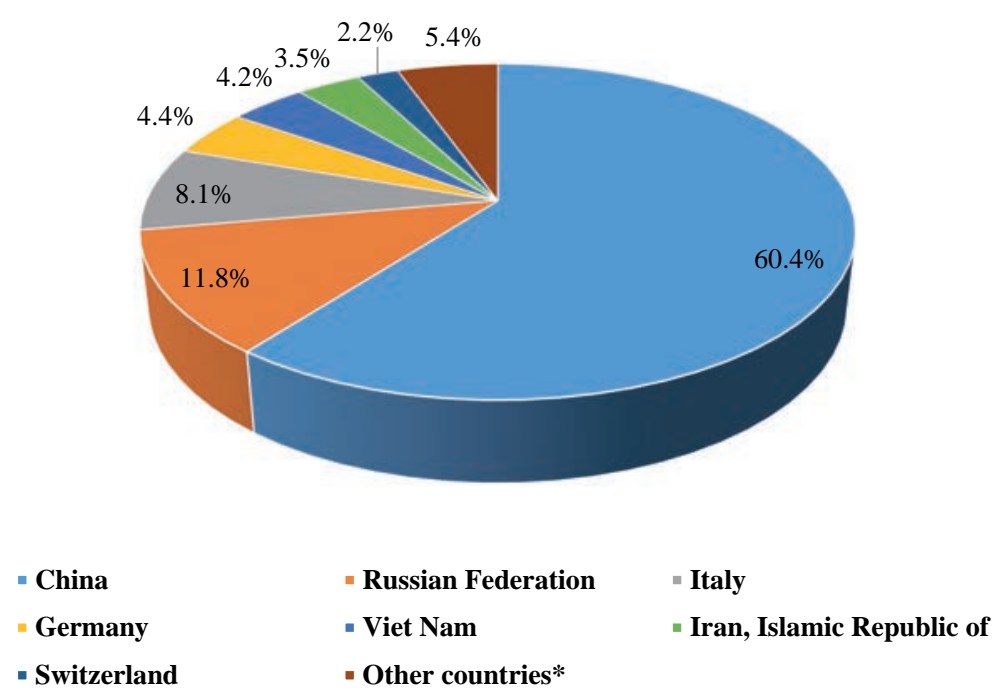

Figure 6.3. Average share of exported products of animal origin from Mongolia by country, 20102018, Source: Customs Office of Mongolia (Mongolian Customs, n.d.) 


\subsubsection{Research methodology}

Our research focused on estimating the comparative advantage of the country in order to obtain more insights into the Mongolian potential within an increasingly competitive international environment. Comparative advantage occurs whenever a country has the ability to produce a good or service relatively more efficient or with lower opportunity costs than other countries. In other words, if a country can produce a good at a lower cost relative to other countries, then that country has a comparative advantage in that good and should dedicate more of its resources to the production of that particular good (Ricardo, On the Principles of Political Economy and Taxation, 1817). By trading that good, the country can obtain other goods at a lower price in exchange for the goods in which it has a comparative advantage.

A popular approach to estimating comparative advantage is using Balassa's measure of revealed comparative advantage as abbreviated RCA (Balassa B. , 1965). This measure, sometimes called the Balassa index, is defined as the share of a good in a country's exports divided by the share of that good in world exports. The Balassa index measures an industry's export share divided by the export share of the same industry in the world:

$\operatorname{RCA}_{\mathrm{ij}}=\frac{E_{\mathrm{ij}} / \mathrm{E}_{\mathrm{i}}}{E_{\mathrm{nj}} / \mathrm{E}_{\mathrm{n}}}$

where $E_{i j}$ denotes the exports of $j^{\text {th }}$ products of country $i, E_{i}$ denotes the total export of country $i$, $E_{n j}$ denotes the exports of $j^{\text {th }}$ products of the world and $E_{n}$ denotes the total export of the world. Following Balassa (1965), comparative advantage is 'revealed' if RCA $>1$. If RCA is less than unity, the country is said to have a comparative disadvantage in the commodity or industry (Balassa B. , 1965).

\subsection{Results and Discussion}

To answer the research question 'Which type of animal-originated products of Mongolia are competitive in the world market?', $\mathrm{RCA}_{\mathrm{ij}}$ was calculated using equation (1) for 81 products exported from the livestock sector of Mongolia over nine years (2010-2018). Detailed results are reported in Annex 6.1.

Based on the RCA index estimation, products of animals origin can be divided into two different value chains: i) meat (principal product) and ii) hides and skins (byproduct). The meat value chain starts from a live animal (HS01), continues with meat and edible meat offal (HS02), followed by other animal origin products (HS05), and finishes with preparations of meat (HS16). The hides and skins value chain starts from raw hides and skins (HS41) and has articles of leather as final products (HS42 and HS64). Articles of leather consist of two HS codes, specifically HS4201 and HS6403. HS4201 products are handbags, cosmetic bags, shoulder strips, travel bags, belts, etc. HS6403 products include mainly sports footwear and components of footwear. Mongolia exported 81 types of products originating from meat and hides and skins during the period 20102018 although not all of them have a comparative advantage. The RCA estimation results show that Mongolia tended to increase value-added product exports during the selected years. For instance, the RCA index of prepared meat products (HS160210, HS160250, HS160290) show an increasing trend over time (Annex 6.1). 
In the next step, the overall average RCA index for all products for the period 2010-2018 was estimated, and the products with average comparative advantage (RCA) $>1$ during that entire period were identified. This step resulted in 21 products that had an average comparative advantage (Annex 6.2). The results indicate which products within the two value chains identified above had an average comparative advantage during the examined period. As can be seen from the table in Annex 6.2, none of the articles of leather as final products (HS42 and HS64) had an average comparative advantage during 2010-2018.

\subsection{Conclusion}

Mongolia faces rangeland degradation due to overgrazing, which leads to uncertain long-term development of the livestock sector. According to the average revealed comparative advantage (RCA) index over the period 2010-2018, 21 animal products have a comparative advantage in the world market. These products comprise two important streams of value chains: i) meat and ii) hides and skins. These value chains show that there exist possibilities to produce and export more added-value products of animal origin. Therefore, promoting exports of these products can be an important way to reduce the high pressure on Mongolia's rangelands within a relatively short period of time.

The government of Mongolia is aiming to ensure the sustainability of the livestock sector to secure the livelihoods of the herders' households and improve economic opportunities within the sector. One of their major policies is to increase resilience to climate change by addressing overgrazing and balancing the livestock number with the rangelands' carrying capacity. In this paper, we assumed that an increase of meat export should support decreasing livestock numbers to numbers that would be in balance with the carrying capacity. However, promoting exports will need to be combined with appropriate rangeland management policies, such as a user fee (pasture tax) to control the overgrazing problem. Without such regulations, boosting exports can worsen the overgrazing and land degradation problem by incentivizing herders to have more livestock (International Monetary Fund (IMF), 2019).

Possible policies that would support the export support of meat and other products of animal origin in this context are developing a meat export industry together with strategic animal breeding, reintroducing livestock tax and supporting the growth of more productive animals among others. Our findings suggest that Mongolia's meat export policy should focus in the short run on the large volume of products that have a relatively low level of processing; in the long-run, the policy should encompass a gradual shift to the export of differentiated value-added products rather than large volumes of products with low levels of processing.

Finally, we recommend that Mongolia improves its meat sector regulation and develops formal supply chains in order to both effectively monitor food safety and create high-quality Mongolian brands. Before trading animals or products of animal origin, any exporting country needs to meet a satisfactory level of animal health status and meet both the OIE and importing country's standards. In most cases, import regulations reflect to a large degree the effectiveness of the sanitary procedures undertaken by the exporting country, both at its borders and within its territory. 


\section{References}

[1] National Statistical Office (NSO), "Mongolian statistical information services," National Statistical Office, 2019. [Online]. Available: http://1212.mn. [Accessed 108 2019].

[2] Ministry of Food Agriculture and Light Industry (MoFALI), "Introduction of the pastureland law of Mongolia," MoFALI, Ulaanbaatar, 2018.

[3] National Statistical Office (NSO), "Livestock number and rangeland carrying capacity," Monthly Statistical Bulletin, 2018.

[4] Swiss Agency for Development and Cooperation (SDC), "National report on rangeland health of Mongolia," Green Gold Project, Ulaanbaatar, 2015.

[5] B. Densambuu, S. Sainnemekh, B. Bestelmeyer and U. Budbaatar, "National report on the rangeland health of Mongolia: Second Assessment," Green Gold-Animal health project, SDC; Mongolian National Federation of PUGs, Ulaanbaatar, 2018.

[6] B. Agipar and P. Byambaa, "Herd composition and pasture carrying capacity in Mongolia," Unpublished research report, Ulaanbaatar, Mongolia, 2019.

[7] International Monetary Fund (IMF), "Mongolia selected issues," International Monetary Fund Country Report No. 19/298, pp. 24-27, 282019.

[8] National Statistical Office (NSO), "Statistical yearbook of Mongolia," National Statistical Office, Ulaanbaatar, 1990-2018.

[9] A. Bakey, Sustainable development of pastoral livestock in Mongolia (In Mongolian), Ulaanbaatar: Munkhiin useg Llc, 2016.

[10] Mongolian Customs, "Mongolian Customs: Trade statistics data," Mongolian Customs, 93 2020. [Online]. Available: http://www.customs.gov.mn/en/services/trade. [Accessed 93 2020].

[11] International Trade Center (ITC), "International trade statistics 2010-2018," International Trade Center, 83 2020. [Online]. Available: www.intracen.org. [Accessed 83 2020].

[12] Ministry of Food Agriculture and Light Industry (MoFALI), "Statistical information of the agricultural sector of Mongolia," Ministry of Food Agriculture and Light Industry, Ulaanbaatar, Mongolia, 2019.

[13] Asian Development Bank (ADB), Making Grasslands Sustainable in Mongolia Herders' Livelihoods and Climate Change, Manila: Philippines, ISBN 978-92-9254-373-0 (Print), 978-92-9254-374-7 (PDF), 2014.

[14] Government of Mongolia, "Export quota of Mongolia 2019, National Security Counsel's resolution number 1, 2019-1-15,", Government of Mongolia, Ulaanbaatar, Mongolia, 2019. 
[15] D. Ricardo, On the Principles of Political Economy and Taxation, London: John Murray, 1817.

[16] G. Lafay, "Avantage comparatif et compétitivité," Économie Prospective Internationale, vol. 29, pp. 39-52, 1987.

[17] K. Higgins and S. Prowse, Trade, Growth and Poverty: Making aid for trade work for inclusive growth and poverty reduction, Overseas Development Institute (ODI), London, 2010 .

[18] N. T. Lang, "The latent absolute advantage of the comparative advantage in theories of international trade," International Business \& Economics Research Journal (IBER), vol. 5(1), p. 27-30, 2011.

[19] B. Balassa, Trade liberalisation and 'revealed' comparative advantage, Manchester, 1965.

[20] Food and Agriculture Organization of the United Nations, "Enhancing Meat Exports from Mongolia, Unpublished project report," Food and Agriculture Organization of the United Nations, Ulaanbaatar, Mongolia,, 2019.

[21] Mongolian Meat Association (MMM), "International market study of meat and meat products, unpublished study report," Mongolian Meat Association, Ulaanbaatar, 2018.

[22] Mongolian General Authority for Veterinarian Services (GAVS), "Annual report of the Mongolian General Authority for Veterinarian Services (in Mongolian)," GAVS, Ulaanbaatar, Mongolia, 2020.

[23] Mongolian Customs, "Trade statistics," [Online]. Available: http://www.customs.gov.mn/en/services/trade. [Accessed 0903 2020]. 


\section{Annexes}

Annex 6.1. Results of Balassa's Revealed Comparative Advantage (BA65) index for animal products in Mongolia, by product type and year

\begin{tabular}{|c|c|c|c|c|c|c|c|c|c|c|}
\hline \multirow{2}{*}{ No. } & \multirow{2}{*}{$\begin{array}{l}\text { HS code of } \\
\text { products }\end{array}$} & \multicolumn{9}{|c|}{ RCA } \\
\hline & & 2010 & 2011 & 2012 & 2013 & 2014 & 2015 & 2016 & 2017 & 2018 \\
\hline \multicolumn{11}{|c|}{ HS01 Live animals } \\
\hline 1 & '010110 & 1.378 & 0.011 & 0.000 & 0.000 & 0.000 & 0.000 & 0.000 & 0.00 & 0.000 \\
\hline 2 & '010121 & 0.00 & 0.00 & 0.000 & 0.016 & 0.000 & 0.428 & 0.402 & 0.031 & 0.000 \\
\hline 3 & '010129 & 0.00 & 0.00 & 0.174 & 0.126 & 0.071 & 0.884 & 0.037 & 0.232 & 0.367 \\
\hline 4 & '010190 & 5.814 & 0.187 & 0.000 & 0.000 & 1.313 & 420.753 & 240.783 & 0.000 & 0.000 \\
\hline 5 & '010290 & 0.000 & 0.000 & 0.000 & 0.000 & 0.000 & 0.076 & 0.000 & 0.000 & 0.000 \\
\hline 6 & '010410 & 0.000 & 0.000 & 0.000 & 0.000 & 0.000 & 0.000 & 0.000 & 0.000 & 0.079 \\
\hline 7 & '010420 & 0.000 & 0.000 & 0.000 & 0.000 & 0.000 & 0.000 & 0.000 & 0.000 & 0.000 \\
\hline \multicolumn{11}{|c|}{ HS02 Meat and edible meat offal } \\
\hline 8 & '020110 & 0.00 & 0.00 & 0.00 & 0.00 & 0.00 & 0.00 & 0.00 & 0.00 & 0.00 \\
\hline 9 & '020120 & 0.00 & 0.00 & 0.00 & 0.00 & 0.00 & 2.12 & 0.00 & 0.00 & 0.01 \\
\hline 10 & '020130 & 0.00 & 0.00 & 0.00 & 0.00 & 0.00 & 0.00 & 0.00 & 0.00 & 0.02 \\
\hline 11 & '020210 & 146.42 & 112.80 & 27.68 & 0.00 & 0.00 & 0.00 & 0.00 & 12.03 & 1.76 \\
\hline 12 & '020220 & 2.61 & 34.54 & 9.18 & 0.00 & 2.88 & 0.00 & 3.20 & 1.31 & 0.42 \\
\hline 13 & '020230 & 0.03 & 0.00 & 0.00 & 0.00 & 0.00 & 0.00 & 0.04 & 0.06 & 0.35 \\
\hline 14 & '020410 & 0.00 & 0.00 & 0.00 & 0.00 & 0.00 & 0.00 & 0.00 & 0.00 & 0.00 \\
\hline 15 & '020421 & 14.76 & 0.00 & 0.00 & 0.00 & 0.00 & 0.00 & 0.63 & 0.76 & 2.53 \\
\hline 16 & '020422 & 0.35 & 0.00 & 0.00 & 0.37 & 0.00 & 0.00 & 0.00 & 3.11 & 2.59 \\
\hline 17 & '020423 & 1.35 & 0.00 & 0.00 & 0.00 & 0.00 & 0.00 & 0.00 & 0.00 & 1.25 \\
\hline 18 & '020430 & 9.95 & 0.00 & 0.00 & 0.00 & 0.00 & 0.00 & 0.00 & 0.00 & 0.00 \\
\hline 19 & '020441 & 58.26 & 2.76 & 0.00 & 8.01 & 0.00 & 0.10 & 1.02 & 0.00 & 8.85 \\
\hline 20 & '020442 & 8.19 & 0.11 & 0.60 & 3.59 & 0.00 & 0.00 & 0.20 & 7.55 & 9.57 \\
\hline 21 & '020443 & 1.06 & 0.10 & 0.00 & 0.07 & 0.00 & 0.00 & 0.00 & 0.00 & 0.40 \\
\hline 22 & '020450 & 401.97 & 11.72 & 19.87 & 0.00 & 0.00 & 1.01 & 1.46 & 0.00 & 21.21 \\
\hline 23 & '020500 & 200.38 & 58.74 & 36.00 & 70.68 & 34.61 & 67.42 & 125.88 & 302.01 & 364.90 \\
\hline 24 & '020610 & 0.00 & 0.00 & 0.00 & 0.00 & 0.00 & 0.00 & 0.00 & 0.00 & 0.13 \\
\hline 25 & '020621 & 0.00 & 0.00 & 0.00 & 0.00 & 0.00 & 0.00 & 0.00 & 0.00 & 0.00 \\
\hline 26 & '020622 & 0.00 & 0.00 & 0.00 & 0.00 & 0.00 & 0.00 & 0.00 & 0.00 & 0.00 \\
\hline 27 & '020629 & 0.12 & 0.00 & 0.00 & 0.00 & 0.00 & 0.00 & 0.00 & 0.00 & 0.37 \\
\hline 28 & '020690 & 43.32 & 3.24 & 9.00 & 21.94 & 2.99 & 1.84 & 1.24 & 3.23 & 25.95 \\
\hline \multicolumn{11}{|c|}{ HS05 Products of animal origin, not elsewhere specified or included } \\
\hline 29 & '050400 & 11.81 & 9.77 & 9.42 & 10.98 & 5.28 & 7.31 & 5.19 & 3.58 & 4.21 \\
\hline
\end{tabular}




\begin{tabular}{|c|c|c|c|c|c|c|c|c|c|c|}
\hline 30 & '050690 & 26.82 & 5.27 & 5.99 & 0.03 & 0.14 & 0.17 & 3.28 & 2.60 & 11.20 \\
\hline \multicolumn{11}{|c|}{ HS15 Animal or vegetable fats and oils and their cleavage products; prepared edible fats; animal.... } \\
\hline 31 & '150290 & 0.00 & 0.00 & 0.05 & 0.00 & 0.00 & 0.05 & 6.10 & 0.00 & 0.02 \\
\hline 32 & '151620 & 0.00 & 0.00 & 0.01 & 0.00 & 0.00 & 0.00 & 0.00 & 0.01 & 0.00 \\
\hline 33 & '151800 & 0.00 & 0.02 & 0.00 & 0.00 & 0.00 & 0.00 & 0.00 & 0.00 & 0.00 \\
\hline \multicolumn{11}{|c|}{ HS16 Preparations of meat, of fish or of crustaceans, molluscs or other aquatic invertebrates } \\
\hline 34 & '160100 & 0.00 & 0.00 & 0.00 & 0.00 & 0.00 & 0.00 & 0.03 & 0.07 & 0.33 \\
\hline 35 & '160210 & 0.00 & 0.00 & 0.00 & 0.00 & 0.00 & 0.27 & 5.08 & 66.36 & 90.04 \\
\hline 36 & 160220 & 0.00 & 0.00 & 0.00 & 0.00 & 0.01 & 0.01 & 0.00 & 0.02 & 0.00 \\
\hline 37 & '160249 & 0.12 & 0.00 & 0.00 & 0.00 & 0.00 & 0.11 & 0.00 & 0.00 & 0.00 \\
\hline 38 & '160250 & 0.38 & 0.06 & 0.13 & 0.00 & 0.16 & 0.76 & 1.86 & 5.15 & 30.53 \\
\hline 39 & '160290 & 2.01 & 4.07 & 1.05 & 0.00 & 0.00 & 0.00 & 1.04 & 14.74 & 281.66 \\
\hline \multicolumn{11}{|c|}{ HS41 Raw hides and skins (other than furskins) and leather } \\
\hline 40 & '410120 & 14.93 & 7.10 & 6.92 & 13.76 & 7.81 & 6.83 & 39.89 & 5.21 & 0.03 \\
\hline 41 & '410150 & 0.00 & 0.00 & 0.00 & 0.00 & 0.00 & 0.00 & 1.29 & 0.21 & 0.00 \\
\hline 42 & '410190 & 0.00 & 0.00 & 0.00 & 0.00 & 0.00 & 0.00 & 0.00 & 15.45 & 0.00 \\
\hline 43 & '410390 & 2.57 & 1.92 & 1.09 & 2.28 & 0.48 & 0.80 & 1.97 & 3.33 & 2.52 \\
\hline 44 & '410411 & 13.82 & 11.42 & 5.92 & 6.86 & 6.77 & 10.13 & 13.29 & 10.81 & 10.96 \\
\hline 45 & '410419 & 0.00 & 3.58 & 6.10 & 0.19 & 0.10 & 0.00 & 0.00 & 0.00 & 0.00 \\
\hline 46 & '410510 & 166.52 & 175.72 & 132.58 & 154.74 & 105.59 & 158.15 & 28.20 & 40.56 & 39.08 \\
\hline 47 & '410621 & 353.70 & 155.88 & 202.44 & 259.34 & 311.74 & 407.25 & 180.03 & 174.87 & 160.53 \\
\hline 48 & '410622 & 0.00 & 0.00 & 1.16 & 0.00 & 0.04 & 0.20 & 0.00 & 0.28 & 0.61 \\
\hline 49 & '410691 & 0.00 & 0.00 & 0.00 & 75.60 & 0.00 & 65.09 & 0.00 & 0.00 & 0.00 \\
\hline 50 & '410711 & 0.00 & 0.00 & 0.00 & 0.01 & 0.00 & 0.51 & 0.00 & 0.00 & 0.00 \\
\hline 51 & '411200 & 0.67 & 0.00 & 0.00 & 0.00 & 0.01 & 0.00 & 0.00 & 0.00 & 0.02 \\
\hline 52 & '411310 & 0.00 & 0.00 & 0.00 & 0.00 & 0.00 & 0.12 & 0.16 & 0.02 & 0.11 \\
\hline \multicolumn{11}{|c|}{ HS42 Articles of leather; saddlery and harness; travel goods, handbags and similar containers; articles .. } \\
\hline 53 & '420100 & 0.03 & 0.02 & 0.07 & 0.06 & 0.16 & 0.01 & 0.06 & 0.20 & 0.02 \\
\hline 54 & '420211 & 0.00 & 0.01 & 0.02 & 0.07 & 0.00 & 0.12 & 0.06 & 0.12 & 0.00 \\
\hline 55 & '420219 & 0.27 & 0.07 & 0.08 & 0.21 & 0.02 & 0.01 & 2.02 & 0.24 & 0.01 \\
\hline 56 & '420221 & 0.00 & 0.04 & 0.03 & 0.06 & 0.00 & 0.10 & 0.02 & 0.02 & 0.00 \\
\hline 57 & '420222 & 0.00 & 0.00 & 0.00 & 0.00 & 0.00 & 0.01 & 0.00 & 0.00 & 0.00 \\
\hline 58 & '420229 & 0.06 & 0.03 & 0.01 & 0.03 & 0.02 & 0.00 & 0.02 & 0.08 & 0.02 \\
\hline 59 & '420231 & 1.09 & 0.07 & 0.03 & 0.02 & 0.02 & 0.10 & 0.03 & 0.04 & 0.04 \\
\hline 60 & '420232 & 0.00 & 0.00 & 0.00 & 0.00 & 0.00 & 0.04 & 0.00 & 0.00 & 0.00 \\
\hline 61 & '420239 & 0.03 & 0.04 & 0.06 & 0.07 & 0.02 & 0.04 & 0.66 & 0.31 & 0.04 \\
\hline 62 & '420291 & 0.06 & 0.01 & 0.00 & 0.00 & 0.01 & 0.01 & 0.02 & 0.00 & 0.01 \\
\hline
\end{tabular}




\begin{tabular}{|c|c|c|c|c|c|c|c|c|c|c|}
\hline 63 & '420292 & 0.00 & 0.00 & 0.00 & 0.00 & 0.00 & 0.00 & 0.00 & 0.00 & 0.00 \\
\hline 64 & '420299 & 0.12 & 0.17 & 0.01 & 0.03 & 0.00 & 0.03 & 0.05 & 0.04 & 0.05 \\
\hline 65 & '420310 & 0.03 & 0.02 & 0.05 & 0.04 & 0.04 & 0.14 & 5.47 & 0.13 & 0.02 \\
\hline 66 & '420329 & 0.00 & 0.00 & 0.01 & 0.00 & 0.00 & 0.00 & 0.00 & 0.00 & 0.00 \\
\hline 67 & '420330 & 0.23 & 0.03 & 0.04 & 0.04 & 0.00 & 0.18 & 0.15 & 0.13 & 0.04 \\
\hline 68 & '420340 & 0.00 & 0.00 & 0.00 & 0.00 & 0.03 & 0.00 & 0.02 & 0.03 & 0.01 \\
\hline 69 & '420500 & 0.00 & 0.00 & 0.01 & 0.01 & 0.00 & 0.01 & 0.00 & 0.02 & 0.01 \\
\hline \multicolumn{11}{|c|}{ HS64 Articles of leather; saddlery and harness; travel goods, handbags and similar containers; articles .. } \\
\hline 70 & '640319 & 0.00 & 0.00 & 0.03 & 0.04 & 0.00 & 0.02 & 0.04 & 0.06 & 0.00 \\
\hline 71 & '640340 & 0.00 & 0.00 & 0.00 & 0.00 & 0.09 & 0.02 & 0.00 & 0.00 & 0.00 \\
\hline 72 & '640351 & 0.00 & 0.00 & 0.00 & 0.00 & 0.00 & 0.02 & 0.00 & 0.00 & 0.00 \\
\hline 73 & '640359 & 0.02 & 0.30 & 0.01 & 0.00 & 0.00 & 0.01 & 0.02 & 0.13 & 0.27 \\
\hline 74 & '640391 & 0.00 & 0.00 & 0.01 & 0.01 & 0.00 & 0.02 & 0.01 & 0.01 & 0.01 \\
\hline 75 & '640399 & 0.00 & 0.00 & 0.03 & 0.02 & 0.00 & 0.02 & 0.02 & 0.02 & 0.00 \\
\hline 76 & '640419 & 0.00 & 0.00 & 0.00 & 0.00 & 0.00 & 0.00 & 0.00 & 0.00 & 0.00 \\
\hline 77 & '640510 & 0.00 & 0.01 & 0.00 & 0.00 & 0.01 & 0.00 & 1.28 & 0.71 & 0.26 \\
\hline 78 & '640520 & 0.04 & 0.02 & 0.04 & 0.00 & 0.00 & 0.01 & 0.00 & 0.00 & 0.00 \\
\hline 79 & '640590 & 0.91 & 0.57 & 0.26 & 0.60 & 0.83 & 1.38 & 1.22 & 1.39 & 1.24 \\
\hline 80 & '640610 & 0.00 & 0.81 & 0.34 & 0.00 & 0.00 & 0.00 & 0.00 & 0.00 & 0.00 \\
\hline 81 & '640690 & 0.00 & 0.00 & 0.00 & 0.00 & 0.00 & 0.00 & 0.03 & 0.03 & 0.02 \\
\hline
\end{tabular}

Annex 6.2. The selected livestock-oriented products that are competitive in the world market

\begin{tabular}{|c|c|c|c|c|c|c|c|c|c|c|c|c|}
\hline \multirow{2}{*}{ \# } & \multirow{2}{*}{ HS code } & \multirow{2}{*}{ Product label } & \multicolumn{9}{|c|}{ RCAikt } & \multirow{2}{*}{$\begin{array}{l}\text { RCA } \\
\text { index } \\
\text { (Overall } \\
\text { average) }\end{array}$} \\
\hline & & & 2010 & 2011 & 2012 & 2013 & 2014 & 2015 & 2016 & 2017 & 2018 & \\
\hline \multicolumn{13}{|c|}{ HS01 Live animals } \\
\hline 1 & '010190 & $\begin{array}{l}\text { Live mules } \\
\text { and hinnies }\end{array}$ & 5.8 & 0.2 & 0.0 & 0.0 & 1.3 & 420.8 & 240.8 & 0.0 & 0.0 & 74.3 \\
\hline \multicolumn{13}{|c|}{ HS02 Meat and edible meat offal } \\
\hline 2 & '020210 & $\begin{array}{l}\text { Frozen } \\
\text { bovine } \\
\text { carcasses and } \\
\text { half- } \\
\text { carcasses }\end{array}$ & 146.4 & 112.8 & 27.7 & 0.0 & 0.0 & 0.0 & 0.0 & 12.0 & 1.8 & 33.4 \\
\hline 3 & '020220 & $\begin{array}{l}\text { Frozen } \\
\text { bovine cuts, } \\
\text { with bone in } \\
\text { (excluding } \\
\text { carcasses and } \\
\text { half- } \\
\text { carcasses) }\end{array}$ & 2.6 & 34.5 & 9.2 & 0.0 & 2.9 & 0.0 & 3.2 & 1.3 & 0.4 & 6.0 \\
\hline
\end{tabular}




\begin{tabular}{|c|c|c|c|c|c|c|c|c|c|c|c|c|}
\hline 4 & '020421 & $\begin{array}{l}\text { Fresh or } \\
\text { chilled sheep } \\
\text { carcasses and } \\
\text { half- } \\
\text { carcasses } \\
\text { (excluding } \\
\text { lambs) }\end{array}$ & 14.8 & 0.0 & 0.0 & 0.0 & 0.0 & 0.0 & 0.6 & 0.8 & 2.5 & 2.1 \\
\hline 5 & '020441 & $\begin{array}{l}\text { Frozen sheep } \\
\text { carcasses and } \\
\text { half- } \\
\text { carcasses } \\
\text { (excluding } \\
\text { lambs) }\end{array}$ & 58.3 & 2.8 & 0.0 & 8.0 & 0.0 & 0.1 & 1.0 & 0.0 & 8.9 & 8.8 \\
\hline 6 & '020442 & $\begin{array}{l}\text { Frozen cuts } \\
\text { of sheep, } \\
\text { with bone in } \\
\text { (excluding } \\
\text { carcasses and } \\
\text { half- } \\
\text { carcasses) }\end{array}$ & 8.2 & 0.1 & 0.6 & 3.6 & 0.0 & 0.0 & 0.2 & 7.5 & 9.6 & 3.3 \\
\hline 7 & '020450 & $\begin{array}{l}\text { Fresh, chilled } \\
\text { or frozen } \\
\text { meat of goats }\end{array}$ & 402.0 & 11.7 & 19.9 & 0.0 & 0.0 & 1.0 & 1.5 & 0.0 & 21.2 & 50.8 \\
\hline 8 & '020500 & $\begin{array}{l}\text { Meat of } \\
\text { horses, asses, } \\
\text { mules or } \\
\text { hinnies, } \\
\text { fresh, chilled } \\
\text { or frozen }\end{array}$ & 200.4 & 58.7 & 36.0 & 70.7 & 34.6 & 67.4 & 125.9 & 302.0 & 364.9 & 140.1 \\
\hline 9 & '020690 & $\begin{array}{l}\text { Frozen edible } \\
\text { offal of } \\
\text { sheep, goats, } \\
\text { horses, asses, } \\
\text { mules and } \\
\text { hinnies }\end{array}$ & 43.3 & 3.2 & 9.0 & 21.9 & 3.0 & 1.8 & 1.2 & 3.2 & 25.9 & 12.5 \\
\hline \multicolumn{13}{|c|}{ HS05 Products of animal origin, not elsewhere specified or included } \\
\hline 10 & '050400 & $\begin{array}{l}\text { Guts, } \\
\text { bladders and } \\
\text { stomachs of } \\
\text { animals } \\
\text { (other than } \\
\text { fish), whole } \\
\text { and pieces } \\
\text { thereof, } \\
\text { fresh,... }\end{array}$ & 11.8 & 9.8 & 9.4 & 11.0 & 5.3 & 7.3 & 5.2 & 3.6 & 4.2 & 7.5 \\
\hline 11 & '050690 & $\begin{array}{l}\text { Bones and } \\
\text { horn-cores } \\
\text { and their } \\
\text { powder and } \\
\text { waste, } \\
\text { unworked, } \\
\text { defatted, }\end{array}$ & 26.8 & 5.3 & 6.0 & 0.0 & 0.1 & 0.2 & 3.3 & 2.6 & 11.2 & 6.2 \\
\hline
\end{tabular}




\begin{tabular}{|c|c|c|c|c|c|c|c|c|c|c|c|c|}
\hline & & $\begin{array}{l}\text { degelatinised } \\
\text { or simply ... }\end{array}$ & & & & & & & & & & \\
\hline \multicolumn{13}{|c|}{ HS16 Preparations of meat, of fish or of crustaceans, molluscs or other aquatic invertebrates } \\
\hline 12 & '160210 & $\begin{array}{l}\text { Homogenised } \\
\text { prepared } \\
\text { meat, offal or } \\
\text { blood, put up } \\
\text { for retail sale } \\
\text { as infant food } \\
\text { or for dietetic } \\
\text {... }\end{array}$ & 0.0 & 0.0 & 0.0 & 0.0 & 0.0 & 0.3 & 5.1 & 66.4 & 90.0 & 18.0 \\
\hline 13 & '160250 & $\begin{array}{l}\text { Prepared or } \\
\text { preserved } \\
\text { meat or offal } \\
\text { of bovine } \\
\text { animals } \\
\text { (excluding } \\
\text { sausages and } \\
\text { similar } \\
\text { products, ... }\end{array}$ & 0.4 & 0.1 & 0.1 & 0.0 & 0.2 & 0.8 & 1.9 & 5.1 & 30.5 & 4.3 \\
\hline 14 & '160290 & $\begin{array}{l}\text { Prepared or } \\
\text { preserved } \\
\text { meat, offal or } \\
\text { blood } \\
\text { (excluding } \\
\text { meat or offal } \\
\text { of poultry, } \\
\text { swine and } \\
\text { bovine ... }\end{array}$ & 2.0 & 4.1 & 1.0 & 0.0 & 0.0 & 0.0 & 1.0 & 14.7 & 281.7 & 33.8 \\
\hline \multicolumn{13}{|c|}{ HS41 Raw hides and skins (other than furskins) and leather } \\
\hline 15 & '410120 & $\begin{array}{l}\text { Whole raw } \\
\text { hides and } \\
\text { skins of } \\
\text { bovine "incl. } \\
\text { buffalo" or } \\
\text { equine } \\
\text { animals, } \\
\text { whether or } \\
\text { not dehaired, } \\
\text {... }\end{array}$ & 14.9 & 7.1 & 6.9 & 13.8 & 7.8 & 6.8 & 39.9 & 5.2 & 0.0 & 11.4 \\
\hline 16 & '410190 & $\begin{array}{l}\text { Butts, bends, } \\
\text { bellies and } \\
\text { split raw } \\
\text { hides and } \\
\text { skins of } \\
\text { bovine "incl. } \\
\text { buffalo" or } \\
\text { equine } \\
\text { animals, ... }\end{array}$ & 0.0 & 0.0 & 0.0 & 0.0 & 0.0 & 0.0 & 0.0 & 15.4 & 0.0 & 1.7 \\
\hline 17 & '410390 & $\begin{array}{l}\text { Raw hides } \\
\text { and skins, } \\
\text { fresh, or }\end{array}$ & 2.6 & 1.9 & 1.1 & 2.3 & 0.5 & 0.8 & 2.0 & 3.3 & 2.5 & 1.9 \\
\hline
\end{tabular}




\begin{tabular}{|c|c|c|c|c|c|c|c|c|c|c|c|c|}
\hline & & $\begin{array}{l}\text { salted, dried, } \\
\text { limed, } \\
\text { pickled or } \\
\text { otherwise } \\
\text { preserved, } \\
\text { whether ... }\end{array}$ & & & & & & & & & & \\
\hline 18 & '410411 & $\begin{array}{l}\text { Full grains, } \\
\text { unsplit and } \\
\text { grain splits, } \\
\text { in the wet } \\
\text { state "incl. } \\
\text { wet-blue", of } \\
\text { hides and } \\
\text { skins ... }\end{array}$ & 13.8 & 11.4 & 5.9 & 6.9 & 6.8 & 10.1 & 13.3 & 10.8 & 11.0 & 10.0 \\
\hline 19 & '410419 & $\begin{array}{l}\text { Hides and } \\
\text { skins of } \\
\text { bovine "incl. } \\
\text { buffalo" or } \\
\text { equine } \\
\text { animals, in } \\
\text { the wet state } \\
\text { "incl. wet- } \\
\text { blue", ... }\end{array}$ & 0.0 & 3.6 & 6.1 & 0.2 & 0.1 & 0.0 & 0.0 & 0.0 & 0.0 & 1.1 \\
\hline 20 & '410510 & $\begin{array}{l}\text { Skins of } \\
\text { sheep or } \\
\text { lambs, in the } \\
\text { wet state } \\
\text { "incl. wet- } \\
\text { blue", tanned, } \\
\text { without wool } \\
\text { on, whether } \\
\text {... }\end{array}$ & 166.5 & 175.7 & 132.6 & 154.7 & 105.6 & 158.2 & 28.2 & 40.6 & 39.1 & 111.2 \\
\hline 21 & '410621 & $\begin{array}{l}\text { Hides and } \\
\text { skins of goats } \\
\text { or kids, in the } \\
\text { wet state } \\
\text { "incl. wet- } \\
\text { blue", tanned, } \\
\text { without wool } \\
\text { on, ... }\end{array}$ & 353.7 & 155.9 & 202.4 & 259.3 & 311.7 & 407.3 & 180.0 & 174.9 & 160.5 & 245.1 \\
\hline
\end{tabular}





\section{Chapter 7}

Synthesis 


\section{SYNTHESIS}

This chapter summarizes, and reflects upon, all other chapters of the thesis; presents a discussion of the main findings, and provides the conclusions of the study. The chapter starts by presenting the research questions that are related to each chapter's key results and findings. This is followed by the conclusions and policy implications from each of the other chapters. This chapter ends with a discussion about the policy on institutional arrangements for community-based, rangeland management in Mongolia.

\subsection{Research objectives and questions}

Mongolia is a country with a vast rangeland area, where nomadic people live based on herding; extensive animal husbandry is their source of livelihood. Livestock is still a major economic sector in Mongolia.

Like other socialist countries in the World, Mongolia had a transition from a centralized socialist regime to a market economy, after 1990. The collapse of the (soviet) socialist system had a huge impact on rural livelihoods, and the country's economy. One of the consequences of this change was livestock privatization. Rangeland management by the state virtually disappeared, rendering the herding system de facto open access (Fernandez-Gimenez, 2006; Dorligsuren, 2008; Amgalan et al., 2010; Enkh-Amgalan, 2019).

Rangeland degradation caused by overgrazing is one of the most significant environmental challenges that Mongolia is facing. Livestock numbers have tripled, from 25.8 million in 1990 to 70.1 million in 2019 (NSO, 2020). According to various scientific studies, the livestock population is in excess of the carrying capacity of the rangeland; by more than 30 million head (MoFALI, 2018; NSO 2018; Densambuu et al., 2018; SDC, 2015).

The objective of this study was 'to obtain insights into the relationship between poverty and sustainability of rangeland use under different arrangements for community-based rangeland management systems in different agro-ecological regions of Mongolia.' In order to achieve the research objective, a number of questions, and sub-questions were addressed.

The first research question(s) were answered in Chapters 1 to 6 . What are the characteristics of current rangeland management in Mongolia? To what extent is the pastoral livestock sector in Mongolia different from that in other countries?

Rangeland, or grassland, covers about 80 percent of the total land area of Mongolia and supports the livelihood of almost 170,000 households, herding more than 70 million head of livestock (NSO 2020). Rangeland degradation caused by overgrazing is one of the most significant environmental challenges that Mongolia is facing, mainly because livestock numbers tripled during 1990 to 2019 (NSO 2020). The number of livestock increased from 25.8 million in 1990 to 70.1 million in 2019. Exceeding the carrying capacity of the pastureland has caused scarcity of fodder, and increased vulnerability to drought (dzud, and other natural disasters) which can cause the loss of millions of livestock in a short period of time.

State collectives and cooperatives in Mongolia were dissolved in the 1990s, as part of the transition to a free market. Livestock were privatized, while pastures remained in public hands 
according to the 1992 Constitution. The dismantling of the collectives left a regulatory void in the area of pasture management; and the services they once provided deteriorated, or disappeared. Consequently, herders became responsible for all production inputs, risks, and decisions. Some of the consequences of these significant changes in patterns of pastureland use were: an increase in year-round and out-of-season grazing in areas previously used for emergency reserves (or during one or two seasons only); the concentration of livestock near settlements and water points; and overall declines in mobility (in terms of the number and distance of seasonal movements).

Several laws and provisions - partly related to pastureland management - have been enacted since the transition. The Land Law, of 1994 and amended in 1998, 2002, and 2018, is the present cornerstone of the legal framework governing pastureland. It makes a distinction between land use, possession, and ownership. It allows for individual ownership of land in urban areas and small plots of 0.07 ha per person, and collective possession of land for winter and spring camps. However, individual or collective ownership or possession of 'pastureland' is forbidden. Under the same law, pasture management responsibilities have been devolved to aimag and soum governors, who, in coordination with the Agency of Land Administration and Management, Geodesy and Cartography (ALAMGC) are supposed to elaborate yearly pastureland management plans. This provision is hampered by implementation difficulties due to the insufficient fiscal resources of local governments, and the lack of administrative capacity.

Pastureland use and management planning have been delegated to local-level institutions, but there is little horizontal coordination among them in terms of coordinating their planning activities and managing the common boundaries of emergency reserve areas. Although the Land Law urges soum and bag governors to consult with herders on the establishment of an annual management plan, this is a discretionary prerogative and herders have no legal right to actively participate in this planning process.

Despite the lack of a legal basis for participatory pasture management, donor projects are implementing participatory approaches to natural resource management. This has included encouraging contract-based cooperation between soum governors and herder groups since 1999 (Mau \& Chantsallkham, 2006; Amgalan et al., 2010; Ulambayara \& Fernandez-Gimenez, 2017). Following advice from external experts, some donor projects began to support community-based natural resource management in Mongolia, as a option to address problems of rural poverty and resource degradation in the absence of strong pastoral institutions. The process of engaging herder communities in resource management expanded from the initial efforts to address the consequences of the dzud, to institution-building objectives through the devolution of rights to herder groups (Upton, C., 2005).

According to the latest study of Community Based Natural Resources Management (CBNRM), across all ecological zones, herders groups had significantly greater information diversity, leadership, and knowledge exchange compared to non-CBNRMs. Once a herders' groups has been established by using a bottom-up approach and all members have discussed problematic issues openly, it is easier to enforce group bylaws and other rules to manage rangeland. It is expected that this will overcome challenges and difficulties in improving rangeland quality, and thereby positively affect sustainable rangeland management (E.Tumur et al., 2018). 
The second research question(s) were answered in Chapters 2 and 3. Which specific properties distinguish rangeland from other common pool resources? What are the implications for the design of institutional arrangements to promote sustainable rangeland use?

Common pool resources, such as forests, aquatic resources, and rangelands, contribute significantly to rural livelihoods in many parts of the world (Fernandez-Gimenez, 1999; 2002; Meinzen-Dick et al., 2006; Mwangi \&Markelova, 2009). Although humans have used rangelands for consumptive and non-consumptive purposes for centuries, it was only in the early 1900s that researchers first began to study problems associated with the management of rangelands. In this context, sustainable management of rangeland refers to "the manipulation of rangeland components to obtain the optimum combination of goods and services for society on a sustained basis" (Holechek et al., 2001). Economic theory and observed practice across the world suggests that a variety of common-pool resources (forests, rangeland, fisheries, water, air) are threatened by open access, which leads to a dissipation of the resource rents by overuse (Gordon, 1954). In economic terms, they are rival and non-exclusive goods. While full privatization is one way of eliminating open access (Harden, 1968), it is often not feasible, and particularly not in the case of the Mongolian rangeland where the mobility of animals both within and across years is required (Amgalan et al., 2010).

Rangeland in Mongolia can be considered a typical case of 'resources that are highly mobile over large expanses of territory, or of those, such as irrigation water, which require a collective infrastructure to be exploited. In these peculiar circumstances, collective regulation under the common property regime is the only way to avoid the inefficient management and/or the degradation of the resource under conditions of 'open access' (Baland \& Platteau, 2003).

Sustainable rangeland management has received considerable attention amongst common pool resource scientists and scholars during the last two decades (Baland \& Platteau, 2003; Fratkin\& Mearns, 2003; Mearns, 2004; Mau \& Chantsallkham, 2006; Mwangi, 2007; Ho \& Azadi, 2010; Ykhanbai et al., 2011). Fraktin (1997) reviewed governance and development issues of pastoralism in different countries including Maasai pastoralists in East Africa, and pastoralists in India, Mongolia, and China, and argued that the future of pastoralist populations is far from certain. Pastoral practices, including the tendency of individual herders to maximize their herds, coupled with an increasing number of herders, are viewed as major factors promoting desertification. In Western China, rising livestock prices have contributed to a rapid increase in the number of animals and a sharp decline in the available rangeland area per livestock unit. While in Northern China, rangeland degradation is caused by changing livestock demography, mushrooming permanent grazing encampments, year-round grazing, and an almost entirely new disaster preparation and response method (Cao Jianjun et al., 2013).

There are many examples of successfully managed common pool resources (Harden 1968; Baland \& Platteau, 1997; 1998; Fratkin \& Mearns, 2003; Baland \& Francois, 2005; Ho \& Azadi, 2010). Several of these examples have shown how to avoid a tragedy in a situation where the population is growing rapidly and the absolute number of people who live in poverty is steadily increasing (Heijman, 1991; Fernandez-Gimenez \& Batbuyan, 2004).

Defining rangeland boundaries and membership of user groups are important factors and essential prerequisites of secure tenure and therefore successful common property rangeland management regimes (Fernandez-Gimenez, 2003). There is a considerable body of literature that 
tries to identify the sets of conditions that are crucial for the sustainable governance of commonpool resources. Agrawal (Agrawal, 2001; 2003) summarises the conditions put forward in the influential works by Wade (1988), Ostrom (1990) and Baland and Platteau (1997), as well as extending the set of conditions distinguished in these studies further, and grouping them into six clusters:

- resource system characteristics,

- group characteristics,

- the relationship between resource system characteristics and group characteristics,

- institutional arrangements,

- the relationship between resource system and institutional arrangement, and

- external environment.

The third research question was answered in Chapters 3 and 5 . What are the impacts of current institutional arrangements for community-based rangeland management on rangeland conservation?

Since 1999, Mongolia had become a de facto testing ground for community-based rangeland management (Mau \& Chantsallkham, 2006). The government of Mongolia and donor organizations supported and strengthened institutions involved in the rangeland conversation. According to herders' views, pasture degradation is one of the major risk components for herding, and is closely related to secure pasture land tenure. Although significant progress has been made on pasture land tenure, there is still room (and need) to improve the sustainable development of the sector. Therefore, uncertain pasture tenure is still at the heart of the risks facing herders. Better pasture management can only happen with better designed and more strictly enforced or institutionalized rules of tenure (Jeremy, 2006).

In Chapter 5 of the thesis, the impacts of current institutional rangeland conservation, using an econometric model, was tested.

According to Ostrom (Ostrom, 2008, 2009), well-defined resource boundaries allow the exclusion of outsiders from using the resource and the successful implementation of a resource management plan. According to current regulations in Mongolia, every soum is obliged to develop an annual land management plan. A rangeland management plan is a major part of the soum annual land management plan. Within the framework of this regulation, the soum territory is divided into different rangeland areas for the PUGs within a soum. However, differences exist in the degree to which this regulation is actually implemented. Out of the selected 330 herder households that were interviewed, 82 percent of respondents indicated that the PUG members mutually agreed on the rangeland boundaries and showed their approval by signing on a map.

The level of mobility of a resource is expected to affect resource management as greater mobility makes management more difficult for users because of problems associated with the reliability and cost of information (Agrawal, 2003). We include the number of inter-annual moves and the movement distance as indicators of mobility in our model. The number of inter-annual moves varies from 0 to 29, with an average of 6.4, while the movement distance varies from 0 to $244 \mathrm{~km}$, with a mean value of $78.7 \mathrm{~km}$, for the herders in our sample. 
Opportunities to store the benefits from a resource, facilitates resource management by reducing problems associated with the reliability and cost of information. In the case of rangeland, the preparation of hay substantially contributes to the security of livestock systems and thus helps to prevent livelihood crises for herder families. Hay preparation is an important element of collective action and a crucial risk mitigation factor.

Concerning the resource variables, in terms of the mobility of animals, both short and long otor moves (distances) have a positive impact on rangeland quality. In other words, supporting the seasonal movement, and implementing rotational grazing management schemes, are important for rangeland quality. Movement distance has a negative effect on the rangeland quality; longer distance moves may mean greater deterioration of rangeland quality.

The study results show that selected current institutional arrangements have significant impacts on rangeland quality. A well-defined rangeland boundary is key to supporting rangeland quality. And this is in line with the current government policy to introduce this scheme within the framework of an annual land management planning scheme. A U-shaped relationship between user group size and resource quality currently exists in Mongolia. Intermediate group sizes lead to the greatest monitoring effort, and have the best natural resource quality outcomes (Yang et al., 2013).

The fourth research question was answered in Chapters 2,5 , and 6 . What are the impacts of existing institutional arrangements for community-based rangeland management on poverty alleviation?

Chapter 2 investigated interrelations amongst herders' behavior, pastureland degradation, and poverty using game estimation. Chapter 5 analyzed impacts of community-based rangeland management on poverty alleviation. Chapter 6 studied international market possibilities (for products of animal origin) to increase livestock sector income while decreasing the number of animals (without declining the livelihoods of herder communities).

The game estimation results suggest a so-called non-coordination game for steppe regions soum Ugtaal and a chicken's game for the Gobi region soum Gurvansaikhan.

Increasing herders' payoffs from the herding business - by taking a more market-based approach - would also be very important in Gurvansaikhan. By making it easier to provide for current needs, herders can give more consideration to future effects, and this would lower their discount rate. The game estimation results for Gurvansaikhan suggest this will increase the chance of ending up in an equilibrium, where everyone aims for low growth in animal numbers.

In Chapter 6, an econometric model was used for testing the impact of community-based rangeland management on poverty. According to the results, a variable indicating a change of livelihood (comparing two years) had a positive effect. This variable represents the relationship between resource and group characteristics, and indicates a gradual change in the level of demand.

According to the different estimation results, individual herders compete with each other to use free inputs of rangeland to maximize their herd size. This leads to rangeland degradation and increases poverty in the long run. Conversely, introducing community-based rangeland 
management supports regulated rangeland management with regards to meeting rangeland carrying capacity. Better institutional arrangements for rangeland management guarantees sustainable development of rangeland use, as well as the sustainable livelihoods of herder communities.

Government regulation is important to secure the positive impacts of institutional arrangements for community-based rangeland management of poverty alleviation.

\subsection{General conclusions and implications}

Mongolia faces rangeland degradation due to overgrazing, which leads to the uncertain long-term development of the livestock sector.

After communist rule collapsed the weather became one of the main regulatory factors of animal numbers in Mongolia in the late 1990s and the early years of the twenty-first century. Favorable conditions in recent years (except two big dzuds) allowed large increases and many new entrants in the sector, leading to overgrazing and land degradation. In a way, nature corrected the overuse when severe winters and droughts hit Mongolia in the two main dzud periods; first in 1999-2000 and the second in 2009-2010. These brought animal numbers back to the level close to sustainability. This correction mechanism worked but had disastrous consequences for the people who were dependent on their herds for food and income. Letting nature handle things also has the drawback that land degradation caused by overuse can cause permanent damage to the land.

Herders currently benefit from an increased number of animals, therefore environmental degradation has not yet proved to be a sufficiently limiting factor in this regard for most herders. However, they are starting to understand that the increasing number of animals is not the best strategy to thrive and survive, and leads to severe pasture degradation. So, herders are looking for alternative strategies.

A large majority of herders simply do not have enough animals to sustain themselves in the traditional way. They are forced to combine subsistence livestock-keeping with a variety of other jobs, or they can choose to become more market-oriented herders. If they do this wisely, they can increase their incomes, improve their health, and maintain the pastures. However, this depends on renewed forms of land and water management institutions.

The game estimation results tentatively suggest that the current conditions in Ugtaal provide incentives to some herders to maximize their herds; and to others to keep growth low. If this result holds when some of the simplifying assumptions are relaxed, it would suggest that topdown coercive measures would be required to force all herders into lower growth, more sustainable, herding strategies. This could, for instance, be achieved through fines or taxes. A different approach would be to assign land; or use rights to individual herders or herder groups.The game indicates that such strategies would mean lower overall payoffs.

This could partly be compensated by a move towards more market-based livestock rearing. Our analysis of the terms of trade herders faced during the period shows that smaller herds do not necessarily have to mean lower incomes as well. Better use could be made of both the urban and 
export markets. These markets can be provided with livestock products in exchange for grains, which then become more important in pastoralists' diets.

Increasing herders' payoff from the herding business by taking a more market-based approach would also be very important in the Gobi region. By making it easier to provide for current needs, herders can give more consideration to future effects, and this would lower their discount rate. The game analyses estimation results for the Gobi region suggest this will increase the chance of ending up in an equilibrium where everyone aims for low growth in animal numbers.

Government agencies can support a move towards more market-based livestock rearing and the accompanying change in diets. This can be done, for instance, by stimulating food trade (e.g. giving credit and training to grain providers) and by stimulating dietary changes (e.g. by modifying school dinners or by including recipes in the popular media). In Mongolia, some changes are already visible. One can expect further developments along this road of ever more market-oriented pastoralism. Results of the comparison of the Caloric Terms of Trade (CToT) between different regions also suggests that market access is very important. Improving infrastructure could provide market access to more distant regions and increase the profit herders could make from marketing their animal products.

A more market-based approach could be combined with a move towards intensification of the sector. At least for those regions that are close to a large market, and with the ability to supply additional forage (such as concentrated feed). This could result in further reductions in the pressure on pastures, which is especially serious in the areas near to these large centers.

Even a system with smaller herds, where a larger share of animal products is marketed, needs well-functioning institutions for successful management of water sources and emergency relief during disasters. These institutions do not have to be set up by the government alone.

Considering Mongolia's old communal society, herder cooperation should be actively stimulated by creating more herder groups in which agreements about water sources and land management are made. If herders cooperate and have faith in such institutions, the need to maximize the herd as a form of insurance will also diminish.

The key innovation of the community-based rangeland management in Mongolia is the full organization of herders on a territorial basis, which is necessary for the transfer of the leadership role in pasture management from local governments to the herders themselves. Only if all the herders in a given territory belong to the same organization can they conclude an agreement among themselves, and with other pasture user groups on the management of resources. In doing so they bring the open-access issue under control. However, pasture user groups cannot perform these management functions on their own. They need support and collaboration from soum and aimag governments, which until now have had the authority to allocate pasture rights, and which must assist with the enforcement of the rules that are agreed upon within and among PUGs.

Establishing PUGs is recognized as an important tool to support the collective action of herders. And this system would be best introduced in conjunction with alternative income generation activities and economic support to compensate for losses associated with limiting herd sizes. 
The study results show that selected characteristics of PUGs have significant impacts on rangeland quality. A well-defined rangeland boundary is key to supporting rangeland quality, and this is in line with the current government policy to introduce the scheme within the framework of an annual land management planning scheme. A U-shaped relationship between user group size and resource quality currently exists in Mongolia, intermediate group sizes lead to the greatest monitoring effort, and have the best natural resource quality outcomes (Yang et al., 2013). The poverty among herder households has a negative impact on rangeland quality, as expected. The explanation for this is that PUGs with poorer households and greater income disparities have fewer opportunities to implement good rangeland management strategies. Supporting the seasonal move of households and implementing rotational grazing management schemes are also important for rangeland quality.

Once a PUG has been established by using a bottom-up approach, and all members have discussed problematic issues openly, it is easier to enforce PUGs bylaws and other rules to manage rangeland. It is expected that this will in turn overcome challenges and difficulties.

Still, external aid remains is an important factor in rangeland management; the government and donor organizations should therefore consider supporting the collective action approach to managing rangeland, but at an appropriate level.

The government of Mongolia is aiming to ensure the sustainability of the livestock sector; to secure the livelihoods of herder households, and improve economic opportunities within the sector. One of their major policies is to increase resilience to climate change by addressing overgrazing and balancing the livestock numbers with the rangelands' carrying capacity. In the final chapter of the thesis, it is assumed that an increase in meat exports would support decreasing livestock numbers, to a level that would be in balance with the carrying capacity. However, promoting exports will need to be combined with appropriate rangeland management policies, such as a user fee (pasture tax) to control the overgrazing problem. Without such regulations, boosting exports can worsen the overgrazing and land degradation problem by incentivizing herders to have more livestock (IMF, 2019).

According to the average Revealed comparative advantage (RCA) index over the period 20102018, 21 animal products have a comparative advantage in the world market. These products comprise two important streams of value chains: i) meat and ii) hides and skins. The value chains show that there is a possibility to produce more added-value in these value chains, which would possibly generate alternative incomes and jobs for herders who cannot continue their previous way of life.

Possible policies that would support the export of meat and other products of animal origin in this context are developing a meat export industry together with strategic animal breeding, reintroducing a livestock tax, supporting the growth of more productive animals, and so on. The findings suggest that Mongolia's meat export policy should focus in the short-term on the large volume of products that have a relatively low level of processing. In the long-term, the policy should encompass a gradual shift to the export of differentiated value-added products, rather than large volumes of products with low levels of processing.

Finally, it is recommended that Mongolia improves its meat sector regulation and develops formal supply chains in order to both effectively monitor food safety and create high-quality Mongolian 
brands. Before trading livestock or products of animal origin, any exporting country needs to meet a satisfactory level of animal health status and meet both World Organisation for Animal Health (OIE) and importing country's standards. In most cases, import regulations reflect, to a large degree, the effectiveness of the sanitary procedures undertaken by the exporting country; both at its borders and within its territory.

\section{References}

Agrawal, A. (2001). Common property institutions and sustainable governance of resources. World Development 29(10): 1649-1672.

Agrawal, A. (2003). "Sustainable governance of common-pool resources: context, methods, and politics." Annual Review of Anthropology 32: : 243-262.

Amgalan, O., D. Avaadorj, B. Batbuyan, A. Batmandakh, M. H. Binswanger, B. Bolormaa, D. Buyankhishig, J. Chantsallkham, D. Dorligsuren, M. Dovuuch, B. Erdenetsetseg, M. Erdenetuya, E. Tumur, E. Ganbat, R. Himmelsbach, S. Jigjidsuren, T. Khishigjargal, M. Olonbayar, B. Purev, K. Schuler, T. Sukhtulga, M. Suvd, Udval and Y. Zagdsuren (2010). Livelihood study of herders in Mongolia, Swiss Agency for Development and Cooperation (SDC), Mongolian Society for Rangeland Management (MSRM), Selengepress Co.Ltd. Ulaanbaatar Mongolia

B. Densambuu, S. Sainnemekh, B. Bestelmeyer and U. Budbaatar. (2018). National report on the rangeland health of Mongolia: second assessment," Green Gold-Animal health project, Swiss Agency for Development and Cooperation (SDC); National Federation of Pasture User Groups (NAFUG) Mongolia, Ulaanbaatar

Baland, J. M. and J. P. Platteau (1997). "Wealth inequality and efficiency in the commons .1. The unregulated case." Oxford Economic Papers-New Series 49(4): 451-482.

Baland, J. M. and J. P. Platteau (1998). "Wealth inequality and efficiency in the Commons, part II: the regulated case." Oxford Economic Papers-New Series 50(1): 1-22.

Baland, J. M. and P. Francois (2005). "Commons as insurance and the welfare impact of privatization." Journal of Public Economics 89(2-3): 211-231.

Baland, J.-M. and J.-P. Platteau (2003). Chapter 4: Economics of common property management regimes. In: K. G. Maler and J. R. Vincent (eds.), Handbook of Environmental Economics. Vol. 1. Amsterdam, Elsevier.

Cao J., T., E.T. Yeh, N. M. Holden, Y. Qin and Z. Ren (2013). "The roles of overgrazing, climate change and policy as drivers of degradation of China's grasslands." Nomadic Peoples 17(2): 82-101.

Dorligsuren, D. (2008). Changes in livestock number and pasture area of Mongolia. Paper presented at XXI International Grassland Congress \& VIII International Rangeland Congress, Hohhot, P.R. China, 29th June - 5th July, 2008. 
Enkh-Amgalan, A. (2019). Building sustainable livelihoods for herders: applying integrated approach and pilot testing results, Unpublished paper, Monthly meeting of the American Chamber of Commerce (AmCham) in Mongolia

Erdenechuluun Tumur, Wim J.M. Heijman, Nico Heerink, and Bakey Agipar. (2018). Critical factors enabling sustainable rangeland management in Mongolia, China Economic Review $20(2020) 101237$

Fernandez-Gimenez, M. and Swift, D. M. (2003). Strategies for sustainable grazing management in the developing world. In Proceedings of the VIIth International Rangelands Congress, pages 821831, Durban.

Fernandez-Gimenez, M. E. (1999). "Sustaining the steppes: A geographical history of pastoral land use in Mongolia." Geographical Review 89(3): 315-342.

Fernandez-Gimenez, M. E. (2002). "Spatial and social boundaries and the paradox of pastoral land tenure: A case study from post socialist Mongolia." Human Ecology 30(1): 49-78.

Fernandez-Gimenez, M. E. (2006). Land use and land tenure in Mongolia: A brief history and current issues. pages 30-36. U.S. Department of Agriculture, Forest Service, Fort Collins.

Fernandez-Gimenez, M. E. and B. Batbuyan (2004). "Law and disorder: Local implementation of Mongolia's Land Law." Development and Change 35(1): 141-165.

Fratkin, E. (1997). "Pastoralism: Governance and development issues." Annual Review Anthropology 26: 235-261.

Fratkin, E. and R. Mearns (2003). "Sustainability and pastoral livelihoods: Lessons from East African Maasai and Mongolia." Human Organization 62(2): 112-122.

Gordon, H. S. (1954). The economic theory of a commonproperty resource: The fishery. Journal of Political Economy, 62(2):124-142.

Hardin, G. (1968). "The Tragedy of the Commons." Science 162(3859): 1243-1248.

Heijman, W. J. M. (1991). Depletable resources and the economy. Department of General Economics. Wageningen, Wageningen Agricultural University. PhD thesis.

Ho, P. and H. Azadi (2010). "Rangeland degradation in North China: Perceptions of pastoralists." Environmental Research 110(3): 302-307.

Holechek, J. L., R. D. Pieper and C. H. Herbel (2001). Range management principles and practices. Upper Saddle River NJ, Prentice-Hall.

IMF. (2019). Mongolia selected issues, International Monetary Fund (IMF) Country Report No. 19/298, pp. 24-27.

Mau, G. and J. Chantsallkham (2006). Herder group evaluation. Ulaanbaatar, United Nations Development Program (UNDP) Mongolia. 
Mearns, R. (2004). Decentralisation, rural livelihoods and pasture-land management in postsocialist Mongolia. European Journal of Development Research, 16(1):p133 - 152.

Meinzen-Dick, R., E. Mwangi and D. S (2006). "Securing the commons." Policy Brief No. 4 CGIAR Systemwide programme on collective action and poverty rights. Washington, D.C., IFPRI.

MoFALI. (2018). Introduction of the pastureland law of Mongolia, Ministry of Food Agriculture and Light Industry (MoFALI), Ulaanbaatar

Mwangi, E. (2007). "Subdividing the Commons: Distributional Conflict in the Transition from Collective to Individual Property Rights in Kenya's Maasailand." World Development 35: 815-834.

Mwangi, E. and H. Markelova (2009). "Collective Action and Property Rights for Poverty Reduction: A Review of Methods and Approaches." Development Policy Review 27(3): 307-331.

NSO. (2018). Livestock number and rangeland carrying capacity, Monthly Statistical Bulletin, National Statistical Office (NSO), Ulaanbaatar

NSO. (2020). Statistical Yearbook of Mongolia, National Statistical Office (NSO), Ulaanbaatar, Soyombo Printing.

Ostrom, E. (1990). Governing the Commons: The Evolution of Institutions for Collective Action. Cambridge University Press, Cambridge; New York.

Ostrom, E. (2008). "The challenge of common-pool resources." Environment 50(4): 8-20.

Ostrom, E. (2009). Social-ecological systemsa general framework for analyzing sustainability of socialecological systems. Science, 325:419.

SDC. (2015). National report on the rangeland health of Mongolia, Green Gold-Animal health project, Swiss Agency for Development and Cooperation (SDC), National Federation of Pasture User Groups (NAFUG) Mongolia, Ulaanbaatar

Tungalag Ulambayara and María E. Fernández-Giménez. (2017) How community-based rangeland management achieves positive social outcomes in Mongolia: a moderated mediation analysis, Land Use Policy 82 (2019) 93-104

Upton, C. (2005). Institutions in a pastoral society: Processes of formation and transformation in postsocialist, Central Asia and its neighbors, Comparative Studies of South Asia, Africa and the Middle East A Duke University Press, Vol. 25, No. 3, 584-599

Wade Robert. (1988) Village republics: Economic conditions for collective action in South India, New York and Cambridge, Cambridge University Press.

Yang, W., W. Liu, A. Vina, M.-N. Tuanmu, G. He, T. Dietz and J. Liu (2013). "Nonlinear effects of group size on collective action and resource outcomes." PNAS 110(27): 10916-10921

Ykhanbai, H., B. Narantungalag, S. Tserendash, T. Saipolda, U. Beket, Z. Tsogt, B. Bolormaa, T. Tserenbaljir, E. Bulgan, T. Odgerel, B. Bynyie, B. Miagmarjav, N. Munknasan, N. Togtokhbayar, L. 
Erdenetugs and N. Baatarbileg (2011). Community based co-management of natural resources in Mongolia. Ulaanbaatar, ADMON. 



\section{SUMMARY}

Mongolia's transition from a centralized socialist economy to a market economy since 1990 has led to enormous changes in the country's socio-economic and environmental conditions. The livestock privatization was one of the most significant reforms in a country that promotes herders to increase their herd size to improve their livelihood. Although rangeland is under state authority by law, its strict control on rangeland management disappeared, and the herding system of Mongolia turned into de facto open access. There are differing opinions as per conflicts between private livestock versus public rangelands, and the pastoral livestock sector of Mongolia is a classic case of "tragedy of commons." Thus, Mongolia was faced with the dilemma of increasing the number of livestock and the need to manage natural resources properly. As livestock is the primary livelihood of rural households and provides most of the foodstuffs for Mongolia, an increase in livestock number is supported. However, a massive increase in livestock number creates high pressure on the rangeland and leads to rangeland degradation caused by overgrazing and other problems in the long run.

Rangeland degradation caused by overgrazing is one of the most significant environmental challenges that Mongolia is facing. According to the recent statistics, livestock numbers have tripled within the last two decades, which has put pressure on the rangelands, exceeding the rangeland carrying capacity by more than 30 million heads. Although the number of livestock has reached its highest record, the livestock number-based inequality is high within the herder households. Herders with less than 200 livestock, which is below the subsistence level, take up more than 50 percent of the total herder households.

The main reason for the increase in livestock number is a lack of Government policy on rangeland management and markets to regulate its natural expansion. Because privatization of the livestock took place before the appropriate livestock support services could be introduced, that would have replaced the former negdel service and state procurement system.

The objective of this study was 'to obtain insights into the relationship between poverty and sustainability of rangeland use under different arrangements for community-based rangeland management systems in different agro-ecological regions of Mongolia.' The objective is achieved by answering four research questions throughout the five separate chapters.

Chapter 2 analyzed herders' behavior using game theory to characterize which type of game is being 'played' in the Mongolian livestock sector and provides better insight into the dynamics of the pastures' carrying capacity. The game estimation results suggest a so-called non-coordination game for steppe regions and a chicken's game for the Gobi region. Increasing herders' payoffs from the herding business would also be significant in the Gobi region by taking a more marketbased approach. It has shown that when we allow the carrying capacity to be dynamic by letting it depend on weather conditions, the cycle of animal losses and increases can be explained better.

Chapter 3 described the current institutional arrangements of rangeland management in Mongolia and the stakeholders participating in this area. The government of Mongolia and donor organizations supported and strengthened the institutions involved in rangeland management. This chapter analyzed the approaches of the donor organizations such as the World Bank, UNDP, 
and SDC. Since 2006, the territory based PUG approach have been promoted by the Administration of Land Affairs, Geodesy and Cartography. The nested PUG system vision is comprehensively organized throughout Mongolia and takes the lead in rangeland and livestock management and improvement.

Chapter 4 deals with the specification of rangeland management in the Gobi region where it needs to have a long-distance move to seek better grazing areas or areas with less $d z u d$ and drought and have high pasture yields and adequate water supply. The case study presents general conditions in the Gobi region and introduction of PUG approach. The institutional arrangement of rangeland management in Gobi region needs a specific policy to regulate large mobile communities within and across soum and aimag territory.

Chapter 5 analyzed the performance of the newly introduced institutional arrangement for community-based rangeland management in Mongolia. In recent years, community-based rangeland management approaches such as PUGs have been introduced in selected regions of Mongolia to explore appropriate mechanisms for countering rangeland degradation. The results show that the current select institutional arrangements have significant impacts on rangeland quality. A well-defined rangeland boundary is key to supporting rangeland quality, which is in line with the current government policy to introduce this scheme within the framework of an annual land management planning scheme. Inequality in herd sizes within a PUG negatively affects rangeland quality; the impact of group size resembles an inverted U-shaped relationship. Intermediate group sizes have the highest monitoring effort on rangeland management and lead to the best outcomes in rangeland quality.

Chapter 6 investigates the comparative advantage of selected livestock-oriented products using the revealed comparative advantage index to show export opportunities for different types of livestock-oriented products. The study results illustrate that there are possibilities to develop export-oriented livestock production in Mongolia in various stages. The export of livestockoriented products, combined with other policies, is a way to substantially reduce the animal number to sustainable levels, reduce overgrazing pressure, and increase export income. Longterm policy on meat and other livestock-oriented products should provide a legal framework of rangeland use to secure Mongolia's livestock sector's sustainable development.

In general, many herders do not have enough animals to sustain themselves traditionally. Therefore, herders need to combine subsistence livestock-keeping with various other jobs to become more market-oriented herders to increase their income, health, and maintain the rangeland. The key innovation of the community-based rangeland management in Mongolia is herders' entire organization on a territorial basis, which is necessary to transfer the leadership role in pasture management from local governments to the herders themselves. However, pasture user groups cannot perform these management functions on their own. They need support and collaboration from soum and aimag governments to allocate pasture use rights and must assist with enforcing the rules that are agreed upon within and among PUG. Moreover, this system would be best introduced in conjunction with alternative income generation activities and economic support to compensate for losses associated with limiting herd sizes. The government of Mongolia aims to ensure the sustainable livestock sector, to secure herder households' livelihoods, and improve economic opportunities within the sector. One of their significant policy is to increase resilience to climate change by addressing overgrazing and balancing the livestock 
numbers with the rangelands' carrying capacity. For instance, an increase in meat exports would support decreasing livestock numbers to a level that would balance the carrying capacity. However, promoting exports will need to be combined with appropriate rangeland management policies, such as a user fee (pasture tax), to control the overgrazing problem. Possible policies that would support the export of meat and other products of animal origin in this context are developing a meat export industry and strategic animal breeding, reintroducing a livestock tax, supporting the growth of more productive animals.

The research on this thesis contributes to the literature by i) adding a new country case to the World rangeland management study where still have nomadic pastoral livestock, ii) testing the interrelation between poverty and rangeland use, iii) analyzing the adoption of CBNRM approach in Mongolia's condition within the theoretical framework of sustainable governance of commonpool resources, and, iv) systematically analyzing the characteristics of pastoral livestock and its linkage to the market system. 


\section{ХУРААНГУЙ}

1990 оноос хойш Монгол улс төвлөрсөн төлөвлөгөөт социалист эдийн засгаас зах зээлийн эдийн засагт шилжсэн нь тус улсын нийгэм эдийн засаг, байгаль орчны нөхцөл байдалд acap их өөрчлөлтийг авчирсан юм. Малыг хувьчилсан нь малчдын амьжиргааг дээшлүүлэхийн тулд малын тоо толгойгоо нэмэгдүүлэхийг дэмжсэн хамгийн том шинэчлэлийн нэг байв. Хуулийн дагуу бэлчээр нь төрийн мэдэлд байдаг боловч бэлчээрийн менежментийн хатуу хяналт үгүй болж, Монголын бэлчээр нь нийтийн эзэмшлийн өмч болсон. Хувийн өмчийн мал сүрэг, нийтийн эзэмшлийн бэлчээрээс улбаатай төрөл бүрийн маргаантай асуудлууд бий болж, Монголын бэлчээр "нийтийн эзэмшлийн эмгэнэл" онолын сонгодог жишээгээр дурдагдах тохиолдол гарч байна. Ингэснээр, мал сүргээ өсгөхийн зэрэгцээ байгалийн баялгийг зүй зохистой ашиглах асуудлуудтай тулгарав. Мал аж ахуй нь хөдөөгийн өрхийн амьжиргааны гол эх үүсвэр төдийгүй, хүн амыг хүнсээр хангагч гол салбар тул малын тоо толгойн өсөлтийг дэмжсээр ирсэн. Гэвч малын тоо толгойн хэт өсөлт нь бэлчээрт ихээхэн ачаалал өгснөөр, бэлчээрийн даац хэтрэн бэлчээрийн доройтолд хүргэж байна.

Малын тооны хэт өсөлтөөс бэлчээрийн даац хэтэрч бэлчээр доройтсон нь Монголын хувьд хүрээлэн буй орчны хамгийн их тулгамдсан асуудлуудын нэг боллоо. Статистик мэдээгээр сүүлийн хорин жилд малын тоо толгой гурав дахин өсөж, бэлчээрийн даацаас 30 гаруй сая толгойгоор давжээ. Хэдийгээр малын тоо толгой дээд амжилтдаа хүрсэн ч, малчин өрхүүд хоорондын малын тоо толгойн тэгш бус байдал өндөр байна. Тухайлбал, амьжиргааны баталгаажих түшингээс доогуур буюу 200 хүрэхгүй толгой малтай малчид нийт малчин өрхийн 50 гаруй хувийг эзэлж байна.

Малын тооны хэт их өсөлтийн гол шалтгаанд бэлчээрийн менежментийг зохицуулах Засгийн газрын бодлогын дутмаг байдал, мал ба мал аж ахуйн бүтээгдэхүүн борлуулах зах зээл байхгүйг дурдаж болно. Мөн түүнчлэн нэгдлийн үед ажиллаж байсан мал аж ахуй, мал эмнэлгийн үйлчилгээ, түүхий эд бэлтгэлийн тогтолцоог зах зээлийн нөхцөлд нийцүүлэн зохицуулалт хийхгүйгээр мал хувьчлалыг зохион байгуулсан нь салбарыг гажуудалд хүргэх нэг нөхцөл болсон юм.

Энэхүү судалгааны ажлын зорилго нь “нутгийн иргэдэд түшиглэсэн бэлчээрийн менежментийн систем Монгол орны бүс нутгуудад хэрхэн хэрэгжиж байгаа судлах, ядуурал ба бэлчээрийн тогтвортой ашиглалтын харилцан хамаарлыг тодорхойлох" явдал юм. Судалгааны зорилгодоо хүрэхийн тулд судалгааны 4 асуултад 5 бүлгээр хариулт өглөө.

Бүлэг 2-д тоглоомын онолыг ашиглан малчдын зан төлөвөөр Монголын мал аж ахуйн салбар тоглоомын онолын аль хувилбарт хамаарах мөн бэлчээрийн даацыг динамикаар өөрчлөгдөх үеийн нөхцөл байдлыг судалж үзэв. Тоглоомын онолын үр дүнд тал хээрийн бүсийн хувьд бэлчээрийн даацыг анхаарахгүйгээр малын тоогоо уралдан өсгөх, говийн бүсэд малчид малаа өсгөхдөө илүү хамтран ажиллах стратегийг баримталдаг нь харагдлаа. Харин сонгогдсон хоёр сумын аль алинд нь зарим жудагтай малчин малынхаа тоог бэлчээрийн даацад тохируулах гэж бариад бусад нь өсгөөд байвал жудагтай малчин хохирч, харин малаа өсгөсөн малчин хожих дүн гарч байна. Энэ нь малыг бэлчээрийн 
даацад тохируулах бодлогыг нийт малчдад жигд хүргэх шаардлагатай бөгөөд эсрэг тохиолдолд нийгмийн шударга бус байдалд хүргэхийг харуулж байна.

Бүлэг 3, Монгол улсын бэлчээрийн менежментийн институтийн байдал түүнд оролцогч талуудын үйл ажиллагааг судлав. Монгол улсын Засгийн газар болон хандивлагч байгууллагуудын зүгээс бэлчээрийн менежментийн институтийг бэхжүүлэх болон тэднийг дэмжих чиглэлээр ажиллаж иржээ. Дэлхийн банк, Нэгдсэн Үндэстний байгууллага, Швейцарын Хөгжил Хамтын Ажиллагааны байгууллага болон тэдгээрийн авч хэрэгжүүлсэн арга хэрэгслүүдийн талаар харьцуулан шинжиллээ. 2006 оноос эхлэн Газар Зохион Байгуулалт, Геодези, Зураг Зүйн Газраас газар нутгийн байршилд суурилсан малчдын байгууллага БАХ байгуулах аргачлалыг тууштай дэмжин, үндэсний хэмжээнд нэвтрүүлж эхэлсэн. БАХ-ийн сум, аймаг, үндэсний түвшний үүр хэлбэрийн системийн хэтийн зорилго нь дээрх малчдын байгууллагыг улс орон даяар байгуулж мал аж ахуйн менежмент болон түүнийг сайжруулахад тэргүүлэх үүрэгтэй оролцоход оршино.

Бүлэг 4-т бэлчээрийн ургац, усан хангамж сайтай, зуд, ган багатай газар нутгийг хайж урт холын нүүдэл хийх шаардлагатай болдог говийн бүсийн бэлчээрийн менежментийн онцлог шинжийг судалсан. Бүлэгт оруулсан жишээ сумаар говийн бүсийн бэлчээрийн ерөнхий төлөв байдал, БАХ-ийн хандлагын хэрэгжилтийг төлөөлүүлэн тайлбарласан болно. Судалгааны үр дүн говийн бүсийн бэлчээрийн менежментийн институтийн гол зохицуулалт нь сум, аймгийн хил дамнан нүүдэллэх их нүүдэлд нийцсэн бодлого боловсруулах шаардлагатайг харуулж байна.

Бүлэг 5, Монгол улсад шинээр нэвтрүүлж буй нутгийн иргэдэд түшиглэсэн бэлчээрийн менежментийн институтийн хэрэгжилтэд дүн шинжилгээ хийлээ. Сүүлийн жилүүдэд бэлчээрийн доройтлыг бууруулах тохиромжтой аргыг эрэлхийлэх зорилгоор БАХ зэрэг нутгийн иргэдэд түшиглэсэн бэлчээрийн менежментийн аргыг Монгол улс тодорхой бүс нутгуудад туршин хэрэгжүүлж байна. Энэхүү институтийн хэлбэр нь бэлчээрийн чанарт хэд хэдэн чухал нөлөөтэй болох нь бидний судалгааны үр дүнгээс харагдаж байна. Юуны өмнө малчдын байгууллагын бэлчээрийн хил хязгаарыг нарийвчлан тодорхойлох нь бэлчээрийн чанарыг хянахад чухал үүрэгтэй байна. Энэ хандлага нь засгийн газрын бодлоготой нягт уялдаж байгаа ба түгээн дэлгэрүүлэхийн тулд сумын тухайн жилийн газар зохион байгуулалтын төлөвлөгөөний чухал бүрэлдэхүүн хэсэг болгон ашиглаж байна. БАХ-д багтаж буй малчдын малын тоо толгой хэт их зөрөөтэй байх нь бэлчээрийн менежментийг хамтран хэрэгжүүлэхэд сөргөөр нөлөөлж байна. Бүлэгт байх нийт малчин өрхийн тоо буюу бүлгийн хэмжээ нь бэлчээрийн чанартай урвуу харсан U хэлбэрийн харилцан хамааралтай байв. Энэ нь малчны бүлгийн хэмжээ дундаж хэмжээтэй байх нь бэлчээрийн менежментийн мониторинг хийхэд хамгийн тохиромжтой ба бэлчээрийн чанарт эерэг нөлөө үзүүлж байгааг илэрхийлж байгаа юм.

Бүлэг 6, Энэ бүлэгт мал аж ахуйн гаралтай бүтээгдэхүүний өрсөлдөх чадварыг харьцангуй давуу талын RCA индексийн аргыг ашиглан судалж, экспортын боломжийг нь тодорхойлов. Судалгааны үр дүнд Монгол улс экспортод чиглэсэн мал аж ахуйн гаралтай бүтээгдэхүүнийг төрөл бүрийн түвшинд хөгжүүлэх боломж байгаа нь тогтоогдсон. Мал аж ахуйн гаралтай бүтээгдэхүүний экспортыг бусад бодлогуудтай уялдуулах замаар малын тоо толгойг тогтвортой түвшинд барих, бэлчээрийн хэт ачааллыг бууруулах, экспортын орлогыг нэмэгдүүлэх боломж байна. Мах болон малын гаралтай бүтээгдэхүүний талаар 
баримтлах урт хугацааны бодлого нь бэлчээр ашиглалтын хууль эрх зүйн үндэслэл болж Монгол улсын мал аж ахуйн салбарын тогтвортой хөгжлийг хангахад чиглэгдэх ёстой.

Бэлчээрийн мал аж ахуйг уламжлалт аргаар эрхэлж буй тохиолдолд ихэнх малчид амьжиргаагаа хангахуйц тооны малтай байх боломжгүй юм. Иймээс, малчид орлогоо нэмэгдүүлэх, бэлчээрээ хадгалж үлдэхийн тулд мал аж ахуйг өөр салбартай хослуулах эсвэл арилжааны чанартай мал аж ахуйг өсгөн үржүүлэх шаардлагатай байна. Монгол улсын хувьд нутгийн иргэдэд тулгуурласан бэлчээрийн менежментийн хамгийн гол ололт нь газар нутагт тулгуурлан малчдын байгууллагыг зохион байгуулан, бэлчээрийн менежментийг хэрэгжүүлэхэд манлайлах үүргийг орон нутгийн удирдлагаас малчдад шилжүүлж буй явдал юм. Бэлчээр ашиглалтын бүлэг нь менежментийг дангаараа хэрэгжүүлж чадахгүй тул сум, аймгийн засаг захиргаанаас тэдэнд бэлчээр ашиглах эрхийг хуваарилах, бэлчээр ашиглагчдын бүлгийн дүрэм журмаа хэрэгжүүлэхэд нь туслалцаа үзүүлэх шаардлагатай. Энэхүү систем нь малын тоог хязгаарласнаас алдах орлогыг нөхөхүйц мал аж ахуйгаас өөр орлогын бусад эх үүсвэрийг нэмэгдүүлэх, эдийн засгийн дэмжлэгтэй хамт хэрэгжиж байж илүү үр дүнд хүрнэ. Монгол улсын Засгийн газраас мал аж ахуйн салбарын тогтвортой байдлыг хангахдаа малчин өрхийн амьжиргааг хангах салбарын эдийн засгийн нөхцөлийг сайжруулахад анхаарч байна. Засгийн газраас хэрэгжүүлэх шаардлагатай чухал бодлогуудын нэг нь малын тоо толгойг бэлчээрийн даацад нийцүүлэн байгаль цаг уурын өөрчлөлтөд салбарын дасан зохицох байдлыг сайжруулах явдал юм. Махны экспортыг богино хугацаанд эрчимтэй нэмэгдүүлэн малын тоо толгойг бууруулах бодлого баримтлах нь энэ бодлогыг хэрэгжүүлэх нэг арга зам нь байж болохоор байна. Гэхдээ экспортыг дэмжих бодлогоо бэлчээрийг төлбөртэй ашиглуулах гэх мэт бэлчээрийн доройтлоос сэргийлэх менежментийн аргуудтай хослуулан хэрэглэх нь гарч болох бодлогын сөрөг нөлөөллөөс сэргийлэх болно. Мах ба дайвар бүтээгдэхүүний экспортыг нэмэгдүүлэхийн тулд мах экспортын салбарыг хөгжүүлэх, малын үүлдэр угсааг сайжруулах, малын хөлийн татвараар ашиг шим сайтай мал өсгөх явдлыг урамшуулан дэмжих зэрэг бодлогуудыг хэрэгжүүлэх боломж харагдаж байна.

Энэхүү докторын судалгаагаар і) Дэлхийн бэлчээрийн менежментийн судалгаанд нүүдлийн мал аж ахуй бүхий шинэ орны жишээг оруулсан, ii) ядуурал ба бэлчээр ашиглалтын хоорондын хамаарлыг судалсан, iii) нийтийн эзэмшлийн нөөц зохицуулалтын онолын хүрээнд Монгол улсад нутгийн иргэдэд түшиглэсэн байгалийн нөөцийн менежментийн хэрэгжилтэд дүн шинжилгээ хийсэн, iv) бэлчээрийн мал аж ахуй түүний зах зээлтэй холбогдох байдлын талаар системтэй судалгаа хийсэн зэрэг хувь нэмрийг салбарын судалгаа шинжилгээнд шинээр орууллаа. 


\section{ACKNOWLEDGEMENTS}

I cannot find enough words to express my sincere gratitude and acknowledge the many people's support.

I am thankful for my promoters and co-promoter, Professor Wim Heijman, Professor Nico Heerink and Professor Bakey Agipar, whose encouragement, guidance and support from the initial to the final stage allowed me to attain this accomplishment. The completion of this thesis is indebted to the unwavering support of Professor Wim Heijman, who has and still is paying great attention to my PhD progress in Mongolia. The distance of eight thousand kilometres was not a problem for Professor Wim Heijman in supervising my research work through email and longdistance phone calls. Furthermore, I have learnt a lot from Professor Nico Heerink on how to survive in the academic world. Significantly, the ceaseless comments, corrections on the most challenging article writing, publishing, and other thesis parts were extremely helpful. I am always thankful for Professor Bakey Agipar's support in me, ever since my undergraduate study up till now. Professor Bakey Agipar always being available for discussions, helped me understand practical issues in my research area. Once again, I am deeply grateful to my three Professors for their invaluable support, patience and encouragement.

I express my thanks to coauthors for the gratifying collaboration that resulted in the different papers and book chapters. Likewise, my acknowledgement goes to the scientific conferences participants, the herders and other respondents who participated in the survey and the fieldwork, the experts that validated the models and the students that supported me in my research. It is not possible to mention all of you by name, but I acknowledge all your inputs.

I would like to express my thanks to all the people in Agricultural Economics and Rural Policy Group (AEP) and Development Economics Group (DEC) of Wageningen University and Research. The special thanks go to the Annelies, Marian, Karen, Dineke, and Betty. All of your academic and administrative support made my life easier and more meaningful during my stay in Wageningen, the Netherlands.

I acknowledge the assistance provided by my colleagues in Green Gold pasture ecosystem management program in Mongolia, namely Dr. D.Dorligsuren, Dr. Ts.Enkh-Amgalan, Mr. Sukhtulga, Dr. Bulgamaa, Mr. G.Gankhuyag, Mr. U.Budbaatar and others.

I am grateful to the Mongolian University of Life Sciences (MULS), School of Economics and Business, for allowing me to keep working at the University until the completion of this special journey, and to MULS colleagues who made reviews, analysis of my papers during scientific workshop and conferences.

Finally, my deep and sincere gratitude goes to my lovely wife Ganchimeg, and my three precious sons Temuulen, Tushig and Tuvshin. This journey would not be complete without my family's unyielding support and love. I express my gratitude to my parents, brothers and sisters for standing by me since my childhood to this moment, and for their moral support. To my friends who supported me, and to any persons whom I may have left out inadvertently, know that I am grateful. 


\section{BIOGRAPHY}

Mr. Erdenechuluun Tumur, born in 1975 in Tsagaan-Uul soum, Khuvsgul province of Mongolia. He enrolled at the Mongolian State University of Agriculture (MSUA) in 1993 as a bachelor student of agricultural economics. In 1997 he became the assistant lecturer beside his master's course at the MSUA. He defended his master's degree of business administration in 1999 with the title of "Structure and Typology of Flour Market in Mongolia" under the supervision of Prof. Bakey Agipar.

Mr. Erdenechuluun Tumur has obtained his second master's degree in MSc Agricultural Economics and Management at the Wageningen University in 2002. This master's thesis was supervised by Prof. Henk A. J. Moll under the title of "Weather Risk of Pastoral Livestock in Mongolia".

Since 1997 to present Mr. Erdenechuluun Tumur is working at the Mongolian University of Life Sciences ${ }^{18}$ (MULS) as an assistant lecturer, lecturer, and a specialist for international relations, MULS representative in Europe and senior researcher-lecturer. Besides his teaching, he is actively involved in research projects with national and international researchers' team. Between 2006 and 2008, he worked for Green Gold Pasture Ecosystem Management Programme, Swiss Development Agency as a technical expert and a head of pasture co-management section. Most of his research focuses on rural and agricultural development, regional economics, herder's households' study, disaster risk management, and pasture land management.

Mr. Erdenechuluun Tumur became the founding director of the Institute of Natural Resources and Agricultural Economics (NGO), since 2013. The Institute conducts collaborative national and international research activities with multidisciplinary researchers from the MULS.

${ }^{18}$ According to the decision of the Governing Board of the university the English name of the university as entitled "Mongolian state university of agriculture" changed into "Mongolian university of life sciences" in July 2014. 


\begin{tabular}{lllr}
\hline Name of the learning activity & Department/Institute & Year & ECTS \\
\hline $\begin{array}{l}\text { A) Project related competences } \\
\text { Writing research proposal }\end{array}$ & WUR & 2009 & 2 \\
Advanced Econometrics (AEP-30306) & WUR & 2009 & 6 \\
$\begin{array}{l}\text { Advanced Microeconomics (ECH-32306) } \\
\text { Economic models (AEP-30806) }\end{array}$ & WUR & 2009 & 6 \\
$\begin{array}{l}\text { Research Methodology: From Topic to } \\
\text { Proposal }\end{array}$ & WURS & 2010 & 6 \\
\end{tabular}

\section{B) General research related competences}

Introduction course
PhD competence assessment
"Community Development to Improve
Rangeland Management in Mongolia"

"The characteristics of current Rangeland management in Mongolia"

"Design principles defining for sustainable rangeland management in Mongolia"

"Design principles defining for sustainable rangeland management in Mongolia"

"Design principles defining for sustainable pastureland management in Mongolia"

"Livestock commercialisation support

better Pastureland Management"

"Inclusion of herding households in food value chain of Mongolia"

Field supervision of master student
WASS (ex. MGS) 2009

WGS

2009

International Conference on

2009 1

Climate Change and Adaptive Capacity Development: Combating Desertification and Sustainable Grassland Management in Gobi Region, Mongolia

AGRIMBA-AVA 2011 Congress, Wageningen

First International summer conference on Natural Resource and Agricultural Economics in Mongolia, Ulaanbaatar, Mongolia

WASS PhD day

Econ Conference, Wageningen

University

University of Oxford, Chinese

2014

Academy of Sciences, Global land

Project, Mongolia

AGRIMBA-AVA 2015 Congress,

2015

1

Porec

Wageningen University

2012

1

\section{C) Career related competences/personal development}

Project and time management

WGS

2010 


\section{Acknowledgement of financial support}

The research described in this thesis was financially supported by European Union EUROASIA program and the Government of Mongolia.

Financial support from Wageningen University for printing this thesis is gratefully acknowledged.

Cover Design: Erdenechuluun Tumur

(C)Tuvshin Erdenechuluun

Printed by ProefschriftMaken 
